\title{
Political Ecology of Health of South Sudanese Immigrants and Refugees in Ottawa
}

by

Katie MacPherson

A thesis submitted to the Faculty of Graduate and Postdoctoral Affairs in partial fulfillment of the requirements for the degree of

Master of Arts

in

Geography and Environmental Studies

Carleton University

Ottawa, Ontario

(C) 2017, Katie MacPherson 


\begin{abstract}
Emerging research suggests that despite access to health care, South Sudanese in Canada experience dismal health. Applying political ecology of health (PEH) framework, this qualitative study builds on literature, to examine factors underlying this health decline. Focus groups and in-depth interviews with South Sudanese in Ottawa $(n=31)$ reveal multiple factors acting alone or in interaction with processes at multiple temporal and spatial scales. Specifically, findings show that trauma suffered before arrival and from ongoing conflict in South Sudan affects everyday health. The findings also show that a deep political and moral sentiment of solidarity with the motherland mediates household decisions about health. In addition, fierce intra-ethnic rivalry stirred by war in South Sudan greatly affects South Sudanese, eroding social and psychological resources necessary for health. Furthermore, the findings indicate that weak integration of South Sudanese men in Canada breeds feelings of loss of social status, triggering family instability and gendered health impacts.
\end{abstract}

Key words: Immigrant, refugee, migration, relocation, South Sudanese, health experience, gender, ethnicity, political ecology. 


\section{Acknowledgements}

First, I would like to acknowledge the members of the South Sudanese communities in Ottawa who participated in this study. Without your kindness, generosity and participation, this study would not have happened. Thank you.

Second, thank you to my supervisor, Professor Paul Mkandawire. Thank you for your tremendous amount of support and guidance. You have believed in me since day one, and helped me become more confident as an academic and person in general. You have been a great mentor and friend throughout this entire process. I could not have done this without you. Also thank you to my committee member Professor Jennifer Ridgley, for your extremely helpful comments and support throughout my degree.

I would like to also thank Professors Kon Madut of Ottawa University and Odwa Atari of Nipissing University for their help in organizing meetings within the South Sudanese communities in Ottawa.

Thank you to my friends in the Geography Graduate Department. Your constant support and friendship helped me through the stressful times. I am forever grateful for all of you, and look forward to continuing our friendships. I would also like to extend this thank you to the staff and faculty for their support, especially Erin.

Finally, I would like to thank my family for their emotional and financial support throughout my time at Carleton University. I would specifically like to thank my Mom, Dad, brothers Ben and Curtis, Aunt Patty, and Grandparents Ed and Linda. And finally, thank you to my Step-dad Bruce Murphy, for motivating me to complete this degree. I have enjoyed our equally intellectual conversations up until this point, and I must admit that I will miss them very much. 


\section{Table of Contents}

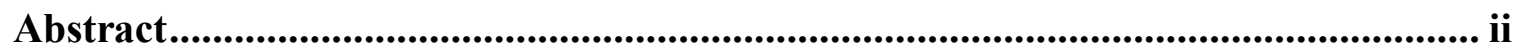

Acknowledgements ............................................................................................................... iii

List of Appendices ....................................................................................................... vii

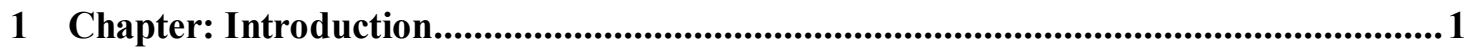

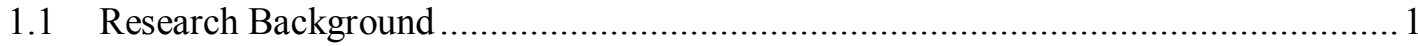

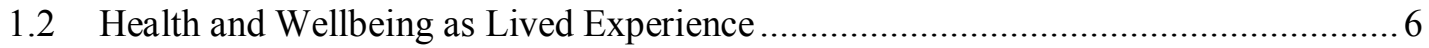

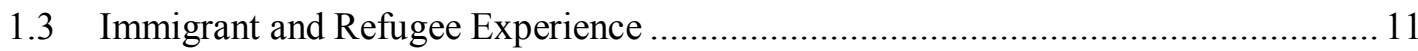

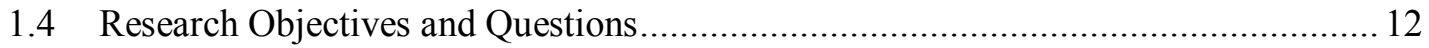

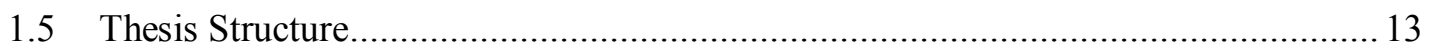

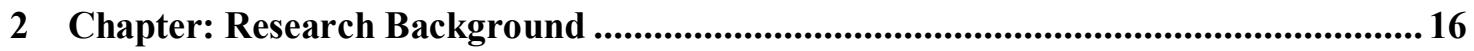

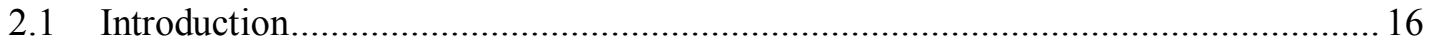

2.2 Colonial History of South Sudan: The Creation of Division between the North and

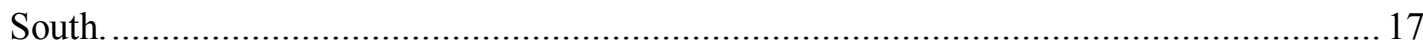

2.3 Colonial Legacies: An Ethno-Regional Divide.................................................... 21

2.4 The Post-Independence and Civil War Eras: Colonial Legacies Leading to

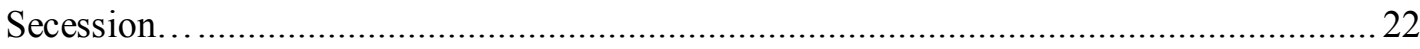

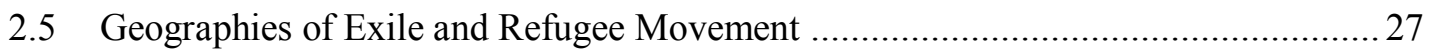

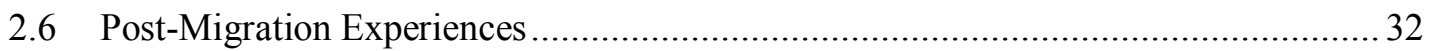

3 Chapter: Political Ecology of Health Framework and Feminist Political Ecology ..... 40

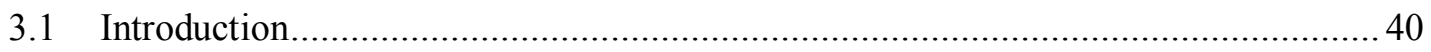

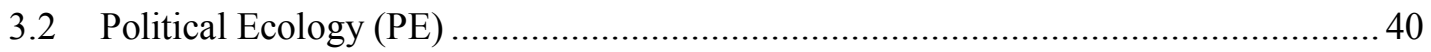

3.3 Applications of Political Ecology of Health Framework (PEH) ............................ 41

3.4 A Feminist Political Ecology of Health (FPEH) ............................................... 45

4 Chapter: Research Methodologies and Methods ............................................................ 49 


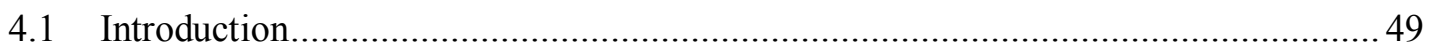

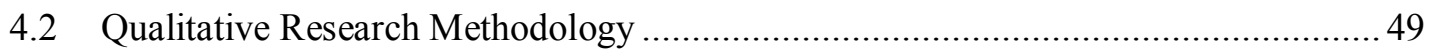

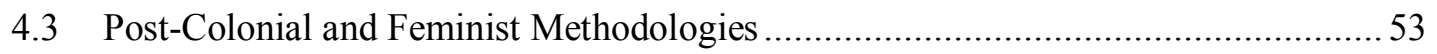

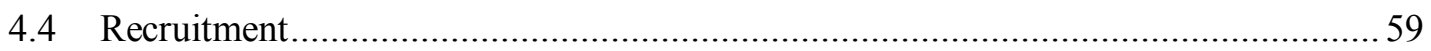

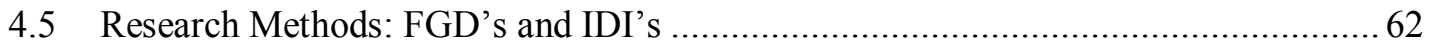

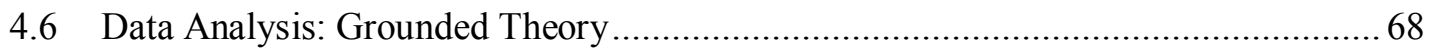

5 Chapter: Research Findings ........................................................................................... 71

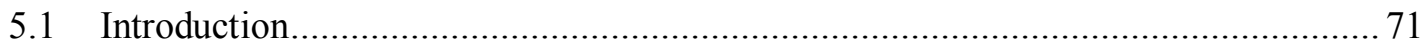

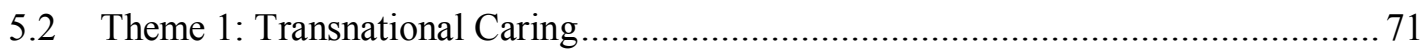

5.3 Theme 2: Interaction with the Healthcare System: Attitudes and Experiences .......... 76

5.4 Theme 3: "Fitting the System": Changing Gender Dynamics in Canada ................... 83

5.5 Theme 4: Ethnic, Tribal and Political Tensions ....................................................... 90

5.6 Theme 5: Generational Differences in Experience Health and Wellbeing ................. 94

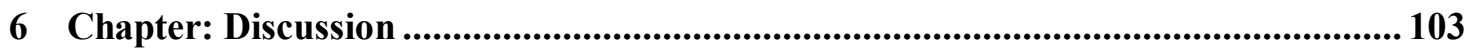

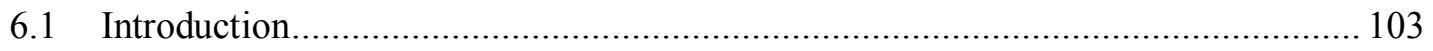

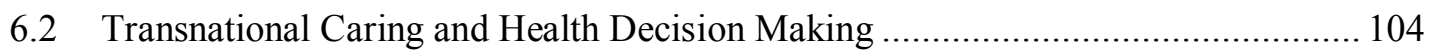

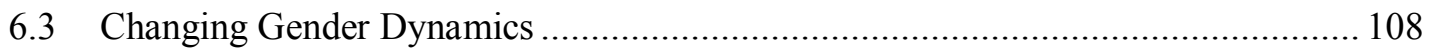

6.4 The Conflict-Generated Diaspora: Ethnic and Political Tensions .......................... 111

6.5 Generational Identities and what this means for Health .................................... 113

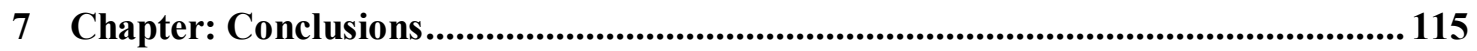

7.1 Introduction into my Final Thoughts ......................................................... 115

7.2 Conclusions and Future Directions for Research .............................................. 115

7.3 Concluding with Advice for Future Health Geographers at Carleton: Make Time and

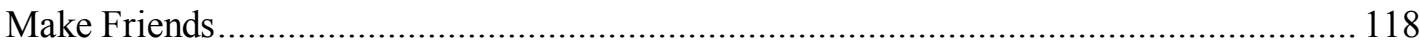

Appendices .......................................................................................................... 120 
References .................................................................................................................. 133 


\section{List of Appendices}

Appendix A - Certificate of Ethics Clearance....................................120

Appendix B - Letter of Introduction...................................... 122

Appendix C - Invitation for Interview......................................... 124

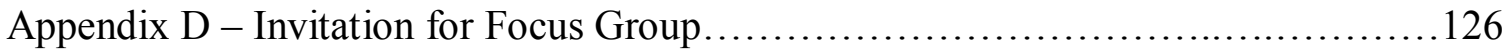

Appendix E - Interview Guide and Checklist for Interview....................... 127

Appendix F - Interview Guide and Checklist for Focus Group.......................130

Appendix G - Codes to Theory Model.......................................132 


\section{Chapter: Introduction}

\subsection{Research Background}

A few studies have raised concerns that despite the fact that Canada has a universal health care system, South Sudanese immigrants and refugees living in Canada, continue to suffer from poor health status. For instance, some studies have reported high levels of poor mental health among this community as evident by high levels of mental health issues such as anxiety and depression (Simich, Hamilton \& Baya, 2006; Simich, Hamilton \& Este, 2010; Tempany, 2009). The studies that have noted mounting mental health problems have identified a link between significant amounts of stress, economic hardships and lack of social support. For example, Simich et al. (2006) with their sample of 220 Sudanese immigrants living in Canada, found that $43.3 \%$ reported to be unhappy and depressed, and $52.6 \%$ reported feeling a constant strain on their health since arriving to Canada; $53.3 \%$ of these participants reported a significant loss of sleep due to factors including bad memories. In addition, Kim, Torbay and Lawry (2007) studied the mental health of 1274 displaced Sudanese women living in South Darfur. Participants were assessed with a Patient Health Questionnaire, and 31\% reported having a major depressive disorder.

In addition, other studies have highlighted increased levels of poor physiological health and growing prevalence of diseases, especially diabetes, hypertension and cancers (Faria, 2014; Grabska \& Fanjoy, 2015; Salman, Kirk \& DeBoer, 2011; Holtzman, 2000). Although this research project is within the context of Canada, most studies have reported increasing rates of physiological health problems of South Sudanese populations within the geographical context of sub-Saharan Africa (Ado, Smeeth \& Leon, 2007). Within 
South Sudan specifically, studies have found increasing rates of hypertension, not only in adults but children as well. Salman et al. (2011) found that mainly due to malnutrition, that over $25 \%$ of children in South Sudan are overweight and obese. Within this group, $5 \%$ already had hypertension, and another $10 \%$ were pre-hypertensive and at high risk.

In addition, published data shows that cancer has been increasing in South Sudan. Elamin et al. (2015) argue that cancers such as breast and prostate cancer are increasing for a multitude of reasons (unhealthy lifestyles, exposure to carcinogens) while resources, and infrastructure to prevent and treat the diseases lag behind significantly. Prostate cancer, for example, is very common among South Sudanese men (10\% of all cancer diagnoses), increasing from the tenth to most common within the last 30 years. Breast cancer, cervical and ovarian cancers are the most common in women, comprising of $40 \%$ of all cancers in South Sudan. Unfortunately, more than two thirds of women suffering from cervical or ovarian cancers in the study by Elamin et al. (2015) were diagnosed in the very late stages, because almost $70 \%$ of participants had never had a Pap smear. Due to lack of services and the financial burden, less than $0.10 \%$ of women have been screened for these cancers. Although this study raises these cancers as a health issue within the context of South Sudan, it is important to consider within the context of Canada. Regular screening and other preventative measures are not a norm in South Sudan, and therefore, despite access to health care in Canada, South Sudanese may not access these services. This is largely understudied. This study will later report findings that suggest pre-migration experiences with the health care system directly shape how South Sudanese access health care in Canada. 
These studies have played a key role in highlighting the magnitude of health issues within the South Sudanese community. However, these studies do not go far enough in elucidating the precise mechanisms responsible for the accumulation of these setbacks. They are overly narrow and do not allow scope for understanding how the health of South Sudanese intersect with the environment in which their lives play out. There is a need for better explanation as to why such disproportionate levels of poor health persist against the backdrop of universal access to health care in Canada. My research seeks to fill part of this gap by examining how the experience of migration, the process of leaving your country of origin and relocating to live in a completely new place outside of your homeland, shapes health and wellbeing, using the case study of South Sudanese immigrants and refugees living in Ottawa.

A large portion of the literature on the health of South Sudanese immigrant populations has emerged out of epidemiology. For example, Conly and Johnson (2008) found that almost half of the Lost Boys and Girls of Sudan (a group of refugees) cohort living in Calgary tested positive for serious infections, common in developing countries, that can lead to detrimental health problems for years to come. Another interesting study by Moukhyer et al. (2008) examines negative health behaviours within South Sudanese groups, and found that poor health behaviours such as inactivity, smoking and unhealthy eating are much more common in older age groups of South Sudanese. It also found that adolescent boys and girls practice different unhealthy behaviours, with girls being less active and boys smoking more, for example. Within the discipline of epidemiology, research has primarily been quantitative, focusing on the incidence and distribution of disease or health behaviour amongst the South Sudanese population, and contributed to 
determining risk factors and targets for health intervention. While insightful, this type of research has often not engaged with the larger contexts of health and wellbeing, instead focussing on individual-level risk factors. In addition, this kind of research fails to consider the place-based experiences of immigrants and refugees. Furthermore, most of these studies have not paid sufficient attention to the views of South Sudanese themselves in terms of their own understanding of health as it relates to their everyday experience as immigrants.

Studies on the mental health of immigrants have somewhat sought to address some of the weaknesses with epidemiological studies by, for instance, applying mixed methodology that involves both qualitative and quantitative methods in attempt to examine the health experiences of South Sudanese immigrants. However, most of these studies have targeted South Sudanese refugee populations geographically located in Africa (Jeppson \& Hjern, 2005; Peltzer, 2004), as well as in Australia (Tankik \& Richters, 2007) although they have informed the very few research projects in Canada. For example, as previously mentioned, Simich, Hamilton and Baya (2006) using qualitative and quantitative techniques, found a link between economic hardship and stress within several South Sudanese immigrant communities in Canada such as Calgary, Edmonton, Winnipeg and Toronto. Results showed that individuals who were experiencing economic hardship were much more likely to experience loss of sleep, constant strain, unhappiness and depression. Simich, Este and Hamilton (2010) examined family and social factors that affect the mental health of South Sudanese migrants in Canadian cities during resettlement, by presenting qualitative analysis of the concept of home and its functional and psychological meanings. Findings highlighted how the 
presence or absence of the social support affects refugees' mental health. Insightful as they are, these studies overly focus on the immediate personal and family circumstances and fail to capture the totality of the experience of international relocation, including the effects of prior experience.

Although some studies, especially within medical anthropology, examine South Sudanese cultural health practices (Gruenbaum, 2006; Higginbottom, 2013), little research exists on how factors such as ethnic identity and cultural beliefs intersect with and influence health care access and outcomes. For example, Goodman (2004) points out in his study on unaccompanied refugee youths from South Sudan in the US, that studies that fail to account for the importance of culture in health experience are often inconclusive in terms of health intervention. For example, his study found that many coping methods within the South Sudanese community were cultural, (coping in silence) and do not fit neatly within the framework of Western mental health intervention.

While insightful, these studies have however failed to elucidate clearly the political ecologic circumstances underlying the health and wellbeing of South Sudanese refugees and immigrants. In particular, most of these studies have not sufficiently engaged with the material and political circumstances that function as a backdrop against which one should understand and situate the health and wellbeing of South Sudanese in Canada. In other words, there are important prior questions that need to be asked or erstwhile circumstances that ought to be properly discerned in order to provide a fuller account of the factors underlying the deteriorating health status of South Sudanese in Canada and to inform appropriate policy responses. 
To fill part of this gap, this study approaches the health of South Sudanese in the context of the totality of experience of migration. Focussing on the broader social and political circumstances, allows for a deeper analysis of contemporary and historical antecedents. In particular, this study examines the ways in which the present health status of South Sudanese in Canada relates to the violence and trauma that initially uprooted South Sudanese from Sudan and the atrocious and unpredictable nature of the civil conflict in the newly independent South Sudan. In addition, this study considers the impacts of social geographies of return migration to South Sudan on family stability and wellbeing, and of intensifying ethnic rivalry in the diaspora, on social support networks required for health and wellbeing. Furthermore, this study focuses on the ways in which structural racism and social and economic integration within Canada intersect with these circumstances and undermine the health of South Sudanese.

\subsection{Health and Wellbeing as Lived Experience}

Throughout the years and across disciplines, the term health has taken on many different meanings that preclude space allowed in this thesis. It suffices to say however, that dominant definitions of health focused on the absence of disease (Engel, 1977). This rather negative conceptualization of health is dominant in the Western biomedical knowledge system and influences our understanding of health. This has produced a narrative that assumes being healthy is being absent of disease, and that short of disease, health automatically obtains. Thus, the understanding is that when disease is absent, health is the default position. Another major conceptual flaw of this definition is that it arguably leads to a tautological position, meaning that it defines health in terms of nonhealth (Callahan, 1973). In addition, defining health as absence of disease is an overly 
reductionist way of thinking about health, and as a result, it does not provide policy makers with a full range of ammunition that they need to improve health. This has prompted some researchers to argue that the biomedical definition has limited practical relevance for improving the health of the population. The biomedical understanding of health, however, remains dominant in health literature, more specifically in disease ecology and epidemiology.

However, in an effort to move away from this negative understanding of health or at least to incorporate positive notions and make it more pragmatic, the World Health Organization (WHO) redefined health. According to the World Health Organization, health is not just the absence of disease, but also a complete state of physical, mental and social wellbeing (1948). This definition of health is more practical and relevant because it provides more information than the foregoing negative definition of health, in terms of what policy makers need to know in order to have a complete diagnosis of population health issues and the range of policies that might be appropriate for improving public health. This definition of health is also much more holistic than its preceding one, providing an indication of a true breadth of the range of stakeholders that ought to be involved in or concerned about matters of health.

However, a major critique is the lack of clarity about what the term wellbeing means. Essentially, this means that there is a danger of defining one nebulous concept, health, in terms of another imprecise concept, wellbeing (Coggon, 2012). Wellbeing in the context of this project is a more subjective state of both the mind and body, where one perceives to have a presence of positive emotions and moods (Ryff \& Keyes, 1995). In addition, living conditions can influence wellbeing (Hiscock et al., 2017). In spite of 
these weaknesses, the balance of opinion is that the positive definition of health is more practical and relevant because it draws focus to social and environmental determinants of health.

However, despite this consensus, establishing pathways through which social and environmental factors operate to affect our health has been an uphill task. Understanding how these social and environmental insults ultimately get under our skin to impair our health is especially important to consider when understanding the health experiences of immigrant communities. Scientific evidence about how social processes interact with health is still emerging but research from the subfield of life-course epidemiology is beginning to provide useful insights. According to Bartley, Blane and Montgomery (1997), a life course perspective takes a historical or temporal approach to disease by seeing an individual's health status as a marker of past position. However, using an ecosocial approach to health, Krieger (1997), also takes a historic, but as opposed to Blane's approach, looks at group health status (as opposed to the individual) as a biological expression of social inequality. This shifts our understanding away from one that sees it as a natural phenomenon towards one that views it as a social and political attribute. However, Blane (1997) makes an important point, which Krieger (1997) in some ways shares, which is that an aspect of life-course approach vital to understanding health is not that there is any single magic wand with an overriding effect on health, but various discrete circumstances that ultimately mesh into a chain of disadvantage.

However, some of the most illuminating arguments that tie poor health to poor social and environmental conditions came from the Whitehall study, which tracked mortality rates among male British civil servants, aged 20-64 for more than 10 years 
(Marmot et al., 1984). A major finding of the Whitehall study was the inverse relationship between grade of employment and mortality. Male civil servants in the lowest employment rank, such as messengers and doorkeepers were three times more likely to die relative to men in the highest grade such as administrators (Marmot et al., 1984). However, remarkably, mortality did not just differ between civil servants at the top and civil servants at the bottom, but civil servants in each grade had a lower mortality rate than the civil servants immediately below it. This is an example of the social gradient, meaning that social inequalities in health are reflective of social position.

Like Krieger (1997) and Blane (1997), Marmot (2003) argues that material circumstances (and political) are related to disease, but what the Whitehall study specifically adds to the literature is the ways in which one's lack of control in life and their inability to participate fully in social life directly relates to stress (2003). Originally developed from studies conducted in macaque monkeys, the concept of allostatic load provides a better understanding of how negative social environments undermine health and wellbeing (Taylor, 2006). When individuals encounter social insults such as low control, social exclusion, racism, discrimination, just as many migrants do, they experience chronic stress. Constant exposure to and suffering from chronic stress, as is often the case with immigrants, leads to superfluous secretion of cortisol. Under normal circumstances, where normal time refers to during an emergency, cortisol is beneficial, as it stimulates the production of adrenaline, which in turn readies individuals for 'fight or flight'. However, persistent secretion of cortisol beyond the necessary period, especially in people who are physically inactive and thus do not require abundant amounts of it, it can lead to physiological damage, organ impairment, and immune dysfunction (McEwen, 
1998). This can lead to a range of bodily dysfunctions that can render individuals susceptible to several conditions including cancer, hypertension, obesity, and diabetes (Marmot \& Wilkinson, 2003).

The risk of these conditions increases significantly when a person smokes, drinks or is overweight, characteristics that migrants have shown to adopt over time (AbraidoLanza et al., 2005). Trying to understand why Mexican migrant women in Michigan experience high burden of disease, Virnuell-Fuentes' (2007) study linked the experience of racial discrimination and depression and anxiety. In this study, first generation women explained that they avoided leaving their homes because they were afraid of being harassed, showing that they lacked control in their lives. The second-generation women explained that they suffered from bullying in school because they did not have the nice clothes like others. This prevented them from fully participating in life in ways that are expected of a 'normal' person.

Marmot (2003) also argues that these conditions are related directly to subsequent health issues such as cardiovascular disease (2003). Thus, we can specifically think about how these social insults that occur outside of the body, can affect what happens inside of the body. More specifically, how they affect us biologically in terms of determining susceptibility to cardiovascular diseases. For example, the discipline of population health applies the concept of relative deprivation to explain this process (Wilkinson, 1997). Relative deprivation, as opposed to absolute disadvantage, affects health through the effect of socioeconomic status. Status is relative social concept; individuals and groups need other individuals and groups to mark their position in society (Marmot, 2003). In other words, status depicts a person's socioeconomic position relative to other people in 
society. Relative deprivation in the space of income can translate into absolute deprivation in the space of capabilities (Sen, 1993). The concern is not about how much material resources someone has, but the range of capabilities that someone is able to accomplish with those resources. This affects the actions people take towards improving their own health (Sen, 1993). Other studies have shown a direct link between the stress and shame that is caused by relative deprivation in social status, and physiological health problems (e.g. Clougherty et al., 2010).

\subsection{Immigrant and Refugee Experience}

According to the Dictionary of Human Geography, the term immigrant refers to a person or people who move from one nation state to another, changing their permanent dwelling place (Johnston et al., 2000). Immigrants move voluntarily and are therefore distinct from refugees. Refugees are individuals who leave their homes out of compulsion because of persecution (Johnston et al., 2000).

During the cultural turn of migration studies in the late 1990's, scholars called for more of a focus on methodologies and sources for understanding the experience of migration, in other words, what it is like to be a migrant (King, 2010). Being an immigrant or refugee is a challenging experience. It comes with a host of hurdles rooted in the experience of having to leave one's own homeland, often forcibly, to seek a new beginning in a completely different country with different social and cultural norms and values. This makes migration a particularly important structural context within which to examine the health of South Sudanese in Canada. 
A leading framework for the analysis of immigrant health is the healthy migrant effect (Kennedy et al., 2006; Lou \& Beaujot, 2005). At the centre of the healthy migrant effect framework is the argument that, on the average, immigrants to the West have better health status than native-born individuals, but this advantage is gradually lost as immigrants acclimatize to social and environmental conditions of their host nation. The argument that immigrants arrive healthy, rests on the fact that migrants undergo stringent medical screening prior to admission to host countries, have healthy behaviours prior to relocation, and the fact that migration is itself a self-selecting process where individuals with superior health status are those that are likely to migrate in the first place. However, this hypothesis has come under increasing scrutiny. This is especially the case with respect to its relevance to refugee populations. Most refugees come from countries with weak and disrupted health infrastructure and social systems, and spend years, even decades, in makeshift camps as internally displaced people, or in exile before obtaining the paperwork needed to resettle in the West (Miller et al., 2016; O'Connor et al., 2014).

\subsection{Research Objectives and Questions}

The overall goal of this study is to provide a better explanation of why, after more than two decades since the first wave of refugees arrived in Canada, and despite having access to healthcare, South Sudanese Canadians continue to experience deteriorating health status. To help answer this question, the following five specific questions guided this research: 
1. What are the everyday experiences of health and wellbeing of the South Sudanese immigrants and refugees in Canada?

2. How do gender inequality and systemic racism affect everyday experiences of health among South Sudanese in Canada?

3. How does the experience of relocating from Sudan relate to family stability and household wellbeing among South Sudanese in Canada?

4. What are the pre- and transitional migration experiences of the South Sudanese immigrants and how do they affect their everyday experience of health in Canada?

5. How do South Sudanese deal with pre- and post-migration stressors and the ongoing conflict in South Sudan within the social and cultural context of Canada?

\subsection{Thesis Structure}

The following chapter, Chapter Two, provides a background to this research, including tracing the colonial history of Sudan and South Sudan that led to the ethnic and political upheaval and bloody civil wars that forced many to flee the country. This chapter also discusses the experiences of South Sudanese immigrants and refugees living in Canada and identifies the gaps that this thesis can fill on the experiences, specially related to health of this population. Next, Chapter Three, focuses on the theoretical 
framework which draws on perspectives of political ecology of health framework (PEH) and feminist political ecology (FPE).

Chapter Four outlines the research methodology that provides the conceptual rationale behind the methods and describes the data collection and analysis that were used. In order to gain a rich understanding of the experiences of health of South Sudanese immigrants and refugees living in Ottawa, qualitative research methodology was deemed appropriate. In addition, the chapter presents a discussion of feminist and post-colonial methodologies and explains their application and relevance to this study, as well as discuss my process of reflexivity. In this regard, I extensively draw on journal entries and field notes that I wrote during my research with the South Sudanese community in Ottawa. These entries are typed in a font that I feel represente my own writing. I also wanted to clearly differentiate between the formal writing of my thesis, and informal thoughts in my journal entries. Then, I discuss the research methods in detail; in-depth, one-on-one interviews and focus groups as well as methods of recruitment and dataanalysis.

Chapter Five outlines the findings of this study, which are organized in five main themes: (1) transitional caring, (2) interaction with the health care system, (3) changing gender dynamics in Canada, (4) ethnic, tribal, and political tensions and (5) generational differences in health experience. Taken together, these themes tell a story of the health and wellbeing of South Sudanese immigrants and refugees living in Canada. Chapter Six provides a discussion of the research findings, situates them in the broader literature, and highlights potential theoretical contributions of this study. Finally, Chapter Seven 
concludes this thesis by providing a summary of the thesis, discusses limitations of the study, and makes suggestions for future research. 


\section{Chapter: Research Background}

\subsection{Introduction}

South Sudan, officially known as Republic of South Sudan, is the newest country in the world, having gained political independence from Sudan in 2011. As space precludes a comprehensive historical account, this chapter only provides a broad overview of significant parts of what is a long history of conflict and struggle that dates back to more than one hundred years ago. By providing historic depth, the aim here is to offer some context for one of the most protracted conflicts in the world, that has seen the forced exodus of millions of South Sudanese to take refuge abroad in countries such as Canada. This historical account is important for understanding not just the genesis of the conflict but also how it relates to present-day circumstances that generate adverse conditions that undermine the health and wellbeing of the South Sudanese. This chapter thus provides a brief, chronological colonial history of Sudan, beginning with pre-modern times, leading up to secession in 2011. A major political highlight of this account is the deep regional divisions, especially between the North and South, and how these separatist pressures not only led to the secession and political independence of South Sudan, but also how they continue in some ways to fuel divisions between existing tribal and ethnic groups such as the Dinka and Nuer, in this new country.

Next, this chapter examines the migration trajectories of Sudanese and South Sudanese feeling civil conflict since the 1970's. Examining the long journeys that South Sudanese have trekked, reveals how the transitional migration (the experience of between home and host countries), is an important part of the context for the present-day health experiences of South Sudanese immigrants and refugees living in Canada. Finally, with 
the history of tensions and experience of migrating to Canada in mind, the final section of this chapter discusses the existing literature on South Sudanese immigrants and refugees within the context of Canada and specifically Ottawa. This discussion provides a background to a number of significant issues pertaining to settlement in Canada that are equally important to understanding South Sudanese' health and wellbeing.

\subsection{Colonial History of South Sudan: The Creation of Division between the North and South}

In January of 2011 South Sudan separated from Sudan and became the world's newest country. After more than four decades of civil war, fuelled by ethnic, racial and geographical tensions between the Northern and Southern regions of Sudan, the country held a referendum that resulted in the secession of South Sudan. Although the friction between the North and the South reached its peak during the time of post-independence, the roots of today's conflict in South Sudan can be traced as far back as the colonial era and pre-modern times. According to Madibbo (2015) this history dates as far back as the Middle Ages when Nubian Kingdoms, located in the Northern area, were the main system of governance. Under this rule, temples and pyramids, rich in culture, were built in the region (Madibbo, 2015). These Kingdoms, according to Alnour (2006), thrived for centuries. During this time, Christianity reached the area and was the official religion until early fifteenth century (Alnour, 2006).

However, this does not mean that other religions did not spread into the region of Nubia. In Egypt at this time, Islam was gaining popularity. After Islam was introduced to Egypt, it was pushed into Nubia but met with strong resistance. Despite this however, "there was a gradual spread of Arabization, the predominance of the Arabic language, 
customs and culture, and Islamization, expansion of Islam in society, in the region" (Madibbo, 2015, p.10). This trend led to Arab immigration into the Northern region of Sudan (Spaulding, 1985). It is important to note that the Southern region was largely unaffected by this process, and remained home to tribes such as the Dinka and Nuer (Spaulding, 1985).

Sudan's pre-modern history marked just the beginning of Sudan's long history of multi-ethnic and multicultural interactions, and these multiple identities created the foundation for conflict during the modern period. Conflict in Sudan is largely rooted in a history of violent colonization. This began when Muhammad Ali Pasha, with his Turkish force, invaded the North of Sudan in 1820 in a quest for natural resources, control of trade routes and to look for slaves (Collins, 2008: Madibbo, 2015). This era was known as the Turkish regime, or Turkiya, and during this time, Egyptian government ruled Sudan.

Turkiya divided Sudan into provinces and the provinces were further subdivided into administrative jurisdictions. The Turkiya rule also presided over the restructuring of Sudan's legal system along the line of that of Egypt's. The Egyptians had particular preference for traditional religious order and built mosques and schools that propagated this religion (Simpson, 1985). In addition, the regime also engaged in a violent slave trading system that exploited the Sudanese people and imposed punitive taxes (Maddibo, 2015). Sudanese deeply resented this rule and made efforts to overthrow it. They galvanized political and military opposition to the Turkiya system and these efforts paved way for the Muslim-Sudanese Mahdist movement under the direction of Al Mahida in 
1885. This force defeated the Turkish Empire in the Northern city of Khartoum and temporarily ended the Turkish regime (Madibbo, 2015).

However, this did not last very long. With the Nile River located in the Northern area of Sudan, the British set to gain control over the region, as well as the river, a decade later (Madibbo, 2015). In order to achieve this political ambition, an Anglo-Egyptian army was sent to Sudan in 1899 to defeat Al Mahdiya and after gaining control of the territory they decided to establish and exercise equal political control over Sudan with what was known as a condominium government (Collins \& Deng, 1985). It is important to point out that a major aim of this administration was to make Northern and Southern Sudan into separate provinces with their own governing administrations (Collins \& Deng, 1985). Madibbo (2015) argues that this was a divide-and-conquer policy, practiced in order to protect financial and political interests, and that this was a main contributor to the conflict and divisiveness within Sudan and between Sudanese.

Under the condominium government arrangement, the British aimed to modernize the economy and undertake liberal political reforms (Collins \& Deng, 1984). Consequently, the policy priorities of the first twenty years under the condominium rule were economic and resource development, building social services and, and most significantly, creating the foundation for a law and order in government (El-Mahdi, 1965). Most of this push was focused in the Northern regions of Sudan. The condominium rule pushed for the central government to be located in the city of Khartoum, and consequently, came the building of governmental headquarters in the Northern city. Government offices, British and Egyptian barracks, mosques, the 
Governor of Khartoum's residence and non-governmental buildings were all constructed here (Fadlalla, 2004).

Meanwhile, another important project was taking place: developing economic resources and social services in the North (Madibbo, 2015). For the most part, economic development occurred only in Northern areas proximal to the Nile Valley. This led to the construction of rail lines in the Northern areas, facilitating trade in agricultural products (El-Mahdi, 1965). The Nile River itself was also a strategic economic resource, and in 1911 the government built a dam to expand cotton farming (El-Mahdi, 1965).

Also during this time, the condominium government worked towards creating a system of education that saw the establishment of the Gordon College in 1905. This College was for those who wanted to become junior government officials (Fadlalla, 2004). Otherwise, in the South, education was provided by missionaries who came to the region to preach Christianity (Collins, 2008). The government did not take an active part in education in the South until the 1930's when an Inspector of Education approved church schools in the Southern Provinces (Collins, 2008).

Overall, throughout the Anglo-Egyptian rule, there was a lack of attention to the Southern provinces. This neglect fuelled the already divisive environment between the North and South. The British justified this inattention on many accounts, and claimed that the South was not ready to be introduced to the modern world (Collins \& Deng, 1984). As a result, the South remained isolated in terms of economic development, political relations and education. The British administration treated the three Southern provinces as a separate region and during this time, the government effectively detached the South from the rest of Sudan (Rahim, 2006). A major development during this time was the 
policy of "closed door" where Northern Sudanese were barred from entering or working in the South (Rahim, 2006). Many see this British Southern Policy as the most powerful force in perpetuating tensions and separatist sentiments between the North and South, specifically in terms of ethnic identity (Collins, 2008)

During its rule, Britain gradually replaced Arab administrators and merchants in the South, further undermining economic integration between the South and the North. The British administration also actively discouraged the spread of Islam and the practice of Arab customs such as the wearing of traditional Arab dress (Rahim, 2006). Along with this, the British tried to renew tribal life and customs traditionally considered to be native or African (Collins, 2008). Eventually in 1930, the British government officially declared the North and South to be distinct and separate both on regional and ethnic lines. It created and implemented an ordinance that proclaimed "blacks in the southern province were to be considered people distinct from northern Muslims" and that the region should be prepared for eventual integration with British East Africa (Rahim, 2006, p. 237). Thus, despite being a rich agricultural region, the South continued to suffer because of the region's separation.

\subsection{Colonial Legacies: An Ethno-Regional Divide}

Although Sudan's colonial history is quite complicated, it is quite clear that its legacy has been marked by ethnic strife. These ethnic and religious divisions tend to geographically overlap with administrative and regional jurisdictions. People in the North are assumed to be Sunni Muslims and this group of people tend to identify themselves as Arab. People from the South are assumed to either practice African religions or Christianity. Generally, they identify as Africans (The Mosaic Institute, 2009). Thus the 
conflict in Sudan follows these racial, ethnic, and geographic divisions or ethno-regional divide (Deng, 2007).

The socio-economic marginalization of the Southern regions, as discussed above, creates and perpetuates ethno-regional divisions and conflicts. The Northern region, which has historically possessed most of the developed infrastructure, is highly populated by Arab-elites who hold most government power and resources (Madibbo, 2015). In addition, the dominant Arab elite in the North favoured their identity and excluded all other identity groups from participation in social and economic activities (Madibbo, 2015). They have also dominated social, economic and political life in Sudan.

Consequently, around the time of independence, marginalized groups of the South mobilized their ethno-regional identities against the Arab-Muslim governments to challenge their treatment and demand equitable resource distribution (Madibbo, 2015). The ensuing conflicts between North and South, notably the bloody first (1955-72) and the second (1983-2005) civil wars have caused numerous tribal and ethnic conflicts, mass killings, exile, and large-scale displacement of millions of Sudanese (Madibbo, 2015).

\subsection{The Post-Independence and Civil War Eras: Colonial Legacies Leading to}

\section{Secession}

As mentioned, the post-independence period (1956-2011) consisted of two extremely violent civil wars. Although these wars are important to investigate, for the purpose of this study, they will not be the main focus of this section. Instead, this segment seeks to investigate the colonial legacies in the post-independence period and how they underpin many factors that led to the secession of the South. It is evident that the tense ethno-regional divide between the North and South, created during the colonial 
period, continued to persist during this time. Consequently, the continuing friction inevitably led to the secession of South Sudan. This section provides a brief account of secession as it applies to the case of Sudan, followed by a discussion of the factors that actually led to secession. Particular attention is paid to the rise of Northern-Arab policies and the failure of the Addis Abba and Comprehensive Peace Agreements to accomplish a unified Sudanese state.

\subsubsection{Northern Neglect and Arab's Power and Policies}

Secession refers to "the creation of a new state by the withdrawal of a territory and its population, where that territory was previously part of an existing state" (Pavkovic \& Radan, 2007, p.34). John R. Wood (1981) equates secession to political disintegration in a context where "political actors in one or more subsystems renounce their loyalty to a jurisdictional centre and redirects it to a centre of their own” (p. 112).

In Sudan, the national government's neglect of socioeconomic development of the regional areas of the South is directly linked to the South's push for political isolation (Collins \& Deng, 1984). Beginning throughout the Anglo-Egyptian condominium government and continuing after independence, the various regional groups in the South had been largely underrepresented, if not neglected by the national government (Collins

\& Deng, 1984). This significantly undermined the government's legitimacy in the eyes of those who lived in marginalized areas, causing many groups to attempt to create their own governments. For example, Southern Sudan had numerous separatist governments, including Sudan People's Liberation Movement (SPLM) (El-Battahani, 2013). 
Another factor is Northern Arab's assimilationist policy of Arabization (Daoud, 2015). The 1990's particularly saw a top down Islamization under the National Islamic Front (NIF). Amidst civil war, the NIF portrayed the SPLM in the media as a threat to the Muslim identity in Sudan and expanded powers to maintain control over the entire county (Daoud, 2015). Consequently, the regime implemented harsh political, economic and legal reforms and in 1991 imposed sharia law in all aspects of life (El-Battahani, 1996). While causing immense suffering, loss of life, displacement in the South, these measures also backfired to the extent that they fuelled resentment and separatist anger.

\subsubsection{Failed Peace Agreements: The Addis Ababa and Comprehensive Peace}

\section{Agreements}

In attempt to respond to the South's political, economic and social grievances, two significant peace treaties have been signed since Independence. The Addis Ababa Agreement (1972-1983) and the Comprehensive Peace Agreement (2005-2006) created an opportunity to resolve conflict in Sudan and provide an appealing national unity to the Southern regions. However, both of them failed, missing the opportunity to achieve unity for Sudan. Instead, the failure of these treaties greatly fuelled the drive for secession of the South.

After nearly a decade of violent civil war, Jaafar Nimeiry was the first president (1969-1985) to reach a solution with the South. His negotiations with the South led to the creation of the Addis Ababa Agreement. Parties ratified this treaty in March 1972 and later in 1973 it was incorporated into the country's constitution (El-Battahani, 2013). The agreement made provisions for political power sharing, including representation of the South in the national government, and autonomy of the South (El-Battahani, 2013). More 
specifically, the agreement stated that regional legislation in the Southern region was to be exercised by a People's Regional Assembly, elected by Sudanese citizens residing in the Southern region (El-Battahani, 2013). In addition, the agreement ensured equality among all citizens before the law (Anderson, 2005 cited in Daoud, 2015).

However, in 1980, oil reserves were newly discovered in Southern Sudan. Pressured by Islamist elements in his government, Nimeiry proposed a plan to the Southern Regional Assembly to redraw the South's borders in order to strategically place the oil reserves within the territorial jurisdiction of the North (El-Battahani, 2013). The Addis Ababa agreement stated that no changes could be made without a Southern referendum. The Assembly rejected this proposal, and in response, Nimeiry unilaterally dissolved the agreement and created a new, much smaller, Southern state (El-Battahani, 2013). Consequently, this ended all of the social, political and economic policies in the agreement, creating outrage among Southern Sudanese. That same year, the Southern Sudanese created the Sudanese People's Liberation Army (SPLA) and went back to war with the North, marking the beginning of the second civil conflict (Daoud, 2015).

War continued until the Comprehensive Peace Agreement (CPA) was ratified in 2005. The two parties, the Sudan's People's Liberation Army/Movement (SPLA/M) and the government of Sudan (National Congress Party or NCP) were the main actors in the CPA negotiations and implementation (Wassara, 2010). The CPA included many of the same core principles of the Addis Ababa Accord. However, there were three main differences, all related to more autonomy being granted to the South (Daoud, 2015). First, as the Addis Ababa Agreement did not grant the South any rights to their resources, the CPA gave the South control over 50 percent, namely oil. Second, the previous agreement 
included minimal Southern representation, and the CPA gave the South proportionate representation in the national government. Third, the CPA allowed the South to maintain armed forces (Daoud, 2015). However, due to continued political corruption, South Sudanese remained unsatisfied and suspicious, and the South seceded in 2011.

\subsubsection{South Sudan Post-Secession}

After secession, South Sudanese held high hopes for a better life in a unified, independent South Sudan (Christopher, 2011; Zahar, 2011). Immediately after secession, South Sudan set out on a mission to rebuild as a strong and unified nation following decades of conflict. After years of neglect and marginalization by powerful Northern governments, many South Sudanese citizens were optimistic to build a collective national identity in South Sudan (Bereketeab, 2014; Cook, 2011; Frahm, 2012; Zambakari, 2014). Unfortunately, this particular vision of nation building never materialised, with civil conflict erupting shortly after secession and continuing today (de Waal \& Mohammad, 2014; Jok, 2014; Zambakari, 2013).

The ongoing conflict has greatly attributed to tensions between South Sudan's 60 to 100 ethnic, cultural and linguistic groups, often referred to as tribalism (Cook, 2011; Jok, 2011). Although no longer unified against an oppressive North, negative othering against a perceived enemy has continued between these groups, both in the community, and within official circles of the state (Frahm, 2015). Disagreement between political leaders, underrepresentation of ethnic groups within government and the subsequent rebellions throughout the country has greatly hindered nation building efforts and social and economic development (Jok, 2011). Thus, the state has been unable to harness its ethnic and cultural diversity to its advantage, and to deliver on promises of security and 
basic services (Frahm, 2015; Jok, 2011). Consequently, a country ravaged by the longest civil wars in post-colonial Africa, is one of the poorest countries in the world, and continues to suffer from extreme underdevelopment.

The issue of oil is important to bring up again here, as it is still a major factor in the conflict in South Sudan in present day. Vickers (2014) argues that oil has aggravated the ethnic conflict in South, stating that the worst of the most recent fighting has been in the oil producing states, and culminating in the massacre of hundreds of South Sudanese in these regions. Since the outbreak of war after secession, oil revenues have been diverted to finance war. Although the government has worked to develop responsible laws to avoid corruption, the war has weakened the rule of law. If oil were to be managed responsibly, revenues could actually be used to fund much-needed development in the country (Shankleman, 2011).

\subsection{Geographies of Exile and Refugee Movement}

This ongoing conflict has had great social and political costs, specifically in terms of violence, trauma and mass displacement. It has led to millions of Sudanese and South Sudanese being internally displaced but also fleeing the country to neighbouring and distant countries and continents. One of these places is Canada. This next section will discuss the migration trajectories and experiences of South Sudanese immigrants and refugees. Those living in Canada whose personal or community histories link them back to Sudan generally fall in two broad categories. First, a relatively small group of Sudanese arrived in Canada in the 1960's, 70's and 80's. This first group came primarily in search of employment or educational opportunities (The Mosaic Institute, 2009). 
The second group of South Sudanese arrived in Canada from the mid-1980's onwards and it was much larger. This group fled Sudan as the country was thrown into another lengthy period of international conflict and political oppression (Madibbo, 2015). Thus, a large amount of Sudanese immigrants who have come to Canada in the last 30 years are asylum seekers, escaping repression of the state, economic collapse, and a violent and protracted civil conflict. They primarily came under the Government Assisted Refugees (GAR) program, privately sponsored refugees program, or members of the family class program (The Mosaic Institute, 2009). In general, few studies have examined the ongoing experiences of refugees throughout their transitional phase (Steel et al., 2011). In other words, the experiences of refugees or immigrants in the period after fleeing their home countries, and before arriving in host countries, have been largely understudied.

The focus on the intermediate period is vital because migration, especially the fleeing of violent conflict, is not simply a matter of getting on a plane from Sudan and flying to Canada. The road to the airport is convoluted and is preceded by many months and years in cities and makeshift camps. South Sudanese experience multiple displacements, finding themselves in cities and camps in border communities such as Udjumani on the boundary with Uganda or in neighbouring countries such Egypt, the Gulf States, and across the Middle East for extended periods of time. They also experience traumatic losses and many significant disruptions of normal life (The Mosaic Institute, 2009). In these areas, many of them are exposed to extraordinary experiences such as aerial bombardment, rape, torture, looting and killing (Zutt, 1994). This period is marked by trauma, uncertainty and desperation. Refugee camps are also breeding 
grounds for diseases. Poor sanitation and congestion in refugee camps, coupled with lack of health care services, can create conditions suitable for outbreak and spread of diseases. Most refugees endure these conditions for extended periods, continuously relocating to different places as they transition to their final destination. In a report by Culture, Community and Health Studies (CCHS), for instance, researchers interviewed over 200 Sudanese refugees across Canada, and $80 \%$ did not come right from Sudan. 33\% were displaced in Sudan and 47\% were displaced more than once. Within the GAR population, $50 \%$ were displaced in Sudan and 50\% displaced multiple times (2004).

Although South Sudanese have been fleeing their country for over 50 years now, research suggests that the transitional experience has not improved, and continues to be one of the most difficult phases of migration. Studies that have looked at the transitional migration narratives of Sudanese living in refugee camps have found and reported common pervasive themes. Kagwanja et al. (2008) in their qualitative study of migration experiences of Sudanese refugees living in Australia, identified four main themes: (1) difficulties meeting and accessing basic needs, (2) loss and family separation, (3) impacts on life activities such as education and employment and (4) experiences of trauma.

First, Sudanese refugees, while living in camps, or even in cities, had, and continue to have struggles accessing basic survival needs such as food, water, shelter and medical care (Kagwanja et al., 2008). Many camps are provided with some food by agencies such as the UN, however, rations are often stolen by rebels raiding the camp, and even when properly delivered, are insufficient to cover the needs of refugees (Kagwanja et al., 2008). For instance, Beswick et al., (2001) conducted interviews with South Sudanese refugees in a camp in Ethiopia. Participants expressed that their main 
worry while living in the camp was that they did not know whether or not they would have anything to feed their children. In this paper, one woman explained this experience while living in a camp, and was quoted saying, "[We] had no food from the beginning. We ate grass and snakes. One woman made alcohol we ate the remains from what was left..." (Beswick et al., 2001, p. 85). Although this situation does not represent all experiences, it highlights the difficult circumstances many Sudanese refugees live through during this transitional period of migration to Canada.

Another issue identified by Khawaja et al. (2008) in their interviews with refugees was family separation and loss. This study in particular reported that a large number of refugees' families and friends had been killed or separated from one another while fleeing war zones. Refugees who have been separated from loved ones often-expressed concern for their welfare and a desire to be reunited. A lot of this displacement happens while fleeing from Sudan to other countries, and many die on route. Beswick et al. (2001) provides more concrete examples that highlight this experience, including an instance of a woman who spoke about her three-month journey to reach a camp across the Sudanese border in Ethiopia. She was travelling with her six children and husband, and when food was finished she said,

[...] we ate groundnuts and grass in the road like animals; we ate the leaves of trees and many people died but we kept going. The lions came up to us; we had no power to run or protect others so the lions ate us... Many people were so hungry they slept under the trees and died (p.85). 
The third challenge identified was the inability to conduct daily life activities such as education and employment (Khawaja et al., 2008). Refugees could not continue these activities because of the destruction of schools and workplaces. Adelnour (2008) provides insight into pre-and post-conflict livelihood strategies of internally displaced South Sudanese. In this study, researchers interviewed South Sudanese refugees in four different refugee camps, Lobonok IDP camp in Juba, Obel IDP camp in Malakal, Akot near Rumbek and Pulshume near Rumbek. Although each camp showed different experiences, a common theme was that South Sudanese drew strong connections between wellbeing and the ability to participate in daily life activities such as work, education, or farming.

The chaotic nature of war and violence that produces refugees also creates optimal circumstances for poor health and emergence of diseases such as malnutrition. The problem of the 'green famine' is particularly relevant to South Sudan, where food shortages continue to occur in the presence of reasonably fertile agricultural land as people leave farms and relocate to safe havens. While displaced in camps, they were also not allowed the opportunity to work with the skills they are trained in. Many stated that their displacement and complete removal from traditional livelihoods has led to a severe lack of confidence in their own existing abilities. In addition, specifically in camps in Northern Sudan and Egypt, the widespread Arabization made attending school or finding work very difficult for South Sudanese (Adelnour, 2008).

The fourth, and perhaps most significant theme is the psychological and physical trauma that refugees and their families experience. Refugees reported physical trauma such as torture, beatings and gunshots (Khawaja et al., 2008). In this specific study, 
refugees explained that they experienced fear of persecution and even death due to violence. For example, in Abdelnour's (2008) study, participants explained that while in Egypt, many experience being threatened because they are Christian, and are beaten by community members, as well as victims to verbal abuse and many forms of racism. In addition, South Sudanese refugees fear and often witness death, often on a daily basis. They explained that rebels would attack the camps and kill large numbers of their inhabitants. Such violence breeds feelings of insecurity, leaving refugees to fear for their lives (Beswick et al., 2001). It is important to note that women experienced violence at a much higher rate than men, as gender-based violence (GBV), is a significant occurrence in refugee camps (Abdelnour, 2008). Abdelnour's (2008) report showed that GBV is practiced through the killing of civilian women, men and children, and through abduction and rape. One woman in Lobonok IDP camp stated that both she and her daughter had been captured and repeatedly raped over a number of days; although she survived the brutal incident, her daughter did not.

\subsection{Post-Migration Experiences}

Much of the literature on refugee adaptation and settlement demonstrates that while pre-migration experiences have a significant impact on psychological distress, post-migration stressors, such as difficulties with resettlement and the loss of social and

cultural support, add appreciably to post-traumatic stress symptoms. This section aims to examine the existing literature on the post-migration experiences of South Sudanese in Canada and Ottawa. Only a select few studies have been conducted on the South Sudanese and Sudanese populations in Canada and Ottawa. This background is important, as it provides insight into the main issues that South Sudanese are 
experiencing in Canada and Ottawa. In addition, this existing literature shapes the research questions of this project. Because research of South Sudanese in Canada and specifically Ottawa is lacking, this literature allows for the identification of gaps and therefore avenues for further analysis in this thesis. Although a majority of the Canadian South Sudanese and Sudanese diasporas share a history of escaping a country plagued by conflict, it is important to stress that they are not monolithic in their backgrounds. Therefore, it is imperative to distinguish the pre- and post-migration experiences of South Sudanese, especially since these distinctions and classifications persist long after they immigrate to Canada (Fanjoy, 2015). The existing research provides useful data on the unique experiences of South Sudanese living in Ottawa, however it is lacking.

According to the 2011 National Household Survey Data from Statistics Canada, there are 16,595 Sudanese living in Canada, 8785 males and 7810 females. Living in Ottawa, there are roughly 965 Sudanese, 485 women and 480 men. Majority of these individuals arrived in Canada between 1991 and 2006 as refugees escaping conflict. According to a study conducted by Culture, Community and Health Studies program (CCHS) in 2004, 90\% of the Sudanese in Ottawa that were interviewed, arrived as government assisted refugees (GAR), 7\% as landed in Canada refugees (LCR) and 3\% family class immigrants (FCI). The Citizenship and Immigration Canada report estimates that it is much larger than what has been reported. It is difficult to know the actual numbers of South Sudanese in Canada and in Ottawa, as census data relies on the assumption that Canadians self-report accurately. In addition, many members of the South Sudanese communities in Ottawa have been in other countries, whether during migration, or throughout Canada, so they report that they are from other places. In 
addition, issues between the Northern and Southern Sudan, prevent people from identifying as Sudanese, specifically if they are from the South. It is also important to note that South Sudan had just become a country at this time.

The province of Ontario hosts the largest number of Sudanese, followed by Alberta, British Columbia, Manitoba and Saskatchewan. The Sudanese population in Canada is relatively young and moderately educated (CCHS, 2004). In fact, the 2011 Statistics Canada data shows that a large number of Sudanese in Canada have acquired their post secondary education outside of Canada. Those from the Northern and central areas of Sudan have higher levels of education, and those from the South are much less educated (Madibbo, 2015). Some living in Canada have managed to successfully economically integrate; gaining employment that corresponds to their qualifications, both academically and professionally. According to data collected by Madibbo (2015) there are Sudanese employed by governments, working as university lecturers, engineers, physicians, IT specialists, and running businesses in fields such as translation and consulting, for example.

In Ottawa, the diasporas are fairly diverse, consisting of many highly qualified personnel, however, many are un- and under-employed; such as former lawyers and teachers who are working as taxi drivers (Madibbo, 2015). Similar to many new immigrant groups, regardless of country of origin or host country, the exclusion from the labour market is caused by the non-recognition of international education credentials, communication problems due to lack of proficiency in English or French, and racism and discrimination (The Mosaic Institute, 2009). In the CCHS report, Sudanese living in Ottawa identified employment as the greatest settlement challenge as well as the second 
highest community concern. Ottawa being a bilingual city plays a large role in this barrier to employment.

Madibbo (2015) writes that because members of the Sudanese diaspora in Canada are largely first-generation, their goals are two-fold: to improve their adaptation, settlement and integration in Canada, as well as contribute to reconstruction and peace building within South Sudan. In terms of the first goal, within the Sudanese diasporas, settlement needs are the same in terms of finding support and social capital from family members and the ethnic community, however, the South Sudanese population is unique in the sense that "internal complexities of ethnic composition exists as a major feature" (CCHS, 2004). Since the late 1990's, Sudanese in Canada started to establish community organizations to provide settlement and integration services and to strengthen the cohesion of the community. Some examples are the Sudanese Association of Ontario in Toronto and the Sudanese-Association of Ottawa. There are also tribal specific organizations and groups such as the Beja Organization of Canada and the Sudanese Neur Community Association of Edmonton. Although all of these enhance settlement to some extent, insufficient funding and infrastructure prevent their success. This is not the only limitation, however. In terms of the Sudanese diasporas in Canada, maintenance of ethnic diversity and cultural values is both a strength and weakness in the settlement and adaptation process. Settlement needs are the same within this group in terms of finding social capital from family members and the ethnic community, however, the South Sudanese population is unique in the sense that there is significant community fragmentation on ethnic and political lines, especially (CCHS, 2004). 
Tribalism acts as the basis for community fragmentation through a person's ethnicity, and this can be more important than belonging to a group of people who come from South Sudan (CCHS, 2004). In fact, according to the CCHS (2004) report, rivalry between different Sudanese ethnic groups was the most important adaptation concern for $27 \%$ of participants. In extension, rivalry between tribes in Ottawa was more important than employment or housing. All other cities had it ranked second or lower, and some cities ranked it at no importance. Unfortunately, this unique issue to Ottawa has not been further explored.

Studies have not considered the ethnic, linguistic, gender differences, deeply held cultural and political identities and a range of different life experiences of Sudanese in Canada. We need to recognize how these divisions in the community can impinge on the health and wellbeing of South Sudanese. Research shows that ethnic bonds are essential for facilitating integration and for emotional and mental wellbeing in immigrant communities (CCHS, 2004). However, one wonders as to the extent to which this might be true for South Sudanese considering the violent nature of the interethnic rivalry, especially in South Sudan's post-independence era. In addition, in order to meet challenges of integration, policy makers and government programs must grapple with several formidable issues, both specific to South Sudanese newcomers and some generalizable to immigrant and refugee groups in Canada. However, providing services can be a difficult challenge when the diversity within the newcomer population is significant (Abusharaf, 2002). For example, linguistic and ethnic differences act as barriers in terms of services, specifically in terms of matching new immigrant and 
refugee service providers. In addition, unique pre-migration stressors call for different needs once in Canada (The Mosaic Institute, 2009).

South Sudanese in Canada remain connected to their home country and maintain close relationships with family and friends there. Members remain closely connected by often making return trips, and continually participating in the many political groups across Canada (Madibbo, 2015). Communication is carried out through emails, phone calls, letters and trips back to South Sudan. South Sudanese refugees and immigrants also send remittances to friends and family back home, and in fact, Sudan is one of the top remittances receiving countries in the world (Abusharaf, 2002). This money assists in securing family basic needs for education, healthcare, food and housing. It also benefits collectives back home, which build schools and clinics in marginalized and war-affected areas (Madibbo, 2015).

South Sudanese in Canada are actively involved in politics of South Sudan. In a number of cities, they have formed chapters of major political parties and organizations such as the Sudan People's Liberation Movement or Democratic Union Party. In addition, they have formed multiple advocacy groups in order to raise awareness about the political situation in South Sudan. Many of these groups go to schools or host events in order to inform South Sudanese as well as others about the situation (Madibbo, 2015). Many of these groups host activities that support the political process, albeit the many different positions, in Sudan. Research has failed to address these divides and their impact on everyday lives of South Sudanese. 
The CCHS (2004) report provides important insights into the South Sudanese population in Ottawa, although it is mainly quantitative. Mental and physical health problems are one of the major focuses of the report. The main concerns were lost sleep over worries and bad memories, but $64 \%$ identified being happy and healthy. Although this link was not directly made, the mentioned "worries" can be assumed to be those listed under the main concerns reported (employment, fragmentation and housing). Coping mechanisms were not addressed, however those living in Ottawa reported most likely to seek support from friends and family. Women were significantly more likely to seek any type of support.

It is important to note the factor of gender while discussing post-migration experiences. According to the CCHS (2004) study, members of the South Sudanese diaspora in Canada are highly affected by changing marriage and gender relations. Eighty one percent $(81 \%)$ said that since settling in Canada, they have experienced increased problems, worries and stress in their marriage. A similar percent said this is the result of changes in gender roles. Marriage often occurs at a young age in South Sudan. According to the Southern Sudan Household Health Survey (2010), 45\% of women are married before the age of 18 , and $7 \%$ marry before their 15 th birthday. In addition, polygamy is widespread in South Sudan, with about $41 \%$ of all marriages being polygamous unions. Marriage is of great importance in the culture, forming the very foundation of society, and is pivotal in determining and shaping the everyday lives of men and women, specifically gender roles. Within the context of marriage in South Sudan, the roles of men and women are very strict, and deeply rooted in tradition. Therefore, when arriving and 
settling in Canada, men and women struggle with the sudden change in gender expectations.

A final significant concern identified by the CCHS (2004) study is the issue of housing. This concern is interesting specifically in terms of Ottawa. Eighty-one percent (81\%) of respondents said that increasing costs of housing was a major problem and a majority live in non-subsidized housing. That said Ottawa has the highest number of Sudanese living in subsidized housing even though the quality of housing is a major problem. For instance, $77 \%$ of those from Ottawa said that size of housing is a major concern. In addition, the number of people using housing services is lowest in Ottawa. This issue has not been explored. The foregoing discussion of Sudan and the South Sudanese people has outlined pertinent issues related to context and scale, historical depth, and structural relationship, three key elements of political ecology, to which the next chapter turns. 


\section{Chapter: Political Ecology of Health Framework and Feminist Political Ecology}

\subsection{Introduction}

In exploring the personal, familial and contextual situations that arise from the experience of migration, and how these circumstances underpin South Sudanese immigrants' experience of health and wellbeing, this study integrates perspectives from political ecology of health framework $(\mathrm{PEH})$. Political ecology of health is an amalgam of political ecology and population health. Because health is a gendered experience, this study also incorporates perspectives from feminist political ecology (FPE). Perspectives from these two theoretical frameworks provide a lens through which to examine the health and wellbeing of South Sudanese immigrants. This chapter first outlines each the tenets of a political ecology of health framework, and in addition, describes the theory of a feminist political ecology. It ends with the explanation of the applicability of both theories to this particular study.

\subsection{Political Ecology (PE)}

Political ecology is a social theory whose primary concern is explaining the complex relationship between issues of the natural environment and broader social, political and economic processes (Bebbington et al., 2009). Blaikie and Brookfield (1987) define the political ecology framework as concerned with integrating the concerns of ecology and political economy into a single analytical framework in order to provide explanation of processes underlying environmental change (cited in Robbins, 2011). In particular, political ecology initially sought to provide a better understanding of why practices which otherwise compromise the integrity and viability of the environment seem rational to local farmers who practice them (Blaikie, 1985). This led to a clearer 
understanding of the processes that underpin peasants' integration into and transformation by the global economy (Blaikie, 1985; Peet \& Watts, 2004).

A major analytical strength of the political ecology framework is its outright rejection of the conventional wisdom that places blame for the failure of soil and environmental conservation programs on the inability to manage these programs or Malthusian accounts of overpopulation. Political ecology represents a shift away from simplistic explanations of land degradation by reframing the debate on soil conservation in social and class terms. According to Blaikie (1985), the apparent environmentally unsustainable activities of people do not result from ignorance, but they are deliberate survival or adaptive choices enacted in direct response to extractive pressures from the state and other social classes that depend on the people for surplus value. By situating people in relation to state power, political ecology shifts attention to mechanisms through which wider political and economic systems dictate agrarian practices at the local level (Bebbington \& Batterbury, 2001).

\subsection{Applications of Political Ecology of Health Framework (PEH)}

Over the years, medical geographers have adapted perspectives from political ecology in order to understand how diseases emerge within the context of human-nature interactions. The major concern of $\mathrm{PEH}$ is discerning pathways through which the workings of the wider political economy filter down to and interact with the local level, social, political and historical and circumstances, to produce a distinct set of conditions that propel people into close contact with disease-causing pathogens (King, 2010; Mayer, 1996). Three aspects of the PEH framework are most relevant for this study in terms of understanding the deteriorating health of South Sudanese in Canada. The first is context. 
From a PEH perspective, context refers to environmental condition, broadly defined, underlying the health and wellbeing of South Sudanese immigrants.

The second is multiscalar analysis, which implies recognition that health results from numerous factors operating at multiple scales of time and space (Kalipeni \& Oppong, 1998). Historical depth is an important consideration here, as it relates to understanding how changes in the structure of society correspond to changes in the health and wellbeing of groups of people over time (Kalipeni \& Oppong, 1998; Mayer, 1996). In $\mathrm{PEH}$, the need for historical analysis is in response to the fact that interactions of society-environment take a long time to produce changes in the health profile of groups or populations (Mayer, 1996). The third element of PEH is structure and human agency; paying attention to how actions of social actors enact changes in their environment in which they live but also how society constrains the actions of those actors (Kalipeni \& Oppong, 1998).

The explanatory power of PEH lies in part in its breadth and flexibility in providing rigorous answers to investigations about past and present sources of disease (Kalipeni \& Oppong, 1998; Mayer, 1996). One of the strongest calls for the application of political ecology to the study of health was from Mayer (1996), who argued that a political ecology of disease approach would help to clarify how the workings of social, economic and political forces taking place on a larger scale cascade downwards to produce distinct changes in the structures and events in local areas. Mayer (1996) argued that a focus on political interests, social institutions and human-environment interactions would contribute a greater systemic understanding of health and disease. 
Mayer's work, however, has been criticised on several grounds, including for placing too much emphasis on disease instead of health and wellbeing (Jackson \& Neely 2014; King, 2010). King (2010), for instance, argues that Mayer's (1996) presentation of political ecology is overly narrow and that "the theoretical and epistemological diversity of political ecology needs to be fully engaged to properly understand human health" (p. 44). Within the sub-discipline of medical geography, most of the critiques of Mayer's work cite earlier work by non-geographers, especially Turshen (1984), as examples of more robust application of PEH to health and disease. Turshen (1984) conducted research in Tanzania and used political ecology to understand how disease is socially produced and linked to political and economic systems that advance power of particular people. In particular, Turshen (1984) asserts that understanding health in Tanzania demands attention to colonial power as well as spatial patterns linked to political and economic arrangements that advanced that colonial power.

Empirical studies that employ PEH to understand health are still limited but steadily growing. Within this literature, however, it is evident that PEH can be adapted to the analysis of health in a variety of geographic and historic settings. From the developing world, for instance, Kalipeni and Oppong (2005) used PEH to look at the correspondence between conflict and the refugee crisis in Africa on the one hand and the spread of disease on the other. Their study argues that the same violence that creates the refugee crisis also disturbs livelihood systems, diverts government spending away from health care and increases exposure to disease in poorly sanitized camps. Hunter (2003) demonstrates how broader political processes and decisions affect population health. Hunter (2003) notes that in 1957, Ghana commissioned a massive agriculture project, 
building 185 clay dams to celebrate independence. He found, that the lack of funds to maintain these dams has caused extremely unclean drinking water. This water is the direct cause of local people's suffering from waterborne diseases such as "bloody urine" at a time when the health care system is fiscally unable to deal with.

Similarly, Bond and Vincent (1991), used PEH in their study of HIV/AIDS in Rakai in Uganda, where they found that more than three quarters of prostitutes test positive for HIV. Interestingly, they found that a particular group who frequently exploit prostitutes, international truckers, have a 33\% HIV positive rate. This high prevalence in this area is attributed to the interconnectedness of this region and industry to the world.

Using case studies of a recent cholera outbreak in Zimbabwe and HIV/AIDS in South Africa, King (2010) argues that a political ecology approach to research is suited to understand the underlying structural conditions that shape and contribute to producing disease and the subsequent social and environmental impacts. King (2010) makes specific reference to access to healthcare, gender power relations and survival strategies in the household as pathways through which an epidemic could affect societies and economies. He stresses that research on human health within a political ecology framework must look at the reciprocal relationships between health and environment, as well as reveal the ways in which health vulnerabilities, and the opportunities for healthy decision-making, are socially produced over time.

A key example demonstrating the application of PEH in the developed world is the study by Richmond et al. (2005), who applied this approach to understand how changes in the environment and economy corresponded to changes in health and 
wellbeing among the Namgis First Nations in British Columbia in Canada. More specifically, the authors found that the Namgis' decreased participation in the local economy, caused by an expanding commercial aquaculture industry that displaced their livelihoods such as fishing, has resulted in overall decline in the health and wellbeing of this group of First Nations.

While not exhaustive, the foregoing analysis demonstrates the applicability of the PEH framework to a range of contexts and thematic issues. The current thesis project attempts to extend the applicability of the political ecology of health framework to the understanding of population health in the context of diaspora. More specifically, the PEH framework allows for the exploration of how health and wellbeing in local contexts are impacted by broader processes such as migration and conflict. In order to adequately understand the everyday health experiences of South Sudanese living in Ottawa, not only do we need to recognize local factors such as the physical landscape, social environment within the home, policies and local laws, but consider how these localized experiences are impacted by, or a product of broader experiences of migrating to Canada, or relationships to family members back in Sudan. For example, how does the issue of ethnic and political tensions in South Sudan trickle down into the lives of those living in Ottawa, and how does this impact health on the everyday local scale? The PEH framework provides a lens to assist in understanding these issues in their scalar complexity, and how they impact health.

\subsection{A Feminist Political Ecology of Health (FPEH)}

Finally, this thesis aims to integrate perspectives from feminist political ecology into the PEH framework in its analysis of the deteriorating health of South Sudanese in 
Ottawa. Feminist political ecology extends analysis of power to include gendered relations (Rocheleau, 1996). In the most basic sense, what a feminist would be concerned with within the context of PEH is the ways in which processes operating at different scales of time and space, produce gendered health impacts in different populations. In other words, feminists would ask about the sense in which there is a gendered dimension to such processes and impacts, and how they might intersect with feminist practices (Elmhirst, 2011). Dianne Rocheleau (1996) has been foundational in integrating feminist perspectives into political ecology framework more generally and she urges political ecologists to extend their analysis of power to include gendered relations.

A major contribution of feminist thought to gender analysis is that gender is not an anchored or fixed factor, but a variable constant (Rocheleau 1996). Gender dynamics are always present, but they change and shift over time and in different contexts. Thus, feminists understand gender not as pre-given, but as resulting from dealings with other people in particular social contexts, and that the precise outcomes of those interactions depend on other variables such as class and race. This, for example, racialized and/or gendered experience becomes integral to understanding people's experience of health.

Understanding gender as a flexible and changeable variable, has called for new scales of analysis in political ecology research. For example, Rocheleau (2008), called to include the household as an important space of inquiry, a call that challenged established areas of research and inquiry. Because the experiences of women were often associated with the private and domestic, they were not considered in research. With the inquiry of the household, women's experiences are now visible and part of the broader research agenda, highlighting important issues of gender inequality and marginalization in the 
day-to-day. Since then, many papers illustrate the analytical value of incorporating scale in the analysis of gender relations (Elmhirst, 2011).

Recent papers that use a feminist political ecology of health framework focus on the connecting of scales ranging from the body to the national. For example, a paper by Ge, Ressureccion and Elmhirst (2011) use a feminist ecology of health approach to show the translation of return migrants' social remittances into new ideas and practices in home communities and how they alter existing social positions and existing gender hierarchies. Studying a rural Chinese village, the authors found that the "leadership and collective action of female return migrants destabilized power and authority in the village" (p. 136). This encourages political ecologies to take feminist conceptualizations of politics seriously and recognize gender as a constitutive force at all scales of analysis, rather than considering gender only existing in closer scales such as the body or household (Elmhirst, 2011). Wright (2010) argues that using a feminist political ecology approach highlights the production and reproduction of power relations at the level of intimate but also at national and international scales. The intersectionality of factors such as being a woman, a racial minority, and an immigrant can create unique life experiences for some groups in ways that directly affect their health.

Recognizing gender as a crucial variable in the experiences of health and wellbeing works to bring attention to the experiences of South Sudanese immigrant and refugee women living in Ottawa. As Fanjoy (2015) suggests, the experiences of migration and integration are often different for men and women, and it is crucial to explore what these experiences are, and how they impact health. In this study, bringing gender to the forefront as an important factor impacting the everyday lives of South 
Sudanese in Ottawa brings attention to issues such as domestic violence, and its link to difficulties of integration for South Sudanese males. It also brought attention to women's roles in supporting their families in Ottawa and back home, as well as often being the main drivers of promoting peace and unity within the diaspora, despite rising ethnic tensions. All of these issues have health implications for women, and they are important to study and understand. FPEH shines a light on these everyday health experiences. 


\section{Chapter: Research Methodologies and Methods}

\subsection{Introduction}

In this chapter, I describe the research methodologies and methods used, as well as highlight their applicability to this research. In doing this, I have separated this chapter into five sections. First, I discuss why the use of qualitative methods and methodologies was appropriate in fulfilling the research goals of this study. Second, I explain my use of post-colonial and feminist methodologies in this study, specifically the practice of critical reflexivity and relationship building. Third, I outline recruitment methods used, including purposive sampling, maximum variation and snowball sampling, along with the challenges I faced during this phase of research. Fourth, I discuss research methods i.e. focus group discussions and in-depth, semi-structured interviews and also outline why I used these methods. This is followed by a discussion about my personal experience with interviewing South Sudanese immigrants as a white Canadian woman. Fifth and finally, I will explain the reasoning behind using grounded-theory as the main form of dataanalysis.

\subsection{Qualitative Research Methodology}

As mentioned, the general goal of data collection is to examine the everyday health geographies of South Sudanese Canadians living in Ottawa, and to determine how these experiences are linked to structural factors like migration, conflict, ethnicity and gender. As a large-scale quantitative study would not have been appropriate for providing an in-depth understanding of how unique experiences of migration, ethnic conflict or gender impinge on the health of South Sudanese Canadians in Ottawa, this study uses a qualitative approach. According to Winchester and Rofe (2010), qualitative research in 
human geography is mainly concerned with elucidating human environments, individual experiences and social processes, all within a variety of conceptual frameworks. In other words, it pertains to understanding the relationship between human experiences, their social and physical environments, and the structures that govern them. In this case, what is meant by structures, is the functioning systems, social, political or economic, where individuals are located (Sayer, 1992).

Qualitative research approaches in human geography recognize that the experiences of people cannot be entirely determined or understood by their personal characteristics, but also their location within a social structure (Winchester and Rofe, 2010). An example of a social structure particularly relevant to this study is patriarchy. Patriarchy is a social structure where men hold power and women are largely excluded from it. The recognition of social structures such as this, allows for the analysis of how factors like gender shape health and wellbeing to extend beyond the characteristics of individuals. This means that the health and wellbeing of South Sudanese women living in Canada cannot be adequately understood by considering their everyday experiences in isolation of their position in a patriarchal society. Because of this, a qualitative approach permits a deeper understanding of how South Sudanese immigrants and refugees came to arrive in Canada and how their lives have unfolded within the cultural and socio-political contexts of their new homes as well as political events back in South Sudan. Answers to these questions establish the context for understanding their health.

This suggests that what qualitative research tries to answer can be broken down into two parts (Winchester \& Rofe, 2010). Qualitative research methodologies are used when the aim of research is to (1) understand how societal structures are constructed, 
maintained or resisted, as well as (2) the individual experiences within structures and places (Norton, 2004). This is particularly why qualitative research methods such as focus group discussions and in-depth interviews lend themselves well to the elucidation or inquiring of how structural factors shape everyday health and wellbeing of South Sudanese immigrants and refugees living in Canada. A focus group research method is one of many group techniques used in qualitative research projects. Generally, this method lasts around 1-2 hours and involves a small group of 4-10 people discussing a topic or issue defined by the researcher (Cameron, 2006). An in-depth, semi-structured interview method is also a qualitative research method that lasts about 1 hour and involves a conversation between the researcher and one participant. A semi-structured interview is an interview with some pre-determined order but also has flexibility with regard to the position and timing of questions (Dunn, 2006).

Throughout the interviews and focus groups, I was able to identify the many structural forces that influenced the lives of South Sudanese immigrants living in Ottawa, and their role in shaping health experiences. This is an essential facet of my research questions and goals, because I am largely interested in how structural factors such as policy, health care, gender inequality, racism, conflict, ethnicity and culture relate to health experiences. Although these factors are pre-determined, primarily derived from the literature on previous studies on the health of South Sudanese immigrants, the openended nature of qualitative approaches, allows me to explore the issue of declining health status among South Sudanese Canadians without predetermined categories of analysis, leading to depth, openness and quality information (Patton, 1990). In other words, participants are allowed the opportunity to identify the significant structural factors to 
their health on their own. For example, within the first focus group discussion, participants were asked to list the main factors influencing their health in daily life such as socioeconomic status and migration. These factors will be discussed at greater length in the methods section of this chapter.

In addition to providing a better understanding of structural factors, focus group discussions and especially interviews, allow space for participants to discuss their individual, everyday health experiences with much more detail and consideration. Through reading the existing literature on declining health of South Sudanese immigrant communities, I hold a basic understanding of some of the health issues this population is facing. But gaining a deeper understanding of how everyday experiences of South Sudanese immigrants and refugees reflect or contest the existing information can only be done through conversations with community members. Partaking in genuine conversations with research participants, allows them to provide their own understandings and experiences of health in their everyday lives in Ottawa, and draw their own conclusions about their own health as well as the wellbeing of the community at large.

Because qualitative approaches such as focus groups and interviews allow for dialogue between community members and the researcher, they incorporate a resistance stance. In research, when people are given the opportunity to speak for themselves and tell stories about their own experiences, they reveal hidden realities that often counter and complicate dominant narrative (Hesse-Biber, 2013). Interviews in particular become a platform for participants to voice experiences that countered existing information about their experiences as immigrants or refugees. For example, throughout the interview 
process in this project, South Sudanese women challenged common narratives about gendered divisions of labour. Although women traditionally stay in the home, many participants told their experiences of also adopting the role as the main breadwinner of

the family. Although participants described this experience as a burden on their health, it was also a source of empowerment. Here it is evident that qualitative methodologies exercised through a feminist political ecology of health lens can highlight the views and experiences of marginalized groups in understanding the dynamics of sexist oppression (Rocheleau, 1996). These stories have been critical to pinpointing the causes of health decline in this community, therefore highlighting the utmost importance for the use of qualitative methodology.

\subsection{Post-Colonial and Feminist Methodologies}

This project employs both post-colonial and feminist methodologies. Although each of these methodological approaches is somewhat different, the nature of this project calls for the consideration of both. Feminist and post-colonial methodologies have quite a few similarities; both are concerned with power, and provide responses to dealing with potentially exploitative and unequal power relationships within research. More specifically, each methodology calls for critical reflexivity and relationship building as a way of mitigating power relationships and thus conducting ethical research (Dowling, 2010). This section will describe both post-colonial and feminist methodologies as they relate to this particular research project. First, I will focus the discussion on post-colonial research methodologies, followed by a discussion of feminist methodologies. After this, I draw from each methodology, and explain the use of critical reflexivity and relationship 
building in multiple stages of my research. This section will segue into the discussion of using semi-structured, in depth interviews and focus group discussion research methods.

To begin, according to Hay (2010) post-colonial research rejects the goals, attitudes, representations and methods of imposed colonial research. With the use of postcolonial methodologies, the aim is to conduct research that is: welcomed by participants, fosters equal relationships between those involved in research studies, values local knowledge and ways of knowing, contributes to the empowerment of marginalized and oppressed people and groups, and provides tools they can use to transform their own situations and conditions. This requires acknowledging and rejecting the dynamics of power that shape colonial research interactions with marginalized groups in order to overcome the ethnocentrism that researchers can bring to their projects (Howitt \& Stevens, 2010). Researchers must be willing to put their preconceptions aside, listen to research participants and be a service to their locally defined concerns.

Similarly, feminist research also recognizes that research activity is interwoven with relations of power. Although there are several strands of feminist methodologies, the main work of those who do research within a feminist geography paradigm is to analyze "power, privilege, oppression and representation, with gender foregrounded as the primary social relation" (England, 2002, p.286). Feminist research recognizes that research often creates situations where people are differently situated in relation to social structures, and therefore occupy different speaking positions and capacities to make changes (Liamputtong, 2007). Feminist methodologies are sensitive to power relations between researcher and research subject, and encourage researchers to reduce the distance by seeking relationships based on thoughtfulness and respect and focus on the 
participants' own understandings of their circumstances, rather than imposing their own (Dixon \& Jones, 2012).

Power relationships in research cannot be completely eliminated, but it is important to be aware of and understand them, respond to them, and modify roles when appropriate (Dowling, 2010). Both post-colonial and feminist methodologies provide responses to these power relationships. In this research project, derived from both methodologies, I apply the practices of critical reflexivity and relationship building. These practices can take many forms throughout the research process. In the remainder of this section, I will describe these two practices as post-colonial and feminist methodologies in relation to how I adapted them in my research process.

First, post-colonial and feminist methodologies recognize that mitigating unequal power relationships requires the researcher to reflect on their position within a research project, especially in terms of considering the ethical implications of their role (Dowling, 2010). This practice is known as critical reflexivity, and is the constant, self-conscious consideration of how your social role and your research interactions impact your research process (England, 1994; Rose, 1997). On numerous occasions throughout the research process, I engaged in conversations with participants and during these interactions, I strived to constantly be conscious of my social position as a White woman engaged in research with African men and women, for instance. Aware that elements of my subjectivity could not be fully controlled, I thought about how I could be influencing the data. I kept notes about how I felt throughout the data collection process. A common theme throughout these notes was concern about how I was influencing the stories that participants shared in interviews and focus groups. As a White woman, I specifically 
toyed with the insider/outsider debate in research; at times being confused about my place in the research project, specifically in relation to participants.

After the first focus group I wrote a passage that worked through my position within my research. Below is a segment of my writing that best captures how I was feeling:

We were collaboratively working on creating a framework that best captures the issues facing the communities. But I'm worried that when there was silence, instead of rephrasing the question, I suggested answers. I am also afraid that I pushed the issue of health too much. I believe that once I brought things up, participants had a lot of great things to say. I just need to be careful not to put answers in their mouths.

Recognizing that my role might have influenced the participants' contributions helped me improve as a researcher in the subsequent focus groups and interviews. In the following focus group, I tried to be more aware of my position as a researcher by acknowledging how I influenced the data collected. Thus, recognizing my outsider status as a White researcher, I became aware that my knowledge is situated and partial, attesting to the idea that concepts such as knowledge and truth are always inseparable from the lived experiences of the researched (Haraway, 1991). This concept presupposes that the denial of biases is unrealistic and undesirable (Haraway, 1991). Feminist methodology emphasizes the role of the situated knower to reflect the importance of diverse ways of knowing (Naples \& Gurr, 2010). Failure to recognize my situated knowledge as a researcher denies the respect for participants' alternative ways of knowing.

Howitt and Stevens (2010) argue that researchers have a responsibility to learn and respect culture, especially as it can directly shape the reception and quality of 
information retained. In both feminist and post-colonial research, a way to ensure this is by involving participants in determining the research goals (Bradshaw, 2001). For example, many researchers seek participants' perceptions of what requires investigation in a community, rather than decide for themselves as experts. With that being said, as a researcher, it is important to listen carefully, especially of how meaning is constructed cross-culturally. This is why I decided to conduct preliminary focus group discussions. Although I had research objectives in mind, I wanted to understand what issues were most important to the South Sudanese community in Ottawa. Therefore, the purpose of these focus groups was to allow participants to voice their concerns and through these discussions, shape the questions I would be asking in my interviews. In addition, because my focus groups and interviews were semi-structured and questions were open-ended, participants could guide discussions to issues they felt more relevant to their lives. At the same time, I had the flexibility to follow-up on points of discussion to ensure that I understood. This is discussed at greater length in the subsection on research methods.

In continuing to strive to remain open to different ways of knowing, I also worked towards building relationships with the research participants. Fostering this relationship is important, especially so participants feel comfortable sharing their personal experiences. In addition to conducting focus groups and meeting participants for interviews, I was fortunate to be invited to bi-weekly South Sudanese community meetings. Because I was in attendance at these meetings in addition to conducting my research, I began to form strong bonds of trust with the South Sudanese community and my research participants. This relationship building became evident throughout subsequent interviews; participants seemed to be much more trusting and comfortable speaking about their experiences. In 
addition to participants feeling more comfortable, I began to feel more comfortable and confident as a researcher. After a discussion with my supervisor, I wrote another journal entry, reflecting on how I no longer felt as intrusive in my interviews. Here is a section of this entry:

Initially I felt afraid to ask participants to follow-up on their answers. Acknowledging that I was the researcher made me feel like I was being intrusive. I didn't understand the line between asking good questions that will elicit the good answers and asking intrusive questions that will elicit discomfort. But as I have built relationships with the community members, as well as interviewed quite a few participants, I feel much better equipped to deal with this dilemma. I not only feel like I have built a level of trust with participants but trust in myself.

As interviews continued, I felt that they began to flow much more like a conversation, than a formal interview. Although I had a research agenda, the interviews became less of an investigation of health and wellbeing, and more of an opportunity for participants to voice their experiences and concerns. As a researcher, I learned how to put my preconceptions aside, listen to participants and be a service to their locally defined concerns. However, mitigating the researcher-participant power relationship became more difficult once I began to interview second-generation South Sudanese refugees and immigrants. As I began asking second-generation participants questions about the conflict and ethnic tensions in South Sudan, I soon realized that because of the research I had done on these issues, I knew things that they did not. It was difficult for me to avoid assuming the role of "the expert" and mitigating unequal power relationships that shape colonial research. After another conversation with my supervisor, I reflected on this experience and wrote: 
I was caught off guard when the participant yesterday was unfamiliar with the tribal groups within the South Sudanese community. I do not want to seem like I am the expert, and make the participants feel bad for being unable to provide insights on certain issues that pertain to the health of the community. I expressed my concerns about interviewing the second-generation participants to [my supervisor] this afternoon, and we talked through it. We talked through it and decided that I should stick with my general and open-ended questions about health, but instead of worry about touching on all of the questions on my checklist, follow up on the issues that they decide to raise. I am going to treat the information they provide, although it may not be what I was looking for, as legitimate data. I will continue to treat these interviews as a conversation allowing participants to voice their local experiences and concerns.

My knowledge of post-colonial and feminist research methodologies helped me recognize this as a potential ethical issue. Reflecting on and talking through this issue with my supervisor helped me mitigate this potentially harmful research relationship with participants. In addition, my experience interviewing and the relationships I had built to that point in my research process, made it easier for me to adjust to interviews with second-generation immigrants. To conclude, applying these methodologies helped me be a good researcher. They equipped me with the tools I need to practice and continue to strive for ethical research.

\subsection{Recruitment}

This sub-section will outline the recruitment methods used in this study, describe how they were used for finding research participants, and through the use of examples, explain their effectiveness in this project. Primarily, recruitment in this study followed the method of purposive sampling and maximum variation. First, purposive sampling is a sampling procedure that intends to obtain a particular group for study on the basis of the specific characteristics they possess (Strauss and Corbin, 1990). By recruiting a group of participants based on specific criterion, I was able to ensure that the participants were 
better placed to shed light on the central issues of the study (Cameron, 2006). In addition, I applied the sampling method of maximum variation. According to Patton (1990) maximum variation allows for "any common patterns that emerge from great variation to be of particular interest and value in capturing core experiences and shared aspects of a phenomenon" (p. 172). In other words, my goal was to find shared health experiences, but I was also prepared to use varying experiences as valuable data.

Because I was particularly interested in understanding the individual experiences of health, this sampling method was ideal, as it has the capacity to highlight "highquality, detailed descriptions of each case and important shared patterns that cut across cases" (Patton, 1990, p. 172). For example, because I was particularly interested in understanding the gendered aspects of the migrant experience, I needed to select a diverse group of both male and female participants. Additionally, because I was also interested in paying particular attention to migration trajectories, recruitment had to ensure a diverse range of migration experiences and trajectories in the sample. Thus, within this project I was not attempting to generalize findings to all people or all groups but looking for information that revealed variations as well as common patterns (Cameron, 2006).

\subsubsection{Recruitment for Focus Group Discussions (FGD)}

Recruiting for focus groups began immediately after ethics clearance early September 2016 (See Appendix A for clearance certificate). I had a contact in the South Sudanese community in Ottawa whom I had previously met. This person agreed to distribute my letter of introduction (see Appendix B) to potential research participants. Within a week, I had enough participants to schedule the first focus group discussion. All potential participants agreed upon a date, place and time, and the first discussion occurred 
the following week. Shortly after the first discussion, I had responses from even more participants and planned a second and third. I was surprised about how quickly and easily plans came together. The experience that I had recruiting participants for focus groups was positive and kept me hopeful for recruiting participants for my following oneon-one interviews.

\subsubsection{Recruitment for In-depth, Semi-Structured Interviews (IDI)}

Unfortunately, recruitment for interviews was not as easy. Because I was able to ensure anonymity in my interviews, I had to recruit participants by myself and without the help of my community contact. The first five interviews were conducted with participants who reached out to me after the focus group. However, when I found myself reaching out to the participants, many expressed interest, but did not have the time, or they simply did not return my calls. For most of October, I unsuccessfully completed any interviews, and I began to be quite concerned about finding more participants. Although I had data from my focus group discussions, interviews were an extremely important component to my thesis. I wanted the chance to listen to the very unique and detailed experiences of individuals. This is something that I could not receive from a large focus group discussion. Although I had been asking participants to provide me with the contact information of other potential participants, I had received no leads. Therefore, in late October, I decided to use chain or snowball sampling more seriously.

Snowball sampling is a useful recruitment strategy as it identifies cases of interest reported by people who know other people involved in similar cases (Bradshaw \& Stratford, 2010). I also chose this method because of its reliance on social networks. Browne (2005) writes that snowball sampling is extremely effective in the recruitment of 
marginal or hidden populations. This strategy's use of social networks, such as friends and family, for example, can be complementary to methods that rely on the categorization of groups, and allows participants to come forward themselves. Because I wanted to examine a diversity of experiences and perspectives, I used my connections to the community and contacted some of the participants that I already interviewed. I explicitly asked these participants if they could provide me with the contact information of potential participants to interview.

\subsection{Research Methods: FGD's and IDI's}

In order to obtain rich, contextual data about the health experiences of South Sudanese Canadians living in Ottawa, I used focus group discussion and in-depth interview methods of data collection. Focus group and interview guides are located in Appendices E and F.

\subsubsection{Focus Group Discussions}

The first method of data collection that I used was focus group discussions. In a focus group, multiple respondents are interviewed together, making it distinct from oneon-one methods of interview (Hesse-Biber, 2006). In total, I conducted three focus group discussions (FGD) involving a total ( $\mathrm{n}=21)$ participants. Of these participants, 12 were women and 9 men, with 19 being first generation and 2 second generation immigrants or refugees. The FGDs took, on average, about 1.5 hours to conduct. Breen (2009) stresses that researchers should know what it is that they want to get out of their research in order to know whether or not a focus group method is appropriate. In applying a political ecology of health, I sought out to understand health experiences on multiple socio-spatial scales, and the structural factors that influence them on a daily basis. 
Focus groups are useful if you are looking for the range of ideas or feelings people have about something (Krueger, 1998). This aspect was useful, because I wanted to know how members of the South Sudanese community in Ottawa understood their own health and wellbeing. Therefore, I decided to use a focus group discussion in order to gain a richer understanding of the health related issues present within the communities. Not only was this an opportunity for me to learn more, but for members of the community themselves, to provide their own insights into the issue. Participants came up with a large and detailed framework of the main issues facing their communities both in general and in Ottawa, more specifically. This exercise was especially helpful in informing the questions to ask in the in-depth interviews, allowing me to explore these issues on the individual level.

In addition, focus groups provide an opportunity for people to explore different points of view, allowing the isolated ideas of individuals to provoke other participants to think of additional examples, and think about them differently (Breen, 2009). Focus group discussions are particularly useful in my research as a platform for the crossfertilization of ideas. In two of the discussions, the group was split into two groups of 3 to discuss the issue of health within the community in Ottawa. Each small group took notes and then came together and shared. This activity allowed for the collaborative generation of ideas and examples on multiple scales. The groups contested and built on each other's contributions. This provided common and differing experiences of health, as well as issues of contention or that many agreed upon.

Finally, Goss and Leinbach (1996) argue that the main advantage of focus group discussion is that during the process, researchers and participants may simultaneously 
obtain insights that can be used to effect social change, and empower the researched. One of the main discussion points was how participants envisioned addressing the issues that were previously raised. Participants collaboratively came up with ideas to enact change within their community. They shared ideas of a community centre for the South Sudanese living in Ottawa. Another idea was planning a youth meeting where all South Sudanese young people could come together and participate in activities such as a soccer game or a university tour. The focus groups provided a space for South Sudanese immigrants and refugees in Ottawa to discuss potential solutions to health issues within the community. Thus, not only did having a focus group aid in determining present health issues, but also creating plans for tackling them.

Each of the focus group discussions used in my research were held on Saturday afternoon in Dunton Tower on the Carleton University campus. Breen (2009) stresses the importance of location; it must be convenient for participants to get to, as well as a comfortable and safe place for them to share their experiences. Because I knew that I would be conducting two more focus group discussions, after the first focus group, I asked participants to provide their thoughts on the selected time and location of the meeting. All participants were happy with the time and location. We collectively decided to continue to hold discussions on Saturday afternoons, as it was the day with most availability for participants. We also chose to continue holding meetings at Carleton University, as many felt that they were already familiar with the location, and could conveniently take public transportation, drive themselves, or carpool with other participants. In addition, as per the advice of the Carleton Research Ethics Board, some participants may not feel comfortable discussing sensitive matters in their homes within 
earshot of other family members or neighbours. Because of this location, I offered participants a travel reimbursement equivalent to the cost of transit to and from the site of the FGD, as well as childcare costs.

\subsubsection{In-depth, Semi-Structured Interviews}

In addition to focus group discussions, this study used semi-structured interviews to collect information required for addressing the question of poor health among South Sudanese Canadians despite having access to Canada's health care. In total $(\mathrm{n}=10)$ interviews were conducted. Of these participants, 5 women and 5 men were interviewed, with 7 being first generation and 3 second generation immigrants or refugees. Each interview took between 30 minutes to 1.5 hours. A semi-structured interview is an interview with some pre-determined order but also has flexibility with regard to the position and timing of questions (Dunn, 2006). Interviews provide rich sources of data on people's experiences, opinions, aspirations and feelings (Kitchin \& Tate, 2000). In applying a political ecology of health framework, I wanted to understand the individual, everyday health experiences of South Sudanese immigrants in Ottawa, within the context of broader structural factors. In depth interviews provided much more information about health experiences on the individual level. Translation services were made available to participants, however all interviews were conducted in English.

Hay (2010) writes that one-on-one interviews create a better environment for more reliable answers. This is because they can be kept completely anonymous, potentially making the participant more comfortable sharing their honest opinions and experiences. In addition, unlike in a group setting, there are no other participants to potentially persuade and influence answers. For example, the women in particular opened 
up much more about their struggles in the home. Although the issue of gender roles came up in the larger discussions, women spoke much more openly about what that really looks like, in the one-on-one interviews.

The collection of a diverse range of opinions and experiences that interviews allow can provide insights into both disagreements and consensus on issues within a group (Dunn, 2006). This was important, because I wanted to know how health experiences were similar or different between South Sudanese, specifically in relation to factors such as gender, migration trajectories, status or generation. Therefore, interviews were particularly useful in determining the unique individual, as well as shared or differing, opinions and experiences of health within the group of participants. This was important throughout my data collection process, especially as I was specifically aiming to understand both the gendered and generational dynamics of health experiences within the community. The interviews provided me with a diverse range of individual experiences of both men and women, allowing me to see their very differing opinions on domestic violence, for example. In addition, interviewing both first and secondgeneration immigrants allowed me to learn about how their outlooks on life differ so greatly, without creating any tension like what could happen in a group setting.

Additionally, in terms of semi-structured interviews, it is important to consider the types of questions that are asked. I followed what Dunn (2006) refers to as a critical dialogue, which "requires that you constantly analyze what is being said and simultaneously formulate the next question or prompt" (2006, p. 116). Barriball and While (1994) describe this as 'probing' what is being said, allowing the interviewee to explore sensitive issues and provoke valuable information. Because the subject matter of 
discussions were often sensitive, this method allowed me to follow up on sensitive topics such as experiences living in refugee camps, without explicitly asking participants to share their experiences. In addition, this method also allowed me the flexibility to validate the meanings of respondents' answers. This was particularly useful in discussions around culturally specific terms or understandings of health and wellbeing. Therefore, the method of critical dialogue allows the researcher flexibility in directing the discussion towards issues of particular interest to this project's goals.

The semi-structured interview method also provided the participants with opportunities to decide or influence the interview arrangement. This was mainly because my questions were open-ended in nature. Although the interview checklist is simply a guideline, and questions were not asked in a particular order, I always started with the same question: "What do the concepts health and wellbeing mean to you in the context of your everyday life?" This gave participants the opportunity to take the discussion in the direction they felt most relevant to them. For example, a number of participants began discussing their daily exercise and meal routines, others spoke about balancing responsibilities at work and in the home and some told stories of how being an active member of the community promotes health. This method allows participants to highlight issues most relevant to their lives as well as the researcher the flexibility to probe issues of particular importance to research goals.

Confidentiality was ensured in FGD's and anonymity and confidentiality in IDI's. Each participant signed a consent form before discussions and/or interviews that outlined the process of ensuring confidentiality and/or anonymity (See Appendices C and D). In FDG's participants agreed to maintain confidentiality i.e. not use identifiers, while 
discussing the experiences of others, as well as outside of the discussion room. However, in this case, there was no full guarantee of anonymity. All participants gave their informed consent to be recorded, and were informed that they would not be referred to by name in these recordings, but by a pseudonym. A separate, written document with their personal identifiers was stored in a secure safe and away from the rest of the data collected in order to preserve confidentiality. All recordings were deleted once verified, paper data will be destroyed once the study is complete, and all other information will be destroyed 5 years after the project's completion. At no time were names or other personal information shared outside of my supervisor and myself. All data pertaining to this project, including recordings, were kept on a password protected and encrypted hard drive in a locked safe, only accessible by my supervisor and myself.

\subsection{Data Analysis: Grounded Theory}

The main method of data analysis used in this study was grounded theory. According to Strauss and Corbin (1990) "a grounded theory is one that is inductively derived from the study of the phenomenon it represents" (p. 23). In other words, a grounded theory is discovered, improved and verified through data collection and analysis of the data that pertains to that phenomenon. A grounded theory approach method was necessary as it yields findings that constitute a theoretical formation of the phenomenon under investigation (Stauss \& Corbin, 1990). Thus, the purpose of this method is to build theory that contributes to the area under study. This method was useful as I attempted to identify personal experiences of health within the South Sudanese community. Additionally, this type of analysis allowed me to organize and conceptualize 
my data so that it could be to guide further action, such as suggestions for policy changes or intervention.

NVivo 11 was used for data analysis to draw out themes in data. More specifically, I used Strauss' (1987) codes-to-theory model (See Appendix G). Using this model, I coded clusters of the data in my interview transcripts, into categories that merit further refinement. In this first round of coding, I identified 13 clusters. Once these categories were evaluated and compared, the categorized data were further pared down into five main themes. In the results section of this project, I wrote about each of these themes, highlighting how they systematically interrelated and lead toward the development of theory. This method of data analysis was of utmost importance to this particular project, as I was grappling with data (interview and focus group transcripts) that included a diverse range of meaning. Codes-to-theory model allowed me to systematically organize the diverse health experiences into broader patterns and help to shed light into issues underlying the health and wellbeing of South Sudanese immigrants in Ottawa.

\subsubsection{Presenting my Findings}

After data analysis, I made a presentation of the findings to a group of South Sudanese community members that met in August 2017. The aim was of this presentation was to inform the South Sudanese community about the key findings that had emerged from the study, and to get a sense of whether my overall interpretation of the findings was accurate and consistent with the expectations of the community. In qualitative research, writing the results of a study is an integral part of analysis itself. As such, personal biases and identities and professional experiences that sometimes remain 
guarded during data collection can still re-emerge at this stage and they can colour the manner in which we see the findings of a study, recount the story, and the interpretation of it. Thus, in addition to providing information about the outcome of this research, the need to guard against any unintended misrepresentations and ensure rigour motivated the decision to share the findings of the study with the wider South Sudanese community.

The community responded well to my findings. I presented a brief summary of each of the five themes in my results chapter. It was not a formal presentation, but more of a round table discussion. After presenting, I opened the floor to any questions, comments or concerns. Many community members were eager to speak. Multiple individuals spoke about how they agreed that the themes raised in my results were issues that they experience personally, and know are experienced by other South Sudanese in Ottawa. This sparked an impromptu focus group discussion, where community members began sharing their experiences with the issues that I raised in my presentation. It is encouraging to know that the themes I have written about in my results are issues that South Sudanese members actually relate to on a level where they feel empowered to share experiences as well as suggest solutions. For example, my presentation sparked a problem-solving oriented discussion, specifically around issues of generational differences of health perception. Overall, members expressed excitement about the attention these issues might receive now that they are included in an academic paper. I understand that members who might have taken issue with some of my results, may not have felt comfortable speaking up. Because of this, I encouraged them to reach out to me individually if they wanted to discuss. 


\section{Chapter: Research Findings}

\subsection{Introduction}

This chapter will discuss the findings from the semi-structured interviews and focus group discussions I conducted with South Sudanese immigrants and refugees living in Ottawa, from August 2016 to November 2016 in Ottawa. The chapter presents some of the significant perceptions and everyday experiences of this population, in regards to their health. The perceptions and everyday experiences are organised into five major distinct but related contexts that form the main themes of the findings of this study: (1) transnational caring, (2) interactions with the health care system, (3) political and ethnic tensions, (4) shifting gender dynamics, and (5) generational differences in health perceptions and experiences. Each of these themes will be illuminated using direct quotes from FGD and IDI transcripts. Each quotation is identified with a pseudonym (to preserve participants' confidentiality), the participant's gender, and immigrant status (first or second generation immigrant or refugee). Through the discussion of these results, I will tell a story that demonstrates how the everyday health experiences and perceptions of South Sudanese Canadians in Ottawa, play out at the intersection of pre-migration, migration and the socio-economic conditions that unfold in post-migration.

\subsection{Theme 1: Transnational Caring}

Accounts of FDG's and IDI's show that South Sudanese refugees and immigrants in Ottawa have faced traumatic migration experiences while they were still in their homeland, in transit, and after arriving here in Canada. These experiences have gravely impacted the lives of South Sudanese living in Ottawa. [Isaac], who migrated from South Sudan in the 1990's, and has been an active member of the community for many years, 
describes his own experiences that speak to the longevity and enormity of the struggles that South Sudanese endured prior to arriving in Canada:

Isaac: The journey itself was difficult, being in refugee camps for $6,7,8$ years so it has its own challenges. So yes, there are cumulative effects of trauma. The first one is like the displacement, and then the second one is the immigration, and then staying in the camp, and then coming to Canada. So there is a huge level of stressors and traumatization that has happened all along the way...I never stayed in a camp, but I experienced my own trauma from the first displacement, and during the war, so I saw the trauma, and I experienced it [...] I am just talking about half way to some people who have experienced trauma multiple times in their journey, to the refugee camps or once they come here. (First generation, male, interview).

Many participants talked about the extended periods of time spent in refugee camps and the horrors they personally experienced or witnessed. In some cases, participants spoke about the experience in general, or told stories of what they have heard from other South Sudanese community members. [Debra] spoke about her experience with fleeing South Sudan and coming to Canada:

Debra: We left in the 1990's and I was in Cairo first, and we thought we were okay, but then there was a lot of violence. People were getting murdered everywhere and there was so much bloodshed. This was bad but if we left we would be in a camp, and in camps people have no food, they are starving to death. So no matter what you were seeing people die. (First generation, female, focus group discussion).

However, in other cases, participants brushed off their experiences, admitting it was difficult, but chose not to dwell on it. Although this was not explicitly recognized or mentioned by participants, it seemed that the reluctance on the part of some participants not to discuss their migration experiences, could be a symptom of, or way of dealing with the trauma. Contrarily, participants were much more open to discussing how their 
experience and continued investment in the current state of conflict in South Sudan impacts their lives in Canada everyday, even if in a negative way. Although migration experiences differ within the South Sudanese population in Ottawa, the group as a whole maintains a very strong connection to the current state of affairs in South Sudan. Their strong ties to their home country, directly impacts their daily life here in Ottawa, in a number of ways. Participants spoke about how their previous lives in South Sudan and the current state of the country, impacts their emotional wellbeing, specifically in terms of causing daily stress. One level of concern, due to participants' nationalistic attachment to the South Sudan, is for the political state of the country. [Megan] explains:

Megan: I think it adds a lot of stress when war starts to happen. It gives them anxiety, um, and then also I think they just kind of all just want to eventually see the country be at peace [...] it's definitely started to make me be stressed about the state of the country and like have anxiety about it. I think I have also started to adopt the idea that like hoping one day the country will just be a peace like, which isn't a bad thing because I think I should care about what's going on there [...] emotionally it can be tough, though (second generation, female, interview).

An added level of concern for South Sudanese living in Canada is worries of the safety and security of families and close friends still in South Sudan. [Rosie] discusses how stressful it can be, when you have family members there during heightened conflict:

Rosie: Most of the time there is war in the city and you know your family is there, your brothers, sisters, nephews, just in the fighting, it's really, it's like you know last July I was in Juba, my brother was in Juba uh I have cousins and my younger brother still there $[\ldots]$ and I was begging him to leave, leave, leave $[\ldots]$ the fighting was very heavy in the neighbourhood where they live so I couldn't get a hold of them for like four of five days. And the fighting was just going on and on. These are the things that cause stress (First generation, female, interview). 
Most South Sudanese immigrants keep up to date with events in South Sudan, on a daily basis. This is done through watching the news on television, reading the news online, social media, or phone calls to loved ones living there. Although they can easily follow this news, it is not always easy to watch or read about what is happening, especially at such a distance. Participants explained that perhaps one of the most stressful aspects of having family back in South Sudan is feeling utterly helpless. [Anita] explains her experience with a family member in danger, and not being able to do anything about it while living in Ottawa:

Anita: I wanna say a couple of months ago, my uncle is there, and so he has like a higher position and there was this one moment where something was going on, and it was said that he was going to be executed, so it was a really scary moment because we know him, he has always been in our lives, and the fact that it was happening over there while we were sitting at home watching TV, was really shocking. And so, he is okay now, but it was the fact that so many things are happening back there that we don't know about and so, I don't know, it's just the fact that anything can happen at any moment, which is really scary (Second generation, female, interview).

In addition to feeling helpless, participants expressed guilt for being in Canada, while family members live in the middle of such a bloody and seemingly endless conflict. Even after more than two decades since the arrival of the first wave of South Sudanese refugees in Canada, many South Sudanese immigrants still hope and believe that they will eventually return to South Sudan to help rebuild the country. Some participants were not very hopeful that South Sudan would be at peace any time soon, but many expressed that their eventual goal in life was to return and assist in the reconstruction of their country. Interestingly, the plan to eventually return home was a main reason why some 
non-citizens, had no intention of obtaining Canadian citizenship. [Megan], a secondgeneration immigrant describes her understanding:

Megan: I think that a lot of them always hope that they would come here, better themselves, and eventually go back and like help the country grow and get better, which I think is why a lot of fathers have gone back to South Sudan, um, so I think that's why they are so kind of caught up in the politics of South Sudan (Second generation, female, interview).

Because South Sudanese immigrants are generally very dedicated to the wellbeing of the state of South Sudan, many of are extremely involved in events in the country. Participants explained that paying close attention, and having close connections to current events in South Sudan is extremely stressful. The constant stream of bad news coming from the country particularly causes this stress. Participants spoke of continuously hearing of bloodshed, violence and political corruption. They felt that it was difficult to live a meaningful life in Ottawa, while always feeling worried about the state of affairs in South Sudan, especially with trying to have the time and resources to send help back home. [Oscar] explains:

Oscar: The problems of politics also create a lot of stress because back home there's war going on and most of the time [...] there is bad news all the time, plus, even if there's no war during this brief period of peace, there is still stress because there needs help all the time, so you try to you know, balance work due here and work due there it affects the health (First generation, male, interview).

[Oscar] means exactly what he says, when he explains that there is work due here and due in South Sudan. It is important to note that years of colonial domination and civil conflict, pillage and neglect has left South Sudan in an impoverished state. As a result, many South Sudanese immigrants send remittances to support their families, or other 
projects in South Sudan. In other cases, these responsibilities involve concrete decisionmaking. Families in South Sudan depend on the participation of their relatives living in other countries, such as Canada, to make decisions about their lives. Thus, although South Sudanese households are spatially dispersed and fragmented due to members fleeing the country to places like Canada, it does not completely absolve them of their familial responsibilities at home. Thus, despite migrating, individuals do not necessarily relinquish the decision-making roles and responsibilities that are grounded in South Sudanese sociocultural fabric. [Oscar] explains his experience, and how it has affected his family's well being:

Oscar: I am the eldest of the kids in my family and when there is problem there I have to talk to A and B and C and try and solve things because they defer to me as the elder, everything defers to me, and I have to try to fix it [...] sometimes you'll be thousands of miles away, but you're still burdened with things that are far away from you, you are supposed to be responsible for them, and if you're not, then they will not be happy, and they will complain a lot (First generation, male, interview).

Thus, South Sudanese immigrants, specifically those living in Ottawa, maintain strong emotional connections to South Sudan, and maintain their decision making power and roles in a number of ways. As I will discuss, these ties that South Sudanese feel, experience, and maintain affect different aspects of their health and wellbeing here in Canada.

\subsection{Theme 2: Interaction with the Healthcare System: Attitudes and Experiences}

Throughout the focus groups and interviews, the issue of accessing healthcare and health related services came up frequently. As mentioned, strong cross-border ties to events and experiences in South Sudan, influences life here in Ottawa. Their struggles in 
the refugee camps and the present precarious state of life in South Sudan were also found to provide baseline reference point for participants' understandings and experiences of health and wellbeing, and to profoundly inform their health-seeking behaviour here in Canada. An overarching theme when discussing health care services, was that South Sudanese immigrants in Ottawa do not always seek formal health care, such as seeing a doctor, for example, despite access to health care services. Participants provided a multitude of reasons for hesitancy to address health problems, highlighting many important explanations as to why their health continues to deteriorate, despite having access to health services.

A main rationale that participants provided was that living through violent conflict and turmoil in South Sudan, as well as enduring poor living conditions while migrating to Canada, made everyday health issues experienced in Canada, in their minds, seem frivolous, and not worthy of addressing. In addition, because of the lack of medical infrastructure in South Sudan, it is not common to undergo routine medical check-ups without any distressing symptoms or seek professional medical help when experiencing health problems with mild symptoms. [Simon] explains how this mentality remains with South Sudanese in Canada:

Simon: Back home we endure a lot of things, we go through a lot of physical pain $[\ldots]$ and 'cause the lack of hospitals and doctors there, you kind of just have to rely on yourself and your neighbours [...] you kind of take that pain, even if something really bad happens to you physically, you just kind of wait it out. So here, I guess, in a way, they brought that kind of mentality. Even though there is a lot of hospitals, a lot of doctors, all of that, you don't get checked up, cause there have been worse things on your mind (Second generation, male, interview) 
Participants expressed that many South Sudanese compare their struggles in Canada to those they themselves experienced when they were still caught up in war, during their time in refugee camps, or their loved-one's are currently experiencing back in South Sudan. Although participants spoke about their daily stressors of living in Ottawa, it was evident that they felt these issues were not as significant as the problems in South Sudan. But many also recognized that through this comparison, many important health issues that exist within their community in Ottawa are being brushed aside. [Muna] explains how this is especially happening with the issue of mental health problems within the community in Ottawa:

Muna: I think that a big part of it is because they tend to compare being here with the struggles that they had to deal with back home. So, whenever [mental health issues] are brought up, you're just kind of brushed off and told oh your problems aren't real. What people are dealing with back in South Sudan is more difficult so I think that is part of the reason why it's not really acknowledged (First generation, female, interview).

Because of this, South Sudanese living in Ottawa feel guilty about struggling with even otherwise serious health issues. Because South Sudanese in Canada are constantly in touch with family members still trapped in conflict in South Sudan and understand the enormous health struggles their kin face on a daily basis, they rarely seek any health care services for mental or physical health problems for themselves out of guilt. [Megan] spoke about how this guilt has created a stigma around mental health problems in the community, and therefore preventing South Sudanese from accessing the services and care that they need. She explains:

Megan: I think it is the stigma. I think there is a lot of shame attached to [seeking health care]. I think probably they feel guilty for feeling depressed when they are 
not going through war like certain people in back in South Sudan. They tend to like minimize their own struggles (Second generation, female, interview).

Because of the shame and stigma, South Sudanese also avoid discussing health problems with one another. And although many participants agreed that this was an effect of comparing struggles to those in South Sudan, many also believed that this was a cultural coping mechanism. Multiple participants mentioned that discussing mental health is something that is unfamiliar to South Sudanese people. [Nadir] explains that discussing emotions or feelings is simply not part of their daily life:

Nadir: In our community talking about mental health or wellbeing in general is not something that you do $[\ldots]$ it's a taboo, no one actually wants to discuss it, nobody wants to talk about it because [...] for us, showing emotions and expressing your feelings about things, it's not a part of our vocabulary (First generation, male, interview).

Participants on multiple occasions explained their hesitancy to openly discuss or address health issues, both physical and mental, to be a product of norms in their culture. When asked to elaborate, participants explained that this was just how they were raised, and were unfamiliar with any alternative way of addressing emotional or personal health issues. Many participants, however, provided examples of how they see cultural norms preventing South Sudanese from addressing health issues, specifically accessing formal health care when experiencing particular health problems or for recommended routine check-ups. For example, [Simon] explains that many South Sudanese feel that the doctorpatient relationship is overly invasive and inappropriate:

Simon: South Sudanese back home, especially the elders, care a lot about being respected, and when they are here, I think it's a matter of if it's appropriate or not to talk to the doctor about certain health issues $[\ldots]$ that could be one big thing, 
because it really comes to honour and ego. You know, if a doctor touches you this way, you do not feel right, you do not feel respected because back home you don't do that, so it threatens your honour and ego" (Second generation, male, interview).

Important cultural symbols of identity within South Sudan, such as honour, ego and respect, are perceived as threatened when discussing or exposing personal health problems to health care professionals. Thus, South Sudanese refugees and immigrants' experiences, such as growing up in South Sudan, directly shape their perceptions of health workers and the way they interact with the health care system. This does not in any way suggest that any type of culturally shaped understandings or approaches to health or health care is better than the other. However, many participants explain the potential problems that come out of decisions to avoid accessing formal health care. [Rosie] explains how some South Sudanese will refuse certain types of medical care, even when it is seriously needed to for survival:

Rosie: If you don't feel the pain, you don't go to the hospital. I had a cousin who just won't do the treatment, and he signed the papers to the doctor after they discovered the cancer in a very early stage and the doctor said you're lucky and you can do the treatment and you'll be fine, and he said no. And he signed a paper that he doesn't want the treatment, and we had like to, um, really force and push him to get, like, treatment, and until when he started feeling pain is when he can say okay, started feeling the pain, you can see now he's ready to go to the hospital, but when there is not pain, he would not go (first generation, female, interview).

It is important to note that this is not the case for all South Sudanese living in Ottawa. Many participants, predominantly the second-generation, expressed no hesitation in seeking formal health care. This will be discussed at greater length in the theme of generational health differences in a proceeding sub-section. Many of South Sudanese immigrants in Ottawa who do not access available health services, choose to cope with 
health issues in a multitude of ways. The most commonly discussed, especially because South Sudanese tend to avoid openly addressing health issues with others, was coping in silence. [Debra] reported that when it comes to health problems, community members will keep them hidden from fellow South Sudanese, leaving them to cope alone:

Debra: Yes, I see many people [...] when mental issues happen, they'll be silent. They don't really want to talk. You can have like a neighbour from your country with a sick child or sick member of the home and you won't see them for one month, two months so you'll feel there is something hidden (First generation, female, interview).

In addition to coping in silence, many participants mentioned that South Sudanese often turn to religion when experiencing difficulties in life. Consequently, a common response to the question of where South Sudanese go for health services and support was Church. These views are encapsulated in a statement by [Hiba] who explains the length South Sudanese will go to seek support from their religion:

Hiba: I think people are going mostly to churches; that's what I see. They will say you know what, there is this pastor who is very good and he goes to this church. People are buying tickets going all the way to Nigeria and South Africa because they know that there are pastors there who pray. Even if they go to the hospital to see a doctor, still they will go (First generation, female, interview).

In addition, many participants explained that instead of coping with health issues,

South Sudanese have a tendency to ignore them, or deny their presence altogether.

[Megan] explains how her family members deal with physical health problems:

Megan: There is problems with diabetes and high blood pressure and heart problems. I think that stems from, well, South Sudanese people's diet is very carb based $[\ldots]$ and they don't tend to focus on like, exercising very much. I just notice a lot of diabetes within my family and heart problems. And even with that, they tend to brush it under the rug and just kind of move forward and they don't really tend to change much about their diet, from what I have seen. It only makes it 
worse (Second generation, female, interview).

Although in many cases, South Sudanese are choosing not to access health care services, and cope in alternative ways, it is important to acknowledge that there are also significant barriers preventing this population from this access. For example, many participants expressed a lack of education about health for immigrants as summed up in a comment by [Raymond]:

Raymond: Here in Canada, people do like a physical. But with [South Sudanese] they just don't know about it. Some people are here for 10 years and have never done a physical test. They don't know that it is available, it is part of the health care system, but you don't do it here unless you are really sick and see a doctor here (First generation, male, focus group).

In terms of routine check-ups or physical examinations, another significant barrier is the issue of communication. Many participants explained that language was a significant barrier to receiving adequate health services. [Oscar] explains a common experience of a South Sudanese adults when accessing health care from a doctor:

Oscar: Sometimes a mother, a single mother, she goes to the doctor, and the translator will be her kids. I think she will not be able to ask too many questions because the daughter is the translator yeah, which means she will be sensitive there, she will be too general and not go too deep into it, because the child is the translator, and there are some things you don't want to share in front of the child. So not direct, you can't be direct sometimes (first generation, male, interview).

In addition, in many cases, particularly single mothers, cannot find the time to access health care services. According to existing research, as well as many of the research participants, there are many single parent families in the South Sudanese communities. [Rosie], a single-mother expresses her frustration with finding services that can accommodate her schedule and responsibilities as a mother: 
Rosie: Sometimes I can be sick, but, I can't go to the doctor, because if I go to the emergency in Gatineau, 16 hours, 20 hours, who is going to get my daughter from the daycare, so it's just better not to go. I come to Ottawa, and I am not someone who falls sick regularly, but one time I wanted to book an appointment and they said no you are not a patient so we can't give you an appointment. Okay, I went to register for the drop in, it is in the afternoon, so I went in the morning to the drop in, and they said no, because you are not a regular patient, you cannot register now, you have to come at $1 \mathrm{pm}$, and if there is space, we will fit. Like if I come at $1 \mathrm{pm}$, I have a daughter to pick at 5pm, when am I going to finish and how is it going to take me, so I just don't go. So it's not easy (First generation, female interview).

Thus, many South Sudanese, especially single mothers, find it difficult to seek medical care promptly as well as balance their multitude of gendered responsibilities, a theme that I next turn to.

\subsection{Theme 3: "Fitting the System": Changing Gender Dynamics in Canada}

A very prominent theme that came up throughout the interviews and focus groups, was the division of labour between South Sudanese men and women living in Ottawa, and the amount of stress this caused women, specifically. Participants explained that in most cases, within South Sudanese homes, even in Ottawa, women take on most, if not all, domestic responsibilities. Consequently, men often take on little or no responsibility. In many cases, it is expected that men do not contribute to domestic labour in any way. Participants, specifically women, told stories of their husbands sitting on the couch and expecting to be fed, while they were busy taking care of the children and cleaning the house. [Eliza], a first generation South Sudanese immigrant woman explains:

Eliza: Men are not allowed to do anything at home. You know they sit with the parents, let's say, I am a family of 9, we are 7 girls and 2 boys, my brother used to be like the king of the house, like the main head of the house. We women are the ones feeding, cleaning, doing the whole work. In Canada or North America or anywhere, it's women first, but for us it's men first, we do all the work and they 
are just sitting and just observing, just supervising or the leaders or the one in charge of observing and making sure what you do is right (First generation, female, focus group).

Many participants also explained how these divisions are deeply rooted in their culture. At a young age, girls are taught to take on domestic responsibilities, while boys are predominantly responsible for labour outside of the home such as farming and herding cattle. But since there is nothing like farming and herding cattle outside the house in Canada, boys find themselves with virtually no domestic chores while at the same time being unable to help their own sisters who are inundated with work. Thus, these responsibilities become normalized within South Sudanese families. [Megan] explains her experience:

Megan: I think that like at a very young age it becomes [a girl's] responsibility to start cooking and cleaning and doing things for like your older siblings and like your father. Actually when I was [in South Sudan], one of my cousins who was my age, we were like sitting down talking and she like got a call and was like oh my god I have to go cook and clean for my older brother who was like 30 and she was like 15 [laughs] (Second generation, female, interview).

Participants expressed that these divisions persist when families migrate from South Sudan to Canada. One of the major themes that kept coming up in the discussions that complicate the division of labour within the families is that many members of South Sudanese families, especially men, have returned back to South Sudan. Participants explained that the main reason why men return to South Sudan is because they think there are greater economic opportunities there, now that South Sudan is an independent country. Because South Sudanese men traditionally take on the role of providing income for their families, many of them are university educated, and before migrating to Canada, hold high-paying jobs. However, when they migrate to Canada, in many cases, their 
credentials are not consistent with what is needed to perform the same job. [Isaac]

explains:

Isaac: Most [South Sudanese men] that like work in administrative positions, managerial positions here, they're working either security guards or something, so they feel like you know, they have lost that stature, and the value that they had when they were home, so most of them went back and they actually reclaimed their positions so they feel like they have reclaimed what they have lost and they feel that they can come and go back. Some went and stayed and didn't come back, left their wives here, got married, established new lives back home. Some have established news lives and come back and forth (First generation, male, interview).

A common way participants described this was men "not fitting the system" in

Canada, having a much more difficult time integrating than women. In other words, many men feel they have lost their sense of dignity and prestige because the system could not provide them with the same white-collar jobs they held while back in Sudan. In some cases, this puts additional pressure on women to find a job. [Isaac] also explains:

Isaac: I will just talk a little bit about transition, when people come here to Canada, men are the slowest to integrate, so women tend to be the first to find jobs, and then, they also have to burden of raising kids, going to work, coming home, making sure that food is ready, and all of this stuff on top of their own personal needs, so it creates stress, of course some kind of emotional, you know, um, problems between spouses, psychological problems because they're seeing themselves, they're the only ones, they're actually responsible for their family, their husbands, their family back home, they have to work in order to, so there's like so much pressure (First generation, male, interview).

[Eliza] explains:

Eliza: Um, I think it becomes very stressful to women, because women are more open to other things, they can go and do any kind of work [...] the husbands they don't cook, they don't do any work at home. Now [the women] come back home, they have to cook, they have to clean, they have to take care of the kids [...] it's like around the clock, the women are working, and despite that you see that they are trying to be strong because they have kids and they have to take care of them, but, in the long run, it definitely will deteriorate their health (First generation, 
female, interview).

Even before men return to South Sudan, women are feeling enormous amounts of pressure to perform domestic tasks on top of maintaining a job. This causes significant stress, negatively impacting the health of women within the South Sudanese community in Ottawa. Thus, when the men do leave, women in the home, specifically mothers, are left with all of the responsibilities. The stress that this causes affects others as well. [Hiba], a single mother explains that it is especially difficult to manage when living in Canada, because the support system she would have at home, simply does not exist here:

Hiba: Back home we have the family members like mother and grandmother, like the whole family could be in one place. Not here [...] so the area that you get help back home is a lot, you feel like no stress for you back home, you get people to help you at home, it relieves the stress and being tired and all these things, that is what I experience here in this house. My house I live with my children, and my husband left for South Africa, so when I live with the kids here nobody helps me. I have to go to school and lots of other things or I stay home doing my whole thing day and night so it is a lot, like in the area that you will be really tired, if you need to rest you cannot rest (First generation, female, interview).

Thus, experiences of being an immigrant in Canada cause stress on both men and women. Post-migration and return migration is specifically creating strain on South Sudanese in Ottawa. Women feel tremendous pressure to fulfill all of the parental roles and men experience the burden of failing to find work, and fulfill cultural expectations of being the main breadwinner, causing many of them to leave their families behind, and return to South Sudan for work. However, what is extremely important to point out in this discussion, is that not only do men leave because they are stressed about loss of their jobs, but also because of frustrations with loss of position and power. Because men are used to holding jobs and providing financially for their families, when they have a more 
difficult time finding that same position in Canada, they begin to feel inferior to their wives. [Christine] explains:

Christine: It is affecting them because they think that the man should be the one that is successful in that area. You know, like the women should not. But if you are not opening your mind, if you are not learning, or if you are not willing to receive new ideas, it's not going to happen. So, that's where the anger increases, because, they get surprised 'how come she is the one doing that?' 'why is she the one that is integrating better?' (First generation, female, focus group discussion).

It is not only the changing economic status of men and women, but also changes in new social dynamics in Canada that causes men to feel a loss of status and power. For example, the range of freedoms and choices that women generally enjoy in a conjugal relationship in South Sudan are different than in Canada, and these changes take a toll on marriages and families. [Roger] explains:

Roger: When women come to Canada, sometimes they are very young, like teenagers, but they are wives. They notice the freedoms they have here, and realize their husbands are boring [...] they have nothing in common. So the women will go out and do things and the man stays home. It is causing great problems in the marriages, like, the men feel they cannot control their women anymore, they are like powerless, and I know of lots of divorce that happens (First generation, male, focus group).

These changes in gender dynamics have greatly impacted the everyday health and wellbeing of South Sudanese immigrants in Ottawa. Perhaps the most serious implication being experienced because of these changes is domestic violence. Participants explained that in some cases, because men experience loss of power, they exert their power through physical and emotional abuse, often on their spouse. [Isaac] clarifies how men become more abusive: 
Isaac: And the man also, because of pride, he doesn't want to feel that, make the wife feel that, you're dependent on me, so they become more aggressive. Men become more aggressive because they [...] think it's like humiliating for them when they are depending on their wives (First generation, male, interview).

[Isaac] elaborates on this frustration, and suggests that it can sometimes turn into violence:

Isaac: $[. .$.$] there is some sign of role reversal because in Canada when you come,$ if you have kids, the wife gets the resources like you know, like the child tax, the child tax benefits and all of that stuff, so the women now, over in an instant [...] have a financial stake in the decision making around the house, and, if the husband is not working, then that roles has been completely overturned, and in most instances husbands don't accept that reality, and then becomes like, there is like some abuse, like either verbal or physical in order to assert the lost position (First generation, male, interview).

Thus, participants identified domestic violence as a significant health issue caused by the challenges of migrating and integrating into a new country and culture. Many participants discussed women's experiences with marriage difficulties in the wake of an increasing number of men trekking back to South Sudan, as well as how they tend to cope with these, and related issues. Many participants said that they are noticing very unusual and dangerous coping behaviours in women. [Debra] explains how women are increasingly turning to substance abuse to cope with being 'abandoned' by their husbands:

Debra: In our culture, you could hardly find people drinking, but now women start to drink you know because they cannot face the reality anymore. They want to avoid it as much as they could, so they're starting to have drinking problems, some of them are on pills, it's just terrible you know, because they are worried oh, my spouse left me, maybe he rejected me that I am not good enough for his life [...] I am failing more, he was right. So you are confirming that the reason why you were left alone, is the quality that you are not human enough for them to be with you, it is affecting them in that area... It hurts so much. Some people cannot 
face it, some people get depressed a lot, and especially mothers. When you are raising kids, you have to provide food, you have to take care of those kids while you function well mentally (First generation, female, interview).

The issue of men leaving families in Canada and remarrying in South Sudan emerged as a significant cause of emotional stress among women left behind by their husbands. It was also reported that some of the men who decide to go back to South Sudan are nonetheless still financially dependent on their wives they leave behind here in Canada. The women left behind feel pressured to continue sending money to their 'distant husbands' back home in the hope of saving the marriage, but they are also deeply concerned that their husbands are spending this money on other women there. Thus, women feel enormous pressure to take on all of their responsibilities without feeling or admitting that they are struggling. Many women feel shame for not being able to handle all of their daily tasks, and internalize it as failure. As mentioned in the previous section, there tends to be a general stigma around talking about health, specifically mental health struggles. This however seems to differ slightly between genders. According to majority of participants, women are relatively more open to socializing in general and to discussing otherwise difficult issues such as mental health as [Roger] explains:

Roger: Women are much more open to these kinds of conversations with each other. Men, they are more secluded to themselves, they, maybe could go back to the whole ego thing, that you're a man, you've got to be strong. I would say males are more kept to themselves, they do not share many things. They'll speak of some things, but, not maybe, personal health things, to their friends, you know. So females, they are more likely to go to the doctor about something and speak to them, than a male would (First generation, male, focus group).

This relative openness has fortunately helped a number of South Sudanese women in Ottawa cope with their mental health struggles. Participants told stories about women 
coming together to talk and check in on one another. This however is strictly something that women do, as men rarely associate with one another on their own time. [Debra] explains:

Debra: Men, it's about power. For women, it's about love and country most. Even though our men don't get along, we start to share with each other and just leave [politics] quietly cause you don't want to talk about it. For women they believe in connection more, and for them it's more like love like country development too and for our kids to have a better growth into a good country but for men it's about power and about I want to force myself and it's mostly power (First generation, female, interview).

Thus, women increasingly feel that coming together as a community to discuss issues, such as health, is a way to cope and heal. However, for men, political tensions prevent them from congregating to discuss these issues and building social networks among kin. What this discussion is referring to is the deep ethnic, tribal and consequently political divisions that exist within the South Sudanese communities in Ottawa. There are currently approximately 100 different tribal groups in South Sudan, and due to the longstanding issues of tribalism still existing in the country, the subsequent divisions continue to play out within South Sudanese immigrant communities. According to much of the recent research on South Sudanese immigrant populations, fragmentation between different ethnic and tribal groups is a major problem, and the case is the same in Ottawa, bringing us to the fourth major theme, ethnic tensions.

\subsection{Theme 4: Ethnic, Tribal and Political Tensions}

Many participants said that the tribal divisions are so deeply rooted, that they become the most important aspect in shaping South Sudanese everyday lives in Ottawa. As already alluded to, these divisions are felt much more by men than women. Many 
participants expressed that especially for men, it begins to consume their lives so much, that it blinds them from other important issues being experienced within the community. Instead of focusing on how the community can come together and address issues, most men tend to focus on the differences between ethnic groups, and avoid interacting with those considered to be outside of their own. [Debra] expressed his dismay with this tendency:

Debra: Because for men, they're more into politics than they are into families $[\ldots]$ to me it is disappointing, I don't believe in the politics and the way it is because it's dividing us and really hurting us so many ways. Why don't we just sit and come up with better ideas? Why aren't we coming with things that are connecting us instead of dividing us?

[Debra] continues:

You know, talking about rights, for example, human rights, it's not there. Respecting the women, it's not there [...] and once the man starts it, you will see the reaction. Suddenly people who used to come out a lot and participated in groups $[\ldots]$ they started to divide and every group is pulling off from the community. So that's the effect and it's really depressing. (First generation, female, interview).

Participants have identified that the different ethnic, tribal and political groups must come together to solve issues within the community. Many also mentioned that community activities would improve health and wellbeing, in many aspects. However, the majority said that the divisions are so deep that they make this prospect next-toimpossible. Even when it comes to more casual gatherings like parties, different group members will not associate, or even attend together. [Isaac] addresses this issue in Ottawa: 
Isaac: In Ottawa here, our community is so fragmented, to the level that is becoming so dangerous. Health-wise, the level of tribal, the fracture, it is very bad. You know, um, every single community is trying to exist on its own, because they see the other one as the evil. So, they never come eye to eye. There are very few of them who actually try and transcend that. But not all of them do (First generation, male, interview).

Even when South Sudanese people come together, they do not tend to discuss issues of health or other migration related experiences and struggles. Much of the existing research on migrant health suggests that the main place of support for immigrant communities is within the diaspora. However, for this particular population, this does not seem to be an effective way of bringing people together to tackle community issues. In fact, discussions with multiple participants about this issue, suggests that when South Sudanese come together, the discussions can actually be detrimental to health and wellbeing:

Isaac: When we came, when I came in, and I was part of that network and we felt you know, we need to be together [...] that there is nothing outside there that we don't have [...] but if people do not explore other options outside the community, they are continuing to experience to main trauma. The biggest challenge for us is through the cycle of violence that is happening at home, people are also experiencing that secondary trauma because you see like oh my family member died and you experience that trauma, you connect with people in a social network, you find the same instances, you revisit that instance and then there is an increased level of anger, uh, and unhealthy relationships, and all of that is like you know, the build up on the actual original trauma (First generation, male, interview).

In addition, majority of participants explained that the topic of politics quickly takes over all social conversations. This not only prevents any productive conversation about tackling community issues that affect them on a daily basis, but also generally creates a stressful and toxic environment. The same participant quoted above, explains that he also understands this as a way community members are reliving trauma. 
Interestingly, he subsequently suggests that branching out into other diaspora

communities may in fact help South Sudanese break ties with the trauma of conflict and

stressors or ethnic tensions as explained by [Isaac]:

Isaac: when we are together, our own, our main focus or our main concern is politics in South Sudan, health in South Sudan, war and you're revisiting the trauma, all over, every time you meet, you revisit that like in a circle and if you go outside and interact with other people from outside the community you are building a new network, a new tentacle that takes you away from the environment that you are living in, and that helps a lot and we are the by-product of it (First generation, male, interview).

Unfortunately, when someone attempts to bring people together to a social gathering in an apolitical environment, community members always assume that there must be a hidden agenda, and are sceptical of the motives of these organized activities:

Isaac: [We] have been trying to do it at a community level, not actually do it at the political level, do it at the social level [...] so let's meet, let's talk, let's just look at what makes us South Sudanese, not what makes us our own different ethnic groups, because that reality cannot change. But can we? I have tried it and some people have accused me of trying to recruit people to actually either support one side or the other. So, it's very difficult and you are always in between, and if you are actually trying to form independent thinking, you are always considered by the other person, as being a sell-out, so it's a very unique space that we are in as a community (First generation, male, interview).

This hatred and distrust extends beyond organized community events or discrete gatherings, but persists on an everyday level. For instance, it was reported that South Sudanese often feel nervous about encountering fellow South Sudanese in public if they are from a different tribe; some participants expressed that this causes a lot of stress and heightened tensions as explained by [Rosie]:

Rosie: I think it reaches a level that some people don't even say hi to each other. I see you, but I don't see you. This is especially between the Dinka and the Nuer, 
it's very difficult, especially after the 2013 conflict [...] I know like one lady, she comes from my hometown, but, because she is married to a Dinka, and there is this barrier between me and her, we can't socialize. Because people are your friends, and then you say something on Facebook and you find people are like, no, not happy with you (First generation, female, interview).

[Simon] also speaks specifically about how it affects health:

Simon: For sure, yeah, to a degree it affects the mental health, um, cause the thing is, they've carried all that hatred, all of that violence that has happened in the past, they carried it here into Canada, or America or wherever they are. I would say mentally it has affected them and their health for sure, because now they are secluding themselves from the larger part of South Sudan, the larger people. If you are from this certain tribe, this other tribe it having a get together or some sort of party, you will not go, because of what happened (Second generation, male, interview).

Thus, to many South Sudanese immigrants living in Ottawa, ethnic tensions and divisions play a significant part in their daily lives and health. However, this was not consistent between generations of immigrants and refugees. In interviews and focus group discussions, participants stated that the younger members of the South Sudanese communities in Ottawa, most often second-generation immigrants, are not as aware of ethnic and tribal divisions. This brings the discussion to the final theme, which is generational differences in health experience.

\subsection{Theme 5: Generational Differences in Experience Health and Wellbeing}

A key issue emerging from the interviews and focus groups is that different generational groups of the South Sudanese have varying views about their health and wellbeing. Specifically, first-generation i.e. South Sudanese refugees and immigrants who came from Sudan, hold different views on some key issues relevant to the health and wellbeing of the community from their children. One of the prominent differences 
between the two groups is with respect to tribal differences and the associated ethnic tensions. [Nicole] a first generation parent said:

Nicole: The second generation does not really recognize ethnic divisions. Some have no idea. Sometimes it is difficult for them to keep up with our own ethnic group. Sometimes they ask questions like, what we are? We have to tell them again and again, they don't pay attention to those kinds of things (First generation, female, focus group).

Comments like these encouraged me to reach out to second-generation immigrants i.e. those born of South Sudanese parents here in Canada, and ask them about their experiences. As most of the first-generation immigrants expressed in their interviews, the younger generation was much less familiar or sensitive to the tensions between ethnic groups and the political strain in their communities. In some cases, second-generation participants were unfamiliar with the tribes their friends and families belonged to, and in a few cases, were unaware of their own tribe. [Megan] a secondgeneration participant explained her understanding:

Megan: Um, I have no idea. I know there is conflict between two of the tribes, and I don't really remember the names. I know it's like, Dinka and then...

Katie: Nuer?

Megan: Yeah, so there's huge conflict between that. I can't remember what I am; my dad would kill me [laughs]. He tells me all the time and I have to ask him what are we again? There is a huge conflict between that. So I feel like that's only amongst the adults, not the kids because we don't care. If you are Sudanese, you are Sudanese (Second generation, female, interview).

Second-generation participants had mixed feelings about their lack of knowledge about the different tribal groups and the tensions that they have created. First, most of them understood it to be a positive thing in some respects. For those who view this 
positively, for example, many of them discussed how they do not let the different ethnic identities in their communities get in the way of building friendships and other relationships. They also recognized that this is an experience that their parents do not have, and felt empathetic towards the difficulties associated with these tensions. [Simon], a second-generation immigrant, explains his experience:

Simon: I cannot speak for the whole youth, but just from speaking to my friends who are from the other ethnic group, we do not really speak about that. We do not take it as the elders do. They were in the war, they had family get murdered [...] things really happened to them that we did not experience, so that's why they still have the hatred and why they are fuelling that kind of fire, but we do not particularly involve ourselves with that. We see it is a problem, but it is not going to divide us because we already made our bonds a long time ago, before this situation happened. There are some youth who are taking sides, for sure. That is the reality, but the majority of them, it just does not bother them, I mean the killing is horrible, but the divide, they will not take it upon them to divide amongst their friends because of that situation (Second generation, male, interview).

Thus, while second-generation South Sudanese immigrants recognize the older generation's experience with tribalism, they are capable of seeing beyond tribe and ethnicity, viewing other members of their diaspora community to be just South Sudanese. However, the second-generation participants also expressed that they wished they knew more about their ethnicity, and cultural background in general. A common experience amongst the second-generation was never explicitly having deeper conversations with their parents about their ethnic or cultural backgrounds. This adds to the confusion many of the second-generation have around tribalism as confirmed by many of the firstgeneration participants. Many of the first-generation members who have children, explained their overt attempts to avoid speaking to their kids about tribalism and the tensions that exist within their community here in Ottawa as argued by [Hiba]: 
Hiba: No, I don't want them to have that intention. I just tell them that there is a problem, and we have to go and make changes. I don't want them to know anything about politics. I encourage them socially, I encourage them in like in a biblical way, let's say love, because God created us to love each other, there is no like, those are my people because God loves everybody. And you know, I tell them the idea that everybody is born in the same way, everybody just has a different way of living, you have different plans for your life, I don't want them to learn anything about politics because politics are really deadly (First generation, female, interview).

Although in most cases, explicit attempts to avoid discussing this topic with their children come with good intentions, this lack of communication, according to many second-generation participants, makes them feel out of touch with their background, and they wish that they knew more. Most participants said that their parents do not speak to them about their personal or family experiences with the conflict back in South Sudan, or immigrating to Canada. [Anita], a second-generation immigrant, discussed what little she knows about her parents' pre- and migration experiences:

Anita: No I haven't heard anything about that kind of stuff, just like well, we came here [...] I find that like my Dad is telling us stuff now, like now that we're older, but like back then we didn't know anything of that, like, I didn't know about any of the hard things they went through. I guess it was the fact that they were trying to shield that from us [...] but I still, like, wish I knew more about it (second generation immigrant, female, interview).

Second-generation participants recognize that the scarcity of conversations with their parents about difficult topics such as migration, conflict and tribalism, is an attempt to protect them from the trauma that their parents have, and continue to experience. Although most participants were accepting of this rationale, they also complained that the absence of difficult conversations with their parents affects other aspects of their relationships with their parents. Majority of second-generation participants expressed 
concern about a general lack of communication between the generations, specifically between parents and children. This lack of communication becomes very difficult for the younger generation, particularly when they are struggling with their own, everyday problems. [Megan] explains that it may have something to do with how their parents grew up:

Megan: I think it's more of a cultural thing [...] thinking about how my parents grew up, I don't think that they had great relationships with their fathers, so I guess that changes with how they interact with you. They don't realize that relationship is important. There just tends to be the lack of communication [...] also this is like more of a society thing, but you know how men are always like taught to be less emotional, that's definitely prevalent in the South Sudanese community so it makes it harder for fathers in particular to interact with their kids (Second generation, female, interview).

Many other second-generation participants felt that speaking to their parents about emotional issues was not an ideal way of dealing with their struggles. It is important to note that this was not because parents do not necessarily care about their children. Rather, being consumed by their own traumatic experience, the South Sudanese parents often do not fully understand the problems their children experience on a daily basis. Secondgeneration participants discussed their struggles with talking to their parents about mental health issues, such as feeling stress, anxiety or depression. [Anita] explains:

Anita: Me and my friends talk about this a lot, and we are all immigrants. It's harder to talk to your parents about stuff like [your health problems]. I think it's because they're immigrants, it's just always something that they can't really sympathize with [...] I guess when you start throwing in things like depression and anxiety, it gets really hard for them to see their child going through that, so they try to downplay it (Second generation, female, interview). 
In most cases, the second-generation South Sudanese immigrants made a connection between their parents' experiences of being immigrants, and their lack of understanding their children's emotional struggles. This suggests that the struggles that come with being an immigrant, specifically those unique to South Sudanese, impacts the way parents view the lives of their children, and in this case, cause them to minimize their struggles. The above quote also highlights how the first-generation South Sudanese tend to avoid facing the fact that their children are struggling, as a way of coping, themselves. Many second-generation South Sudanese immigrants identified that their parents often minimize their own struggles, specifically mental health struggles, because they think that they have experienced much worse throughout their migration experience. This issue became evident in the discussion of access to health care, but here, it becomes apparent that this issue impacts overall family wellbeing because of its detrimental effect on the quality of the relationships between parents and their children. [Megan], a secondgeneration South Sudanese immigrant explains how parents will minimize their children's health struggles, for many of the same reasons:

Megan: It tends to be difficult just because our parents aren't really open to discussing things like [mental health]. Because they are so used to minimizing any kind of mental struggles that they're dealing with that they tend to ignore or dismiss it when someone younger than them brings it up. But I think sometimes even for the younger generation there can be some shame attached to it cause they don't want to bring it up to their parents and feel like, like be dismissed for it.

[Megan] continues:

I think that a big part of it is because they tend to compare being here with like the struggles that they had to deal with back home. So, whenever it is brought up, you're just kind of brushed off and told oh your problems aren't real. What people are dealing with back in South Sudan is more difficult so I think that is part of the 
reason why it's not really acknowledged (Second generation, female, interview).

Thus, many of the second-generation feel that they cannot go to their parents when they are struggling with health issues, particularly mental health, because they often feel that they are dismissed or shamed for what they are feeling. Despite being given unsupportive responses, which in some cases makes it difficult for second-generation South Sudanese immigrants to understand or cope with their struggles, most of the participants understood that their parents only had their best interests in mind. Several of them spoke about how their parents' sacrifices and wanting them to have a better life than they themselves had in South Sudan. This became apparent in discussions with secondgeneration participants, around their experiences with everyday stressors. The most common response to this question was stress caused by pressure from their parents to do well in school, and obtain a successful career. [Megan], a second-generation participant explains:

Megan: Well there's always a lot of pressure because they just want you to do better than them, cause we have so many more opportunities than they had back in South Sudan, so, I don't think the intentions are bad, it's just sometimes the way they communicate it. Also I think their definition of success is a lot different than what second generation South Sudanese children's definition is, especially being that we grew up here in Canada. We have like different perspectives on a lot of things. So to them, success would be having a good paying job, specifically they [laughs] focus on doctor and lawyer. They focus more on like financial gains. I mean I definitely understand why, cause a lot of South Sudanese people didn't get the chance to go to school even though they would have liked to before they had to leave because of the war, so I understand why they put that pressure on us (Second generation, female, interview).

Although second-generation South Sudanese experience a lot of stress to succeed in school, a career, and life in general, they understand why their parents exert that pressure. They appreciate that their parents want their children to thrive, because of the 
difficult lives they have had as immigrants fleeing South Sudan. Most of the younger or second-generation participants also acknowledged many other advantages to growing up in Canada, specifically when it comes to dealing with health problems. Mental health, for example, is much less stigmatized within the second generation, and many participants credited the fact that they are frequently exposed to the topic, growing up in Canada. [Benjamin], a second generation participant explains how growing up in the school system in Canada, has helped make the issue of mental health, a normalized topic:

Benjamin: I think it might be a little bit easier for the younger generation to deal with [mental health] just 'cause it's talked about a lot more in school, so they have most likely heard about it in school and then realize that there are many options for seeking treatment (Second generation, male, focus group discussion).

Participants also expressed how the second-generation, growing up in Canada, have adopted a more "Western" way of maintaining a healthy life. When asked about where or how they seek health care, every second-generation participant said they would go to the doctor; a very different answer and experience than the participants of the first generation. Second-generation participants explained that this method of seeking health care, and other health-promoting aspects in their everyday life, are a product of growing up in Canada. Many used the same phrase used to describe women and integration, "fitting the system" as a way of explaining how they experience and practice health in their everyday lives at second-generation South Sudanese Canadians. This, to them, meant that adopting more "Western" or "Canadian" health practices has helped them live healthier lives than the older generation. [Simon], explains:

Simon: South Sudanese $[\ldots]$ their arrival has not been that long, so now you are seeing second generation, and they are actually entering into the mainstream, and their awareness of health and access to health is much better than their parents, 
and in most instances, they are better informed [...] the older generation, they do not really adventure out much like go hiking, or go for jog or biking. I don't know if I could say it's not in their culture, they just don't do that. They will go to friends house, have some tea, talk, sometimes there's parties, but they just wouldn't go out to go biking or go exercise. Us youth here, who were raised here, have taken up the western lifestyle, where hiking and jogging and all of that is available, but like back home, it's just not the norm to do that" (Second generation, male, interview).

Thus, the second-generation perceive the fact that they grew up in Canada, as a health advantage. They also believed that this gave them other types of advantages. A struggle specifically experienced, and discussed in interviews, by the older generation, is unemployment and underemployment. Second-generation participants felt that growing up in Canada has given them an advantage in terms of getting a job. Participants specifically credited their increased chances of success to being fluent in English. In addition, they again felt that their ability to "fit the system" made it easier to do many different types of jobs. 


\section{Chapter: Discussion}

\subsection{Introduction}

The aim of this study is to examine: (1) everyday experiences of health and wellbeing of the South Sudanese immigrants and refugees; (2) how these experiences relate to challenges such as chronic unemployment, gender inequality and systemic racism; (3) how the experience of relocation relates to family instability and domestic violence; (4) the pre- and transitional migration experiences of the South Sudanese immigrants and how they affect their everyday health practices and experiences in Canada; and (5) how South Sudanese deal with pre- and post-migration stressors and trauma in their everyday lives within the social and cultural context of Canada.

Through the lens of a PEH framework, the findings show that the present health status and wellbeing of South Sudanese immigrants and refugees in Canada emerges at the intersection of a number of processes occurring at a range of social, geographic, and time scales. Of key importance are: (1) the severe trauma stemming from both the previous conflict that violently uprooted them from their homeland and the current ongoing violence in the independent South Sudan; (2) the changing structure of the household in relation to the ever growing number of South Sudanese men who are returning to their motherland; (3) intensifying ethnic rivalry within the South Sudan diaspora itself in Canada; (4) health-seeking behaviour patterns that are rooted in feelings of solidarity and brotherhood with the motherland; and (5) shifting gender relations amidst a growing sense of loss of power and authority among men. These findings extend the application of PEH framework to the realm of health in the diaspora, providing insights into the relevant historic context, scale, and pathways that explain the 
deteriorating health status and general wellbeing of South Sudanese refugees and immigrants in Canada, as reported by a number of studies (Simich, Este \& Hamilton 2010; Simich \& Hamilton 2006; Simich \& Hamilton 2004; The Mosaic Institute 2009; Madibbo 2015). The application of the PEH framework in studies of the health in the diaspora is still scant and this study greatly contributes to the emerging field. The findings of this study highlight the importance of this contribution, especially for future research in related fields.

This discussion section specifically elaborates and contextualises these key findings. First, I will discuss how the emotional investment that immigrants and refugees have in the lives of their families and relatives back home directly affects their everyday health and wellbeing in Ottawa. Second, I demonstrate how the gendered dynamics of integration in Canada affect South Sudanese immigrant and refugee families living in Ottawa. Third, I discuss the issue of ethnic tensions within the community as a barrier to overcoming trauma and to promoting health and wellbeing. Fourth and finally, I discuss the generational differences in the perception and experience of health within the South Sudanese diaspora.

\subsection{Transnational Caring and Health Decision Making}

It is apparent that South Sudanese immigrants and refugees in Canada, and more specifically, in Ottawa, remain in close contact with friends and family members back home in South Sudan. Through this contact, they often provide emotional and financial support to their loved ones in South Sudan. They also pay careful attention to events in South Sudan, specifically the state of the ongoing conflict and the political climate more 
generally. The findings however show that this multifaceted transnational relationship directly affects the everyday health of the population living in Ottawa.

Research within many different disciplines has explored this transnational relationship, specifically in terms of social and material support. For example, perhaps the most written about form of support is financial support through the sending of remittances to family members and relatives back home. Some of the existing literature on South Sudanese immigrant and refugee populations has acknowledged that many of them support family back home economically in the form of remittances (Belloni, 2011; Madibbo, 2015; The World Bank, 2012). However, discussion around other types of support, such as emotional support, is relatively absent in research on South Sudanese immigrant and refugee populations in Canada. In addition, most studies focus on the receiving end of these channels of support, and not the impact on the lives of immigrants and refugees who live in exile (Baak, 2015). The assumption is that by virtue of seeking sanctuary and living in the West, these refugees and immigrants are better off than their families left behind in their motherland.

What this research adds to this literature, alongside a few emerging studies, is that immigrant and refugee populations providing care to families back home can themselves greatly suffer from the emotional burden that comes with this role (e.g. Baak, 2015). It demonstrates an important trade-off in terms of wellbeing; that the demand and feeling of being obliged to fulfill social, economic and political responsibilities in the homeland exerts a significant level of anxiety, and that failure to fulfill these socially prescribed roles toward their families and kin in the motherland can cause shame and undermine personal wellbeing. 
Also of particular significance is in the intimate ways in which care-seeking behaviour of South Sudanese in Ottawa are mediated by past experience prior to arrival and settlement here in Canada or by perceptions of the prevailing circumstances of family members still caught up in the ongoing conflict back home in South Sudan. The findings of this study reveal that self-conscious emotions such as anger, guilt, and shame affect health-seeking decisions among South Sudanese in Canada. This means that simple health-seeking decisions such as doctor's visit can be quite complex and emotive for South Sudanese refugees and immigrants. This also implies while accessibility to health care is a necessary condition for improving the health, it is not a sufficient condition. The findings suggest that South Sudanese immigrants and refugees may not demand health care services even when freely available as a show of solidarity with kin in the motherland.

In terms of preventative health care, these findings imply that South Sudanese may be reluctant to go for annual physical examination or to screen for conditions that present distressing symptoms such as cervical cancer, for instance, because they may view such health-seeking behaviour as self-indulgent. There is need to view this particular finding in light of much of the literature on utilization of health care among immigrants, wherein the issue of cultural retention as a barrier to accessing health care is almost uncritically invoked. Through the application of PEH, it becomes possible to understand why seemingly sub-optimal health-seeking decisions may seem rational or even desirable in the eyes of the South Sudanese community. This implies that policies to improve the health and wellbeing of South Sudanese immigrants in Canada should be 
sensitive to the political and moral context within which South Sudanese families evaluate health-seeking decisions.

The findings also show that news on television, phone, and most often, social media, play a vital role in allowing South Sudanese to maintain connections with relatives and keep abreast of the political situation in the homeland. Most of the literature on the role of information and communication technology in maintaining ties between the diaspora and their home countries view it in a positive light (Hunter, 2015). Polymedia, for instance, is an aid to transnational caregiving. Boccagni (2015) also argues that frequent digital communication enhances the quality of emotional support (feeling cared about, for example) provided to family member in home countries. However, among the South Sudanese, the findings of this study show that social media is an important trigger of trauma because it brings gruesome images of the conflict, from which they had fled, right back into the heart of their living spaces. This is consistent with Awan's (2016) argument about how geographies of crisis and conflict have become increasingly visible because of digital technologies and the complex narratives of place that emerge through seeing these images. Aided by nearly universal access to mobile devices, the increased speed of communication has mean that South Sudanese are under constant exposure to national politics in the homeland, and in real time partake in the consumption of images and videos of the gruesome and bloody conflict taking place over ten thousand miles off the shores of Canada. This exposure generates high levels of anxiety and stress on a daily basis, producing a constant state of anguish and pain that greatly undermine their wellbeing. 
Existing research has found that Sudanese or South Sudanese immigrants and refugees report more concern with post-migration stressors such as difficulties adjusting to new cultural norms, than with pre and transitional migration related trauma (Tempany, 2009). This is consistent with research on other immigrant and refugee populations fleeing conflict, suggesting that they perceive themselves to be safer in host countries (Sundquist et al., 2000). However, the findings of this study points to more complex and nuanced, if not contradictory, emotional states. Living thousands of miles away from the political turmoil and war in the motherland, South Sudanese immigrants and refugees feel secure and safe here in Canada. However, tempering these feelings are also feelings of guilt and shame for not being able to partake in the physical pain and sacrifice that their brothers and sisters are making by staying in the homeland. Thus, the health and care seeking behaviour of South Sudanese in Canada are located within a dialectic of feelings of safety and suffering.

\subsection{Changing Gender Dynamics}

The results of this research project show that the process of immigrant integration has very gendered effects. This is particularly why the application of a feminist political ecology of health lens is important, as it recognizes gender as an important and constant variable in understanding the health and wellbeing of immigrants in multiple contexts. The findings of this study show that South Sudanese men struggle to adapt to gender norms that they obtain in Canada, and this is a root cause of return migration as well as domestic violence. Like any migrant community, adjusting to a new set of norms in a host country is challenging and has significant impacts on health. Studies that have looked at South Sudanese immigrants and refugees in Canada identify a link between 
significant amounts of stress, economic hardships and lack of social support (Simich, Hamilton \& Este, 2010; Tempany 2009). Other studies highlight increased levels of poor physical health and growing prevalence of diseases such as diabetes, hypertension, and other chronic conditions, many of which are also linked to high stress levels (Faria, 2014; Grabska \& Fanjoy, 2015; Holtzman, 2000; Jeppsson \& Hijern, 2005). Additionally, a small number of studies have begun to link family instability and rising cases of domestic and gender-based violence (Tempany, 2009).

The findings of this study suggest that South Sudanese immigrant and refugee women approach employment opportunities quite differently from men. Many of them eagerly jump at the prospect of having a job. This may be because these opportunities may have been previously unavailable to them in Sudan, but it is also often because many South Sudanese women have a stronger foothold in the labour market as they arrived in Canada ahead of their husbands. Therefore, there is a gendered perception in the significance of work that has implications for family stability and household health and wellbeing. In fact, for the South Sudanese Canadians, work has contradictory meanings for men and women. For men, work in Canada signifies a loss of dignity, power and status, while for women it represents social progress, empowerment and freedom. However, work has somewhat contrasting gender effects on South Sudanese women; it represents an escape from men's control, but it also provokes spousal violence.

The findings of this study also demonstrate that the changes in household gender relations relate to the return migration of South Sudanese and the exodus to their motherland in South Sudan. Return migration often connotes immigrants moving from homeland to host countries, and some returning to their homeland after a while. However, 
in many contexts, it is much more complicated, having serious impacts on those who migrate and their families (King \& Christou, 2011). This is the case for South Sudanese immigrants and refugees living in Ottawa. Martha Fanjoy (2015) has written about the return migration of South Sudanese Canadians back to South Sudan. Since the CPA agreement in 2005, a significant number, primarily men, have returned. Besides this chapter by Fanjoy (2015), there are very few studies that explore the issue of return migration to South Sudan (Arowolo, 2000; Kindersley, 2017: Newhouse, 2012), however, as mentioned, this issue has been widely written about in other contexts (Dustmann, 2003; Fussell \& Sastry, 2011; Thomas, 2008). These studies tell a heroic/patriotic story of immigrants returning home to help rebuild their own countries or reconnect with loved ones and rediscover their identities (Fanjoy, 2015; Koinova, 2011).

The findings of this study add to this literature, in that South Sudanese men are under pressure to return to their motherland because of set of push factors i.e. frustrations resulting from their inability to integrate and to adapt to new gender roles in Canada. The findings also indicate pull factors, the glimmer of hope for a better economic future in South Sudan following independence, especially among men with strong ties to emerging political and economic elites. The resulting spatial dispersal of the household, adversely affects the health of family members that stay behind in Canada, as evident by rising incidence of alcohol and substance dependence among South Sudanese women and children. Men's use of violent to reassert control over their spouses also produces a lifeworld among South Sudanese women marked by poor health-seeking behaviour. 


\subsection{The Conflict-Generated Diaspora: Ethnic and Political Tensions}

Existing studies on post-migration difficulties of South Sudanese and Sudanese immigrants and refugees suggests that higher social capital, specifically bonds of mutual support and reciprocity among family members and the South Sudanese community, is significantly predictive of higher psychological wellbeing (Schweitzer, Melville, Steel \& Lacherez, 2006). A study by Goodman (2004), for instance, found that Sudanese who have experienced significant familial disruptions due to war and migration rely on the social support of other Sudanese. In the study by Simich et al. (2006), South Sudanese immigrants in Canada expressed a desire for a community centre where they could seek this kind of social support within the community. Therefore, the existing literature suggests that social capital within the diaspora is a critical factor that assists in coping with trauma.

Certainly, the findings of this study suggest that common interests amongst diasporic communities are positive for the improvement of living in host countries. For instance, some participants in this study recognized the need for community members to come together and discuss health issues, and saw this as the best solution to addressing their problems seriously. Participants admitted that this was challenging at times, because South Sudanese are very private about their health and often cope in silence. However, the findings of this study also suggest significant barriers within the context of growing ethnic tensions rooted in the ongoing civil conflict in the homeland, as also reported by other studies such as Simich and Hamilton (2004) and El-Battahani (2013) that hamper social capital needed to foster good health and wellbeing in the diaspora. The growing ethnic rivalry in the South Sudanese diaspora is testament to the ways in which conflict 
back in South Sudan continues to feed and prolong ethnic rivalry and shape social relations and social wellbeing among South Sudanese immigrants in Canada. This finding agrees with what Demers (2014) has argued about the geographic dispersal of intra-state conflict and the growing participation of the diaspora in conflicts taking place in their homelands, generating factions within the diaspora itself.

Contrary to the study by Simich et al. (2006) which argues that South Sudanese immigrants in Canada have a desire to nurture social support, the findings of this study suggest a level of intra-ethnic tension and rivalry in this community that is hostile to social capital. Because of the manner in which the conflict in South Sudan shapes everyday lives of South Sudanese and strains social relations, South Sudanese face significantly reduced access to social resources within their own diaspora. Since studies indicate that community bonds of mutual trust enhance physical and mental wellbeing, this apparent lack of social resources in terms of long-term relationships among South Sudanese may also in part explain increasing incidence of smoking and high level of alcohol and drug dependence as reported in the preceding section.

That being said however, the findings also show that ethnic tensions and divisions within the South Sudanese vary between men and women. In particular, there is greater desire among South Sudanese women to invest their energies in civic associations across ethnic divides than among men. This means that South Sudanese men and women value social capital differently, raising the question of the nature of cultural values and values that inspire South Sudanese men and women to engage in associational activities. Social capital in this community is a highly gendered process with potentially different health outcomes for men and women. The findings of this study show that reactionary ethno- 
nationalist politics consumes South Sudanese men and structures their life-worlds in ways that take precedence over most other matters. For South Sudanese women, however, ethno-nationalist politics takes lesser importance in everyday life. It occupies a secondary role in terms of shaping their life-worlds relative to the need to forge networks that would help them meet everyday practical needs. However, as opposed to being binary, we should see the distinction in inter-ethnic affinity between South Sudanese men and women as existing on a continuum.

\subsection{Generational Identities and what this means for Health}

Many studies have explored the issue of generational differences within migrant families and communities. For example, Goodman (2004) interviewed South Sudanese refugee youth aged (16-18) and Bolea et al., (2003) conducted a qualitative study with South Sudanese minors in foster care in the US, and found that foster parents and caregivers could not adequately provide emotional support, as the children's trauma could only be fully understood in their cultural contexts. However, these studies often only consider age, not generation, as a determinant of health experience. These factors are not mutually exclusive. For example, in Melbourne, 30 Sudanese young people were interviewed about the trauma of fleeing conflict and the subsequent struggles of resettlement (Tempany, 2009). Here we would have to assume that these Sudanese young people are first generation immigrants, if they are being asked about their experiences in South Sudan, as only those born in home countries adopt first-generation immigrant status.

Overall, the findings of this study point to significant differences in health and wellbeing between second-generation South Sudanese immigrants and the first- 
generation. Among the first generation, their everyday health and wellbeing is closely linked to the events occurring in South Sudan than the second generation. The study found that, having been born in Canada, second-generation immigrants and refugees seemed to display mixed feelings towards South Sudan and seem to relatively unconcerned with political events in the ancestral motherland. Both second and first generation South Sudanese recognized this to be in part a product of household dynamics, especially parents not sharing this information with their children. South Sudanese parents often found themselves conflicted between needing to protect their children from the political corruption and violent conflict occurring in South Sudan, while being worried that these same actions will result in their children having little understanding of their culture in the homeland. Because South Sudanese parents in Ottawa generally choose to protect their children from the events in the homeland, most of the secondgeneration participants did not show a sophisticated understanding of the political climate or the civil conflict in the homeland. Thus second generation South Sudanese experience everyday health and wellbeing differently than the first generation because they have different level of exposure to anxiety and stress. They also generally have different health-seeking behavioural patterns such as attitudes towards physical exercises, mental health, and doctor visits than their parents. 


\section{Chapter: Conclusions}

\subsection{Introduction into my Final Thoughts}

The main objective of this thesis was to understand why, despite access to health care in Canada, South Sudanese refugees and immigrants continue to experience declining health. Very little research on this population in Canada exists, and only a couple of research projects have begun to investigate this issue within Ottawa. Using qualitative research methods and applying a political ecology of health framework, I set out to understand how the unique experiences of being a South Sudanese immigrant or refugee living in Ottawa influences health. Understanding the unique migration experiences of South Sudanese, by applying a PEH framework, I set out to examine how South Sudanese living in Canada relate to and experience the broader political climate of South Sudan, including the violent civil conflict, government corruption and deeply rooted ethnic tensions, within the sociocultural context of Canada. I also believe that a gendered element of analysis was important, specifically in terms of how the experience of traditional South Sudanese gender norms within the everyday context of living in Canada, influences the health of immigrants and refugees living in Ottawa.

\subsection{Conclusions and Future Directions for Research}

Although I am extremely happy with the outcome of this thesis, it has not come without its limitations. First, through employing the method of maximum variation (Patton, 1990), I set out to gain a wide variety of perspectives on the research topic.

While I feel as though I gained many differing experiences and opinions on the issues at hand, I recognize that my sample was limited to a particular South Sudanese community within Ottawa. My main point of contact in the community is well-known for his efforts 
to bring South Sudanese in Ottawa together to discuss issues. Therefore, the participants that I found through him were all similarly active in the community. Additionally, because recruitment appeared to be more challenging than anticipated, I began to employ snowball sampling, and asking my participants to provide me with the information of other participants.

Keeping in mind that the South Sudanese community in Ottawa is quite fragmented, this meant that the majority of my participants were part of a sub-community comprised of South Sudanese who had a history of "putting politics aside" and eagerly working towards addressing important community issues. With the literature to support this (CCHS, 2004; The Mosaic Institute, 2009) many participants in this study expressed that there are several other sub-communities, (some ethnic, some not) which do not associate with each other. Therefore, keeping my sample within this community of South Sudanese did not allow me the opportunity to include the voices of members of other South Sudanese sub-communities in Ottawa. It is likely that they would have different experiences to share within the context of my research. Are they much more involved in the political climate in South Sudan? Do they seek support from other communities in Ottawa? Do they have the same ideas of what the main health issues in the community are? There are so many questions I have left unanswered. Therefore, it would have been beneficial to my study to include the voices of South Sudanese in other sub-communities. For someone who is interested in researching the South Sudanese communities in Ottawa, I suggest branching out into the sub-communities.

Next, a significant aspect of my research goal was to understand how experiences of transitional migration impacts health in the context of Canada. Research suggests that 
many South Sudanese immigrants and refugees have suffered great trauma in their long and often multi-country journey to Canada. Unfortunately, due to very serious ethical implications of asking research participants to speak about these experiences, the Carleton University Ethics Board did not allow me clearance to directly ask questions about these experiences. Although some of these stories naturally came out in discussions, I could not gather specific information and thus draw conclusions about the links between specific migration trajectories and health in the context of Canada. For example, are immigrants who lived in multiple countries before arriving in Canada having greater problems with integration? Do those who lived in the Northern region of South Sudan before leaving have different perspectives on the ethnic and political tensions that exist within the Ottawa community? Perhaps more time to work with the Ethics Board would have allowed me to come up with a way to ethically discuss these experiences. This is definitely something I suggest for future research.

Finally, the generational aspect to my research project was somewhat of an afterthought. Because the Ethics Board only gave me clearance to interview participants over the age of majority, I did not think about incorporating a generational aspect, because I understood that to mean "adult vs. youth". However, late in the interview process, I interviewed a second-generation South Sudanese immigrant in his twenties. Throughout the discussion, I quickly began to learn the stark differences in health experiences in comparison to the first-generation participants I had spoken to previously. This excited me, however, because I was late in the process, I only had time to interview two more second-generation immigrants. Although these interviews provided me with fruitful data and results, I wish I could have interviewed more, to even out my sample 
size. I would definitely recommend that anyone interested in interviewing immigrant and refugee populations in Canada, to generally, incorporate a generational aspect.

\subsection{Concluding with Advice for Future Health Geographers at Carleton: Make}

\section{Time and Make Friends}

I want to end by acknowledging the challenges, but also the amazing experiences that I had being a Health Geographer in the Department of Geography and Environmental Studies at Carleton University. I would not say that my biggest challenge was necessarily a "challenge" but an obstacle that I was not entirely prepared to deal with. My experience with the Ethics Board ended up being much longer than anticipated, therefore, I was set back on when I could begin my interviews. This inevitably set everything else back a few months, preventing me from collecting as much data as I had hoped, and allowing me any free time to go back and add anything I felt like I had missed in my data collection phase (extra interviews, for example). My advice to grad students, specifically those completing an MA thesis in Geography, is to start your ethics application as soon as possible. I truly feel like if I had my ethics application approved by May 2016 (when I had originally planned), and not August 2016, I would have had the time to address many of the limitations to my research, discussed above. Ethical research is the most important aspect of your thesis, and it is essential that you are prepared for the time and effort that goes into ensuring clearance.

Thus, completing a thesis inevitably comes with its stressors. There is an endless amount of resources out there to help you manage the stress, but my number one recommendation is to find a group of supportive friends within your program or another similar grad program. I am extremely fortunate to have been a part of a close-knit cohort 
of Geography graduate students. During the days when I just could not find the right words for that paragraph, or stand to transcribe any more data, my friends in the office were always there to support me and keep me going. As only one of two Health Geographers in the entire department, it was easy to feel isolated and confused. Although my friends were helpful, I would recommend connecting with students in other departments, who study health: History, Anthropology or Health Sciences. During the times that I could not reach my supervisor, it would have been helpful to have someone who is familiar with my research field, to help me talk through some issues. Overall, my experience in the department was extremely positive, and I credit my DGES friends for helping me finish this thesis.

Now at the end of this thesis, I truly believe that the questions that I set out with have been answered. Although not without limitations, I think this project has highlighted a clear understanding of the health and wellbeing of South Sudanese immigrants and refugees living in Ottawa. Through their voices and experiences, there is now a greater understanding of not only what the health concerns are, but a greater awareness of why they continue to persist. Not only does this open the door for future research, but provides key insights into future policy making around refugees, immigrants and health care in Canada. I also hope that this project has empowered South Sudanese community members to be active within their communities, and feel as though their voice is important. Although my time as a grad student is over, I am excited at the opportunity to continue working with this community, making friends, and fighting for a healthier future. 


\section{Appendices}

\section{Appendix A Certificate of Ethics Clearance}

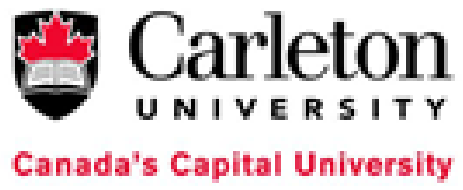

Research Compliance Office

511 Tory | 1125 Colonel By Drive

Ottawa, Ontario K1S 5B6

613-520-2600 Ext: 2517

ethics@carleton.ca

\section{CERTIFICATION OF INSTITUTIONAL ETHICS APPROVAL}

Ethics approval for the following research has been cleared by the Carleton University Research EthicsBoard-A (CUREB-A) at Carleton University. CUREB-A is constituted and operates in compliance with the Tri-Council Policy Statement: Ethical Conduct for Research Involving Humans (TCPS2).

Ethics ID: Project \# 104674

Principal Investigator: Katie MacPherson

Co-Investigator(s): Paul Mkandawire (Primary Investigator)

Katie MacPherson (Student Research: Master's Student)

Study Title: Everyday Health Experience of South Sudanese immigrants in Ottawa: A Feminist Political Ecology of Health Perspective [Katie MacPherson]

Effective: September 07, 2016

Expires: September

30, 2017.

Restrictions:

This certification is subject to the following conditions:

1. Approval is granted only for the research and purposes described in the application. 
2. Any modification to the approved research must be submitted to CUREB-A. All changes must be approved prior to the continuance of the research.

3. An Annual Application for the renewal of ethics clearance must be submitted and approved by the above date. Failure to submit the Annual Status Report will result in the closure of the file. If funding is associated, funds will be frozen.

4. A closure request must be sent to CUREB-A when the research is complete or terminated.

5. Should any participant suffer adversely from their participation in the project you are required to report the matter to CUREB-A.

6. Failure to conduct the research in accordance with the principles of the Tri-Council Policy Statement: Ethical Conduct for Research Involving Humans 2nd edition and the Carleton University Policies and Procedures for the Ethical Conduct of Research may result in the suspension or termination of the research project.

Please email the Ethics Coordinators at ethics@carleton.ca if you have any questions.

APPROVED BY:

Date: September 07,

2016

Andy Adler, PhD, Chair, CUREB-A

Shelley Brown, PhD, Vice Chair, CUREB-A 


\section{Appendix B Letter of Introduction}

\section{Gearangraphy \& Environmental Studies

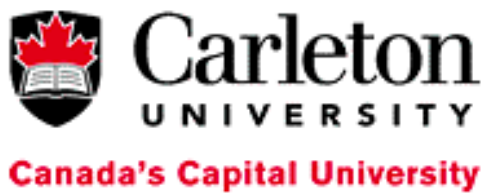

Hello, my name is Katie MacPherson and I am Master's student in the Department of Geography and Environmental Studies at Carleton University. I am currently conducting my thesis project, under the supervision of Paul Mkandawire of the Human Rights program, on the health and wellbeing of South Sudanese Canadians living in Ottawa.

The goal of this project is to hear from South Sudanese Canadians themselves about their everyday experiences in Ottawa. I am specifically interested in gaining an understanding how of these everyday experiences are related to health and wellbeing. The main goal of this project is to identify how the unique experience of being a South Sudanese Canadian impacts health and wellbeing on the everyday level, and how these experiences might be linked to factors such as gender, family and culture, or other structural factors such as access to health care.

Particularly, I am hoping to speak to individuals 18 years of age and who self-identify as South Sudanese. These individuals can be first or second-generation immigrants or refugees.

I will be conducting focus group interviews that will last approximately 2 hours in length. I was also be conducting one-on-one, semi-structured in-depth interviews and each interview is expected to last for one hour. Informed consent will be formally obtained from all individuals who agree to participate by signing a consent form. All necessary precautions will be taken to ensure the safety and confidentiality of individuals who have agreed to participate in this study.

This project yields many potential benefits especially in terms of providing a better understanding of the health of South Sudanese Canadians. The findings of study will be disseminated broadly, and I hope that they can potentially have a collective benefit for the community in terms of government response and/or policy change and suggestions for health improvement programs.

Thank you for taking the time to read this letter. I am very excited about this project, and I hope that we can work together to bring attention to, better understand, and improve health issues in the community. If you require more information or have questions about this project, please feel free to contact me or Paul Mkandawire.

Sincerely, Katie MacPherson, Primary Researcher

katiemacpherson@cmail.carleton.ca

Supervisor

Dr. Paul Mkandawire

Assistant Professor, Institute of Interdisciplinary Studies

Carleton University

PaulMkandawire@carleton.ca

Carleton University Research Ethics Board

Dr. Andy Adler, Chair, Carleton University Research Ethics Board 
613-520-2600 ext. 2517

ethics@,carleton.ca 


\section{Appendix C Invitation for Interview}

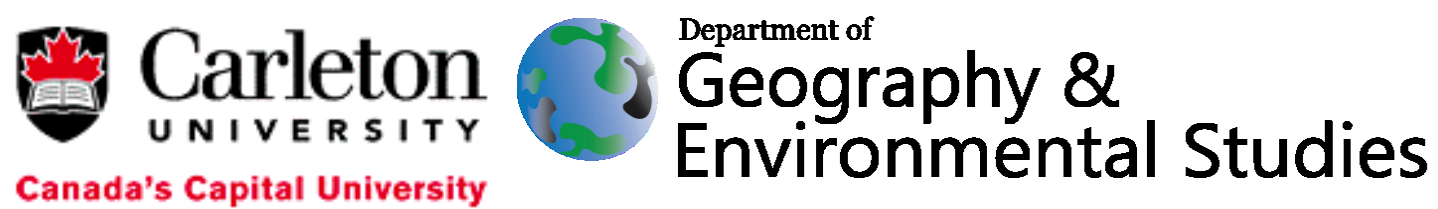

My name is Katie MacPherson and I am a graduate student under the supervision of Paul Mkandawire of the Human Rights Program at Carleton University. I am presently conducting my Master's thesis project on the health and wellbeing of South Sudanese Canadians. I am specifically interested in exploring the everyday health experiences and perceptions of South Sudanese in Ottawa. Thus, I would like to invite you to participate in this study, as it would greatly assist in our understanding of these health experiences.

If you agree to participate in this study you will be asked to answer a series of questions. The questions will cover topics of everyday health experiences, specifically questions related to cultural health practices, coping strategies, family and domestic life and accessing health care as an immigrant or refugee. The interview will be audio recorded, however you may chose the option of a note taker. The interview will last about 1 hour. Translation is provided, if needed.

Every effort will be made to ensure confidentiality of any identifying information that is obtained in this study. All data will be treated as confidential. You will not be referred to by name in the interview recordings, but by a pseudonym. A separate, written document with your personal identifiers will be stored in a secure safe and away from the rest of the data collected in order to preserve your anonymity. All recordings will be deleted once verified, paper data will be destroyed once the study is complete, and all other information will be destroyed 5 years after the project's completion. At no time will your name or other personal information be shared outside of the researchers. All data pertaining to this project, including recordings, will be kept on a password protected and encrypted hard drive in a locked safe, only accessible by researchers. All data will be deleted after 5 years.

Your participation is completely voluntary, and at anytime during the interview, you may refuse to participate, answer questions. After the interview, you have one month to withdraw from the study. If you choose to withdraw, the information you provided will immediately be destroyed and not used in the study.

If you have any questions about this study or your rights as a research participant, you may contact the primary researcher, supervisor or Office of Research Ethics at Carleton University.

Primary Researcher

Katie MacPherson

Department of Geography and Environmental Studies, Loeb Building A303 Carleton University

1125 Colonel by Drive Ottawa, Ontario, Canada, K1S 5B6

katiemacpherson@cmail.carleton.ca

Supervisor

Dr. Paul Mkandawire

Assistant Professor, Institute of Interdisciplinary Studies, Carleton University

PaulMkandawire@carleton.ca

Carleton University Research Ethics Board

Dr. Andy Adler, Chair, Carleton University Research Ethics Board

613-520-2600 ext. 2517

ethics@,carleton.ca 
I have read the Letter of Information, have had the conduct of the study explained to me, all questions have been answered to my satisfaction, and I agree to participate.

Participant Name (Print)

Participant Signature

Date

Researcher's Signature

Date 


\section{Appendix D Invitation for Focus Group}

\section{Carleton
Gepartment of
Envirophy \& $\&$ Cantal Studies \\ Canada's Capital University}

My name is Katie MacPherson and I am a graduate student under the supervision of Paul Mkandawire of the Human Rights Program at Carleton University. I am presently conducting my Master's thesis project on the health and wellbeing of South Sudanese Canadians. I am specifically interested in exploring the everyday health experiences and perceptions of South Sudanese in Ottawa. Thus, I would like to invite you to participate in this study, as it would greatly assist in our understanding of these health experiences.

Participation in this focus-group discussion is voluntary and involves your input and discussion on the issues of the everyday health issues of South Sudanese Canadians in Ottawa. This focus group discussion will be audio-recorded and a translator is available if needed. You may decline answering any questions you do not wish to answer and may decline contributing to the session in other ways if you so wish. You have one month after the focus group to withdrawal from the study. If you choose to withdraw, the information you provided will immediately be destroyed and not used in the study.

Every effort will be made to ensure confidentiality of any identifying information that is obtained in this study, however confidentiality and total anonymity cannot be guaranteed for focus groups. All data will be treated as confidential. Your name will not be identified with the input you give in the session. You will not be identified by name in the final report produced by the researcher. Given the group format of this session we will ask you to keep in confidence information that identifies or could potentially identify a participant and/or his/her comments.

Information containing personal identifiers will be kept separate from the rest of the data in order to preserve anonymity and only pseudonym will be used when the information is used in the thesis. All recordings will be deleted once verified, paper data will be destroyed once the study is complete, and all other information will be destroyed 5 years after the project's completion. At no time will your name or other personal information be shared outside of the researchers. All data, including recordings, will be kept on $\mathrm{n}$ password protected and encrypted hard drive in a locked filing cabinet, only accessible by researchers.

If you have any questions about this study or your rights as a research participant, you may contact the primary researcher, supervisor or Office of Research Ethics at Carleton University.

Primary Researcher

Katie MacPherson

Department of Geography and Environmental Studies, Loeb Building A303

Carleton University, 1125 Colonel by Drive Ottawa, Ontario, Canada, K1S 5B6

katiemacpherson@cmail.carleton.ca

Supervisor

Dr. Paul Mkandawire

Assistant Professor, Institute of Interdisciplinary Studies, Carleton University

PaulMkandawire@carleton.ca

Carleton University Research Ethics Board

Dr. Andy Adler, Chair, Carleton University Research Ethics Board

613-520-2600 ext. 2517

ethics@carleton.ca 
I have read the Letter of Information, have had the conduct of the study explained to me, all questions have been answered to my satisfaction, and I agree to participate.

Participant Name (Print)

Participant Signature

Date

Researcher's Signature

Date 


\section{Appendix E Interview Guide and Checklist for Focus Groups}

\section{and Geography \& Environmental Studies

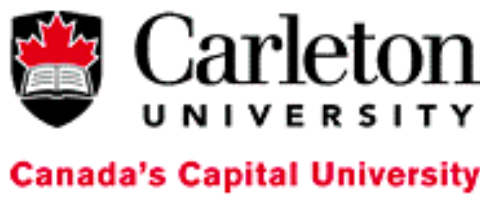 \\ Canada's Capital University}

To begin:

- Introduce myself, translator and anyone else present

- Introduce the research project in a little more detail than outlined in recruitment letter

- Distribute paper for participants to provide demographic/contact information (voluntary)

- Explain how the focus group will run, outline the rules. For example, emphasize confidentiality and respect

- Distribute and discuss consent agreement

- Answer and additional questions

Guide:

1. What do the concepts of "health" and/or "wellbeing" mean to you?

2. Do you think health and/or wellbeing are part of your everyday life? How?

3. Is the South Sudanese community in Ottawa facing any significant health issues? If so, what are they?

4. What are the most important health related issues facing the South Sudanese communities in Ottawa?

5. How should these issues be addressed?

6. Research conducted in South Sudanese immigrant communities in Canadian cities suggests that these communities are experience significantly higher health issues in comparison to non-immigrant populations. Do you agree with this?

7. Are there any particular practices or experiences in your everyday life that you perceive to impact your health either positively (i.e. promote a healthy lifestyle) or negatively (i.e. contribute to health decline)?

8. Are there particular aspects of being a South Sudanese immigrant or refugee living in Canada that impact your own health experiences, or those of the community in general (i.e. being an ethnic minority)?

9. How is everyday life different for first and second-generation immigrants? Is there a difference in their health and/or wellbeing?

10. Where do people in the South Sudanese communities in Ottawa go for health advice and/or support (i.e. family back in South Sudan or neighbours/family/friends in Ottawa)?

11. How does culture impact the health experiences or practices of South Sudanese in Ottawa? 
12. How does one's gender impact health experiences and practices amongst the South Sudanese communities in Ottawa?

13. How has the process of settling to Canada or Ottawa caused any changes in the dynamic of peoples' homes within the community?

14. Are these changes experienced differently for men and women? How?

15. Has return migration affected the homes of South Sudanese community members in Ottawa? If so, does this experience have an impact on experiences of health and wellbeing? How?

To conclude

- Conclude the interview by re-emphasizing the significance of participant's participation

- Thank the participants

- Answer any final questions or concerns

Primary Researcher

Katie MacPherson, Department of Geography and Environmental Studies, Carleton University

Ottawa, Ontario, Canada, K1S 5B6

katiemacpherson@cmail.carleton.ca

Supervisor

Dr. Paul Mkandawire

Assistant Professor, Institute of Interdisciplinary Studies, Carleton University

PaulMkandawire@carleton.ca

Carleton University Research Ethics Board

Dr. Andy Adler, Chair, Carleton University Research Ethics Board

613-520-2600 ext. 2517

ethics@carleton.ca 


\section{Appendix F Interview Guide and Checklists for Interviews}

\section{Carleton
Geportmentophy \&
Environmental Studies \\ Canada's Capital University}

To begin:

- Introduce myself and the research project in a little more detail

- Distribute and discuss the consent form, have form signed

- Distribute form to collect data, or ask for it verbally (voluntary)

- Answer any additional questions or concerns

Questions:

Everyday health experiences

1. What do the concepts of "health" and "wellbeing" mean to you?

2. Do you think health is part of your everyday life?

3 . What aspects of your everyday life contribute to your health and/or wellbeing?

4. Are there any particular practices or experiences in your everyday life that you perceive to impact your health either positively (i.e. promote a healthy lifestyle) or negatively (i.e. contribute to health decline)?

Structural factors

5. Where do South Sudanese in Ottawa go for health advice and/or support (i.e. family back in South Sudan or neighbours/family/friends in Ottawa)?

6. Can you describe the experience of a South Sudanese community member in Ottawa accessing healthcare?

7. How does culture impact health experiences or practices in the community?

8 . How does gender impact health experiences and practices in the community?

9. How does being an immigrant or refugee impact everyday health practices and experiences?

10. What do you believe are the most significant barriers to health in everyday life, that South Sudanese in Ottawa face (i.e. language barriers while accessing health care)?

Social and Cultural Context of Canada

11. Are there particular aspects of being a South Sudanese immigrant or refugee living in Canada that impact health experiences of South Sudanese in Ottawa (i.e. being an ethnic minority)?

12. Does your immigrant or refugee status (i.e. sponsored refugee, permanent resident, etc.) impact health or well being of South Sudanese in Ottawa (i.e. ability to access health care)?

13. How are the everyday lives of first and second-generation immigrants different? Is there a difference in their wellbeing or health status?

14. Does being an immigrant or refugee in Canada create any health barriers in everyday life?

15. Has being an immigrant or refugee in Canada created stress in your own life, or the lives of other South Sudanese community members in Ottawa?

16. How do you, or other South Sudanese in Ottawa, cope with these health issues or stressors?

Relocation and Family Instability

17. How has the process of resettlement (yourself or your family) to Canada or Ottawa caused any changes in the dynamic of homes within the community?

18. How have these changes impacted day-to-day life?

19. Have these changes been challenging and/or caused stress?

20. Have these changes impacted health and wellbeing in any way?

21. Are these changes/challenges experienced differently for men and women?

22. How have the homes of South Sudanese community members been affected by return migration to

South Sudan? 
To conclude

- Conclude the interview by explaining the significance of participant's participation

- Thank the participant

- Answer any final questions or concerns

- Provide contact information for follow up

Primary Researcher

Katie MacPherson, Department of Geography and Environmental Studies, Carleton University Ottawa, Ontario, Canada, K1S 5B6

katiemacpherson@cmail.carleton.ca

Supervisor

Dr. Paul Mkandawire

Assistant Professor, Institute of Interdisciplinary Studies, Carleton University

PaulMkandawire@carleton.ca

Carleton University Research Ethics Board

Dr. Andy Adler, Chair, Carleton University Research Ethics Board

613-520-2600 ext. 2517

ethics@carleton.ca 
Appendix G Codes to Theory Model (Strauss, 1987)

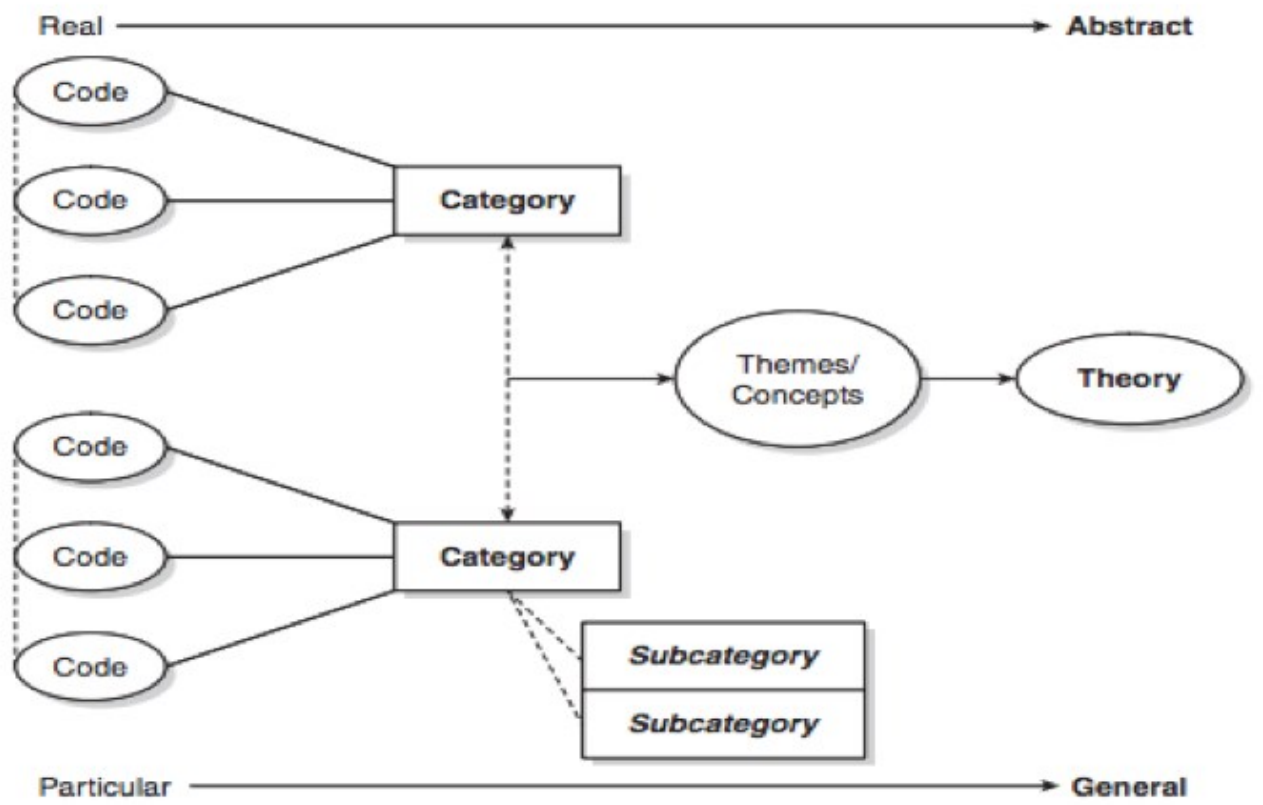




\section{References}

Abdelnour, O. (2006). The Ancient History of South Sudan. Omduran: Marghani Cultural Centre.

Abdelnour, S., Badri, B., El Jack, A., Wheeler, D., McGrath, S., \& Branzei, O. (2008). Examining Enterprise Capacity: A Participatory Social Assessment in Darfur and Southern Sudan. Centre for Refugee Studies.

Abra1do-Lanza, A., Chao, M., \& Florez K. (2005). Do Healthy Behaviors Decline with Greater Acculturation?: Implications for the Latino Mortality Paradox. Social Science \& Medicine, 61, 1243-1255.

Abusharaf, R.M. (2002). Wanderings: Sudanese Migrants and Exiles in North America. Cornell University Press: New York.

Addo, J., Smeeth, L., \& Leon, D.A. (2007) Hypertension in sub-Saharan Africa: a systematic review. Hypertension, 50(6), 1012-1018.

Anderson, D. (2005). Misgivings about the Sudan Peace Accord. Christian Century, 2, 16-34.

Arowolo, O. (2000). Return Migration and the Problem of Reintegration. International Migration, 38(5), 59-82.

Atkinson, A. (1991). Principles of political ecology. Belhaven Press.

Awan, I. (2016). Cyber Islamophobia and Internet Hate Crime, In I. Awan (Ed.), Islamophobia in Cyberspace: hate crimes go viral, (pp. 9-30).

Baak, M. (2015). Transnational families, remittances, wellbeing and obligation for Dinka women in Australia. Emotion, Space and Society, 16, 123-129.

Barriball, K., \& While, A. (1994). Collecting data using a semi-structured interview: a discussion paper. Journal of Advanced Nursing, 19(2), 328-335.

Belloni, R. (2011). The Birth of South Sudan and the Challenges of Statebuilding. Ethnopolitics, 10(3-4), 411-429.

Bereketeab, R. (2014). Redefining National Identity and Nation-Building in Postsecession Sudans: Civil and Ethnic Models. Studies in Ethnicity and Nationalism, 14(2), 302-318. 
Beswick, S., Turshen, M., Twagiramariya, C., Bascom, J., \& Berhane-Selassie, S. (2001). "If You Leave Your Country You Have No Life!"; Rape, Suicide, and Violence: The Voices of Ethiopian, Somali, and Sudanese Female Refugees in Kenyan Refugee Camps. Northeast African Studies, 8(3), 69-98.

Bartley, M., Blane, D., \& Montgomery, S. (1997). Health and the life course: why safety nets matter. British Medical Journal, 314(7088), 1194-1196.

Bebbington, A. (2009). Political Ecology. Retrieved from http://environmentecology.com/political-ecology

Bebbington, A., \& Batterbury, S. (2001). Transnational Livelihoods and Landscapes: Political Ecologies of Globalization. Ecumene, 8(4). 369-380.

Blaikie P., \& Brookefield H. (1987). Land Degradation and Society. London: Methuen

Blaikie, P. (1985). The Political Economy of Soil Erosion in Developing Countries. New York: Routledge.

Blane, D., Brunner, E.J., \& Wilkinson, R. (1996). The evolution of public health policy: an anglocentric view of the last fifty years. In E. Blane, E. Brunner and R. Wilkinson (Eds.). Health and social organization: towards a healthy policy for the 121 century. London: Routledge.

Boccagni, P. (2015). Burden, blessing or both? On the mixed role of transnational ties in migrant informal social support. International Sociology, 30(3), 250-268.

Bolea, P. S., Grant, G., Burgess, M., \& Plasa, O. (2003). Trauma of children of the Sudan: a constructivist exploration. Child Welfare, 82(2), 219-233.

Bradshaw M. \& Stratford E. (2010). Qualitative Research Design and Rigour. In Hay, I. (Ed.), Qualitative Research Methods in Human Geography. Don Mills: Oxford University Press.

Bradshaw, M. (2001), Contracts and member checks in qualitative research in human geography: Reason for caution? Area, 33(3), 202-2011.

Breen, R. (2006). A Practical Guide to Focus-Group Research. Journal of Geography in Higher Education, 30(3), 463-475.

Brown, T., Mclafferty, S., \& Moon, G. (2010). A Companion to Health and Medical Geography. Wiley-Blackwell.

Browne, K. (2005). Snowball sampling: using social networks to research nonheterosexual women. International Journal of Social Research Methodology, $8(1), 47-60$. 
Bryant, R. L. (1998). Power, knowledge and political ecology in the third world: a review. Progress in Physical Geography, 22(1), 79-94.

Callahan, D. (1973). Science: Limits and Prohibitions. The Hastings Centre Report, 3(5), 5-7.

Cameron, J. (2006). Focusing on the Focus Group, In I. Hay (Ed.), Qualitative Research Methods in Human Geography, (pp. 152-172). New York: Oxford University Press.

Christopher, A. J. (2011). The South African geographical journal: being a record of the proceedings of the South African Geographical Society. South African Geographical Journal, 93.

Clougherty, J.E., Souza, K. \& Cullen, M.R. (2010). Work and its role in shaping the social gradient in health. Annals of New York Academy of Science, 1186, 102-124.

Coggon, J. (2012). What makes health public? A critical evaluation of moral, legal and political claims in public health. New York: Cambridge University Press.

Collins, A. E. (2002). Health ecology and environmental management in Mozambique. Health \& Place, 8(4), 263-272.

Collins, R. (2008). A History of Modern Sudan. Cambridge: Cambridge University Press.

Collins, R., \& Deng, F. (1984). The British in the Sudan, 1989-1956. London: Macmillan Press.

Conly, J., \& Johnston, B. (2008). The Infectious Diseases Implications of the "Lost Boys and Girls of Sudan." Canadian Journal of Infectious Diseases and Medical Microbiology, 19(3), 215-216.

Cook, T. (2011). Building a Nation: South Sudanese Share Their Thoughts on the Creation of a Successful State. The National Democratic Institute for International Affairs.

Corbin, J. M., \& Strauss, A. L. (1987). Basics of qualitative research: techniques and procedures for developing grounded theory. In Qualitative Analysis. New York: Cambridge University Press.

Culture, Community and Health Studies Program (2004). The Study of Sudanese Settlement in Ontario.

Daoud, D. (2015). Factors of Secession: South Sudan, In A. Madibbo (Ed.), Canada in Sudan, Sudan in Canada. (pp. 27-51). Montreal: McGill University Press

De Alessi, B. (2013). The CPA Failure and the Conflict in Southern Kordofan and Blue Nile States. UNISCI Discussion Papers, 33, 1-12. 
Demers, M. (2014). Connected struggles: Catholics, nationalists, and transnational relations between Mexico and Quebec, 1917-1945. Montreal: McGill Queen's University Press.

Demmers, J. (2002). Diaspora and Conflict: Locality, Long-Distance Nationalism, and Delocalisation of Conflict Dynamics. Javnost - The Public, 9(1), 85-96.

Deng, F. (2007). Sudan at the Crossroads, MIT Centre for International Studies Audit of the Conventional Wisdom, 1-5.

Dowling, R. (2010). Power, Subjectivity, and Ethics in Qualitative Research. In Hay (Ed.), Qualitative Research Methods in Human Geography, (pp. 26-39). New York: Oxford University Press.

Dustmann, C. (2003). Return migration, wage differentials, and the optimal migration duration. European Economic Review, 47(2), 353-369.

Eidelson, R. J., \& Horn, R. (2008). Who wants to return home? A survey of Sudanese refugees in Kakuma, Kenya. Refuge, 25(1), 15-27.

Elamin, A., Ibrahim, M. E., Abuidris, D., Mohamed, K. E. H., \& Mohammed, S. I. (2015). Part I: cancer in Sudan-burden, distribution, and trends breast, gynecological, and prostate cancers. Cancer Medicine, 4(3), 447-56.

El-Battahani (2013) The Post-Secession State in Sudan: Building Coalitions or Deepening Conflicts? In G. Sorbo and A. Ahmed (Eds.), Sudan Divided: Continuing Conflict in a Contested State (pp. 25-40). New York: Palgrave Macmillan.

El-Mahdi, M. (1965). A Short History of the Sudan. London: Oxford University Press

Elmhirst, R. (2011). Introducing new feminist political ecologies. Geoforum, 42(2), 129132.

Elwood, S. A. (2000). "Placing" Interviews: Location and Scales of Power in Qualitative Research. Professional Geographer, 52(4), 649-657.

Engel, G. L. (1977). The need for a new medical model. Science, 196, 129-136

England, K. (1994). Getting personal: reflexivity, positionality and feminist research. The Professional Geographer, 46, 80-89.

England, K. (2002). Producing Feminist Geographies: Theories, Methodology, and Research Strategies. In S. Aiken and G. Valentine (Eds.), Approaches to Human Geography: Philosophies, Theories, People and Practices, (pp. 286-297). London: Sage. 
Este, D. C., \& Tachble, A. (2009). Fatherhood in the Canadian Context: Perceptions and Experiences of Sudanese Refugee Men. Sex Roles, 60(7-8), 456-466.

Este, D. C., \& Tachble, A. A. (2009). The Perceptions and Experiences of Russian Immigrant and Sudanese Refugee Men as Fathers in an Urban Center in Canada. The ANNALS of the American Academy of Political and Social Science, 624(1), $139-155$.

Fadlalla, M. (2004). A Short History of Sudan. Lincoln: iUniverse.

Fanjoy, M. (2015). There's no Place like Home(s): South Sudanese-Canadian Return Migration, In A. Madibbo (Ed.), Canada in Sudan, Sudan in Canada. (pp. 76-99). Montreal: McGill University Press

Faria, C. (2014). I Want My Children to Know Sudan: Narrating the Long-Distance Intimacies of Diasporic Politics. Annals of the Association of American Geographers, 104, 1052-1067.

Frahm, O. (2012). Defining the Nation: National Identity in South Sudanese Media Discourse. Africa Spectrum, 47(1), 21-49.

Frahm, O. (2015). Making borders and identities in South Sudan. Journal of Contemporary African Studies, 33(2), 251-267.

Fussell, E., Sastry, N., \& Vanlandingham, M. (2010). Race, socioeconomic status, and return migration to New Orleans after Hurricane Katrina. Population and Environment, 31(1-3), 20-42.

Ge, J., Resurreccion, B. P., \& Elmhirst, R. (2011). Return migration and the reiteration of gender norms in water management politics: Insights from a Chinese village. Geoforum, 42(2), 133-142.

Gladden, J. (2013). Coping Strategies of Sudanese Refugee Women in Kakuma Refugee Camp, Kenya. Refugee Survey Quarterly, 32(4). 1-149.

Goodman, J. H. (2004). Coping with trauma and hardship among unaccompanied refugee youths from Sudan. Qualitative Health Research, 14(9), 1177-1196.

Goss, J., \& Leinbach, T. (1996). Focus Groups as an Alternative Research Practice: Experience with Trans-migrants in Indonesia. Area, 28(2), 115-123.

Grabska, K., \& Fanjoy, M. (2015). AND WHEN I BECOME A MAN: Translocal Coping with Precariousness and Uncertainty among Returnee Men in South Sudan. Social Analysis, 1(59). 76-86.

Gregory, D., Johnston, R., Pratt, G., Watts, M., \& Whatmore, S. (2015). Colonialism. In The Dictionary of Human Geography. (5 $5^{\text {th }}$ Edition, pp. 94-98). Wiley-Blackwell. 
Grossman, L. S. (1993). The Political Ecology of Banana Exports and local Food Production in St. Vincent, Eastern Caribbean. Annals of the Association of American Geographers, 83(2), 347-367.

Gruenbaum, E. (2006). Sexuality Issues in the Movement to Abolish Female Genital Cutting in Sudan. Medical Anthropology Quarterly, 20(1), 121-138.

Guthman, J., \& Mansfield, B. (2013). The implications of environmental epigenetics: A new direction for geographic inquiry on health, space, and nature-society relations. Progress in Human Geography, 37(4), 486-504.

Haraway, D. (1991), Situated knowledges: The science question in feminism and the privilege of partial perspective. In D. Haraway (Ed.), Simians, Cyborgs and Women: The Reinvention of Nature (pp. 575-599). London: Routledge.

Higginbottom, G. M., Safipour, J., Mumtaz, Z., Chiu, Y., Paton, P., Pillay, J., \& Paul, D. (2013). "I have to do what I believe": Sudanese women's beliefs and resistance to hegemonic practices at home and during experiences of maternity care in Canada. BMC Pregnancy and Childbirth, 13(1), 51.

Hiscock, R., Asikainen, A., Tuomisto, J., Jantunen, M., Pärjälä, E., \& Sabel, C. E. (2017). City scale climate change policies: Do they matter for wellbeing? Preventive Medicine Reports, 6, 265-270.

Holtzman, J. D. (2000). Nuer journeys, Nuer lives: Sudanese refugees in Minnesota. Boston: Allyn and Bacon.

Horowtiz, D. (1989). Ethnic Groups in Conflict. Los Angeles: University of California Press.

Howitt, R., \& Stevens, S. (2010) Cross-cultural research: ethics, methods and relationships, In Hay (Ed.), Qualitative Research Methods in Human Geography, (pp. 40-68). New York: Oxford University Press.

Hunter, A. (2015). Empowering or impeding return migration? ICT, mobile phones, and older migrants' communications with home, 15(4). 485-502.

Hunter, J. M. (2003). Inherited burden of disease: agricultural dams and the persistence of bloody urine (Schistosomiasis hematobium) in the Upper East Region of Ghana, 1959-1997. Social Science \& Medicine, 56(2), 219-34.

Hunter, L. M., Twine, W., \& Patterson, L. (2007). "Locusts are now our beef” Adult mortality and household dietary use of local environmental resources in rural South Africa. Scandinavian Journal of Public Health, 35, 165-174.

Jackson, P., \& Neely, A. H. (2015). Triangulating health. Progress in Human Geography, $39(1), 47-64$. 
Jeppsson, O., \& Hjern, A. (2005). Traumatic Stress in Context. In Forced Migration and Mental Health (pp. 67-80). New York: Springer-Verlag.

Jessup, J. (1989). A Chronology of Conflict and Resolution, 1945-1985. New York: Greenwood Press.

Kennedy, S., McDonald, J. T., \& Biddle, N. (2006). The healthy immigrant effect and immigrant selection: evidence from four countries. Journal of International Migration and Integration, 16(2), 317-332.

Kim, G., Torbay, R., \& Lawry, L. (2007). Basic health, women's health, and mental health among internally displaced persons in Nyala Province, South Darfur, Sudan. American Journal of Public Health, 97(2), 353-61.

Jok, J. M. (2014). South Sudan and the Prospects for Peace Amidst Violent Political Wrangling. The Sudd Institute.

Jok, J.M. (2011). Diversity, Unity and Nation Building in South Sudan. The Sudd Institute.

Kalipeni, E., \& Oppong, J. (1998). The refugee crisis in Africa and implications for health and disease: a political ecology approach. Social Science \& Medicine, 46(12), 1637-1653.

Khawaja, N. G., \& Milner, K. (2012). Acculturation stress in South Sudanese refugees: Impact on marital relationships. International Journal of Intercultural Relations, $36(5), 624-636$.

Khawaja, N. G., White, K. M., Schweitzer, R., \& Greenslade, J. (2008). Difficulties and coping strategies of Sudanese refugees: a qualitative approach. Transcultural Psychiatry, 45(3), 489-512.

Kindersley, N. (2017). Subject(s) to control: post-war return migration and state-building in 1970s South Sudan. Journal of Eastern African Studies, 11(2), 211-229.

King, B. (2009). Political ecologies of health. Progress in Human Geography, 34(1), 118.

King, R. (2010). Geography and Migration Studies: Retrospect and Prospect. Population, Space and Place, 18(2), 134-153.

King, R., \& Christou, A. (2011). Of Counter-Diaspora and Reverse Transnationalism: Return Mobilities to and from the Ancestral Homeland. Mobilities, 6(4), 451-466.

Kitchin, R., \& Tate, N. (2000). Conducting Research into Human Geography: Theory, Methodology and Practice. New York: Pretence Hall. 
Koinova, M. (2011). Diasporas and secessionist conflicts: the mobilization of the Armenian, Albanian and Chechen diasporas. Ethnic and Racial Studies, 34(2), 333-356.

Krueger, R. (1998). Developing Questions for a Focus Group. Thousand Oaks: Sage Publishing.

Lederman, N. G., \& Lederman, J. S. (2015). What Is A Theoretical Framework? A Practical Answer. Journal of Science Teacher Education, 26(7), 593-597.

Losoncz, I. (2011). Blocked opportunity and threatened identity: Understanding experiences of disrespect in South Sudanese Australians. Australasian Review of African Studies, 32(2), 118.

Madibbo, A. I. (2015) Introduction in A. Maddibo (Ed.), Canada in Sudan, Sudan in Canada (pp. 3-16). Montreal: McGill University Press.

Madibbo, A. I. (2015). Canada in Sudan, Sudan in Canada: immigration, conflict, and reconstruction. Montreal: McGill University Press.

Mansfield, B. (2008). Health as a Nature-Society Question. Environment and Planning A, 40(5), 1015-1019.

Mansfield, B. (2008). The social nature of natural childbirth. Social Science \& Medicine, 66(5), 1084-1094.

Marmot, M. G. (2003). Understanding social inequalities in health. Perspectives in Biology and Medicine, 46(3), 9-23.

Marmot, M., Shipley, M., \& Rose, G. (1984). Inequalities in death - specific explanations of a general pattern? The Lancet, 232(8384), 1003-1006.

Marmot, M.G., \& Wilkinson, R.G. (2003). Social determinants of health: the solid facts $\left(2^{\text {nd }}\right.$ ed.). World Health Organization.

Mayer, J. D. (1996). The political ecology of disease as one new focus for medical geography. Progress in Human Geography, 20(4), 441-456.

McEwen, B.S. (1998). Protective and damaging features of stress mediators. New England Journal of Medicine, 338, 171-179

Miller, L. S., Robinson, J. A., \& Cibula, D. A. (2016). Healthy immigrant effect: preterm births among immigrants and refugees in Syracuse, NY. Maternal and child health journal, 20(2), 484-493.

Mitchell, C. (1989). Conflict Resolution and Civil War: Reflections of the Sudanese Settlement in 1972. Fairfax: Centre for Conflict Analysis and Resolution. 
Mkandawire, P., Richmond, C., Dixon, J., Luginaah, I. N., \& Tobias, J. (2013). Hepatitis $B$ in Ghana's upper west region: A hidden epidemic in need of national policy attention. Health \& Place, 23, 89-96.

Mollett, S., \& Faria, C. (2013). Messing with gender in feminist political ecology. Geoforum, 45, 116-125.

Moukhey, M., van Ejik, J., De Vries, N., \& Bosma, H. (2008) Health-related behaviours of Sudanese adolescents. Pub Med, 21(1). 184-191.

Nagy Hesse-Biber, S. (2013). Feminist Research Practice: A Primer (2 ${ }^{\text {nd }}$ ed.). Boston: SAGE Publications.

Nagy Hesse-Biber, S., \& Leavy, P. (2006). Methods of Data Collection. In The Practice of Qualitative Research (pp. 117-315). Thousand Oaks: SAGE Publications.

Naples, N., \& Gurr, B. (2013), Feminist Empiricism and Standpoint Theory: Approaches to Understanding the Social World. In S. Hagy Hesse-Biber (Ed.), Feminist Research Practice. Boston: Sage.

Newhouse, L. S. (2012). South Sudan Oyee! A Political Economy of Refugee Return Migration to Chukudum, South Sudan. Retrieved from http://hdl.handle.net/1773/22623

Nordas, R. (2008). Identity Polarization and Conflict: State Building in Cote d'Ivoire and Ghana. Oslo: Peace Research Institute.

O'Connor, M. Y., Thoreson, C. K., Ricks, M., Courville, A. B., Thomas, F., Yao, J., \& Sumner, A. E. (2014). Worse cardiometabolic health in African immigrant men than African American men: reconsideration of the healthy immigrant effect. Metabolic syndrome and related disorders, 12(6), 347-353.

Oppong, J. R., Kalipeni, E., Anderson, K., Schurtman, M., Andersson, N., Sousa, C. P. (2005). The Geography of Landmines and Implications for Health and Disease in Africa: A Political Ecology Approach. Africa Today, 52(1), 3-25.

Patterson, D. (2016). Living between borders: transnational marriage and us resettlement patterns in Sudanese refugee populations. Masters Thesis. San Jose State University.

Patton, M. (1990). Qualitative evaluation and research methods. Newbury Park: Sage.

Pavkovic, A., \& Radan, P. (2007). Creating New States: Theory and Practice of Secession. Burlington: Ashgate.

Peet, R. \& Watts, M. (2004). Liberations Ecologies: Environment, Development and Social Movements ( $2^{\text {nd }}$ ed.). London: Routledge 
Peltzer, K. (2004). Trauma and mental health problems of South Sudanese refugees in Uganda. Central African Journal of Medicine, 45(5). 110-113.

Rahim, A (2006). The development of the British Policy in the Southern Sudan 18991947. Middle Eastern Studies, (2)3, 227-249.

Richmond, C., Elliott, S. J., Matthews, R., \& Elliott, B. (2005). The political ecology of health: perceptions of environment, economy, health and well-being among 'Namgis First Nation. Health \& Place, 11(4), 349-65.

Robbins, R. (2011). Political Ecology: A Critical Introduction (2 $2^{\text {nd }}$ ed.). Oxford: Wiley Blackwell.

Rocheleau, D. E., Thomas-Slayter, B. P., \& Wangari, E. (1996). Feminist political ecology: global issues and local experiences. London: Routledge.

Rose, G. (1997), Situating knowledge, positionality, reflexivity and other tactics. Progress in Human Geography, 21, 305-320.

Ryff, C., \& Keyes, C. (1995). The Structure of Psychological Wellbeing Revisited. Journal of Personality and Social Psychology, 69(4), 719-727.

Salman, Z., Kirk, G., \& DeBoer, M. (2011) High Rate of Obesity-Associated Hypertension among Primary Schoolchildren in Sudan. International Journal of Hypertension, 2011, 1-5.

Sayer, A. (1992). Method in Social Science: A Realist Approach. (2nd ed.). London: Routledge.

Schweitzer, R., Greenslade, J., \& Kagee, A. (2007). Coping and Resilience in Refugees from the Sudan: A Narrative Account. Australian \& New Zealand Journal of Psychiatry, 41(3), 282-288.

Schweitzer, R., Melville, F., Steel, Z., \& Lacherez, P. (2006). Trauma, post-migration living difficulties, and social support as predictors of psychological adjustment in resettled Sudanese refugees. Australian and New Zealand Journal of Psychiatry, 40(2), 179-187.

Sen, A.K. (1993). The Economics of Life and Death. Scientific American, 26, 40-47.

Shankleman, J. (2011). Oil and State Building in South Sudan. Retrieved August 19, 2017, from https://www.usip.org/publications/2011/07/oil-and-state-buildingsouth-sudan

Simich, L., Este, D., \& Hamilton, H. (2010). Meanings of home and mental well-being among Sudanese refugees in Canada. Ethnicity \& Health, 15(2), 199-212. 
Simich, L., Hamilton, H., \& Baya, B. K. (2006). Mental Distress, Economic Hardship and Expectations of Life in Canada among Sudanese Newcomers. Transcultural Psychiatry, 43(3), 418-444.

Simpson, S. (1985). Planning and Development during the Condominium, In. M. Daly (Ed.), Modernization of the Sudan (pp. 73-84). New York: Lillian Barber Press.

Spaulding, J. (1985). The End of the Nubian Kingship in the Sudan, In M.W. Daly (Ed.), Modernization in the Sudan (pp.17-27). New York: Lillian Barber Press.

Statistics Canada. (2010). Definition of "immigrant" Retrieved June 23, 2017, from http://www.statcan.gc.ca/pub/81-004-x/2010004/def/immigrant-eng.htm

Steel, Z., Silove, D., Brooks, R., Shakeh M., Alzuhairi, H. \& Susljik, A. (2011) Impact of immigration detention and temporary protection on the mental health of refugees. The British Journal of Psychiatry, 188(1) 58-64.

Stoll, K., \& Johnson, P. (2007). Determinants of the Psychosocial Adjustment of Southern Sudanese Men. Journal of Refugee Studies, 20(4), 621-640.

Sundquist, J., Bayard-Burfield, L., Johansson, L.M., \& Johansson, S.E. (2000). Impact of ethnicity, violence and acculturation on displaced migrants: psychological distress and psychosomatic complaints among refugees in Sweden. PubMed, 188(6), 357365 .

Tankink, M., \& Richters, A. (2007). Silence as a Coping Strategy: The Case of Refugee Women in the Netherlands from South-Sudan who Experienced Sexual Violence in the Context of War. In Voices of Trauma (pp. 191-210). Boston, MA: Springer US.

Taylor, S. E. (2006). How Work Establishes a General Relationship Between Daily Stress, and Wide-ranging Diseases of the Body and Mind. Health Psychology. 56, 160-187.

Tempany, M. (2009). What Research tells us about the Mental Health and Psychosocial Wellbeing of Sudanese Refugees: A Literature Review. Transcultural Psychiatry, $46(2), 300-315$.

The Mosaic Institute (2009). Profile of A Community: A 'Smart Map' of the Sudanese Diaspora in Canada. Retrieved from http://www.mosaicinstitute.ca/reports/c151k

The Republic of Southern Sudan Ministry of Health (2010). The Republic of Southern Sudan: The Sudan Household Health Survey 2010. Retrieved from http://www.southsudanembassydc.org/PDFs/others/SHHS\%20II\%20Report\%20F inal.pdf 
The United Nations Refugee Agency (2016). 2015 UNHCR country operations profile South Sudan. Retrieved from_http://www.unhcr.org/pages/4e43cb466.html

Thomas, K. J. A. (2008). Return Migration in Africa and the Relationship between Educational Attainment and Labor Market Success: Evidence from Uganda. International Migration Review, 42(3), 652-674.

Turshen, M. (1984). The Political Ecology of Disease in Tanzania. Newark: Rutgers.

Vickers, E. (2014). In South Sudan, the only thing oil really fuels is war. Retrieved August 19, 2017, from http://www.independent.co.uk/voices/comment/in-southsudan-the-only-thing-oil-really-fuels-is-war-9485546.html

Viruell-Fuentes, E. A. (2007). Beyond acculturation: Immigration, discrimination, and health research among Mexicans in the United States. Social Science \& Medicine, 65(7), 1524-

Waite, L., \& Cook, J. (2011). Belonging among diasporic African communities in the UK: Plurilocal homes and simultaneity of place attachments. Emotion, Space and Society, 4(4), 238-248.

Wassara, S. (2010). The CPA and Beyond: Problems and Prospects of Peaceful Coexistence, In E. Grawert (Ed.), After the Comprehensive Peace Agreement in Sudan (pp. 83-109). New York: Boydell \& Brewer.

Wilkinson, R. G. (1994). The epidemiological transition: from material scarcity to social disadvantage? Daedalus, 123(4), 61-77.

Wilkinson, R.G. (1997). Social determinants of health: Health inequalities: relative derivation or absolute material standards. BMJ, 314, 591-593.

Winchester, H., and Rofe, M. (2010). Qualitative Research and Its Place in Human Geography, In I. Hay (Ed.), Qualitative Research Methods in Human Geography, (pp. 3-25). New York: Oxford University Press.

Wood, J. (1981). Secession: A Comparative Analytical Framework. Canadian Journal of Political Science, 14, 107-134.

Woodward, P. (2013). Sudan after the South's Secession: Issues of Identity. In G. Sorbo and A. Ahmed (Eds.), Sudan Divided: Continuing Conflict in a Contested State (pp. 89-100). New York: Palgrave Macmillan.

Wright, M. W. (2010). Geography and gender: Feminism and a feeling of justice. Progress in Human Geography, 34(6), 818-827.

Zahar, Marie-Joelle (2011). A Journey of a Thousand Steps: The Challenges of State and Nation Building in South Sudan. Middle East Report, 259, 36-39. 
Zambakari, C. (2012). South Sudan: institutional legacy of colonialism and the making of a new state. The Journal of North African Studies, 17(3), 515-532

Zutt, J. (1994). Children of war: wandering alone in southern Sudan. New York: United Nations Children's Fund. 